\title{
CARACTERIZAÇÃO QUIIMICA DOS SEDIMENTOS DE LAGOS DE VÁRZEAS DA AMAZÔNIA CENTRAL
}

\author{
SÉRGIO ROBERTO BULCĀO BRINGEL \\ Quimico
}

Orientador: Prof. Dr. CARLOS C. CERRI

Tese apresentada à Escola Superior de Agricultura "Luiz de Queiroz", da Universidade de São Paulo, para obtenção do título de Doutor em Agronomia. Área de Concentração: Solos $\theta$ Nutrição de Plantas.

PIR A C ICABA

Estado de São Paulo - Brasil Junho - 1989 
Bringel, Sérgio Roberto Bulcão

B858c Caracterização quîmica dos sedimentos de lagos de vārzeas da Amazōnia Central. Pira cicaba, 1989.

$196 \mathrm{p}$.

Tese - ESALQ

Bibliografia

1. Hidrogeoquĩmica - Amazônia Central 2. Lago - Sedimento - Anālise 3. Sedimento - Ca racterização quĩmica - Amazônia Central 4. Vārzea - Solo - Amazônia Central. I. Escola Superior de Agricultura "Luiz de Queiroz",Pi racicaba.

$\operatorname{CDD} 551.482$ 


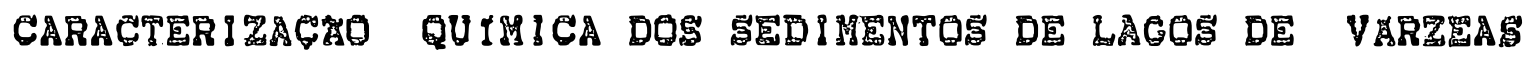
DA AMAZONJ A CENTRAL

Aprovada em: $30 / 06 / 1989$

Com18săo jungadora:

Prof. Dr. Klaus Relchardt

CENA/USP

Prof. Dr. Francisco de Assis F. de Mello

ESALQ/USP

Prof. Dr. Toshiaki kinjo

ESALQ/USP

Prof. Dr. Reynaldo Luiz Victória

CENA/USP

Prof. Dr. Carlos Clemente Cerrl

CENA/USP

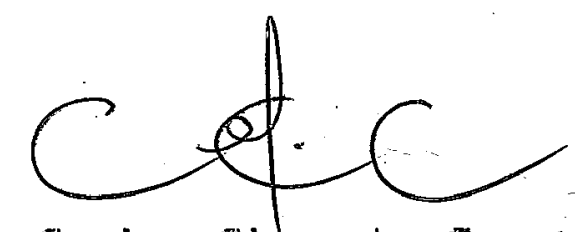

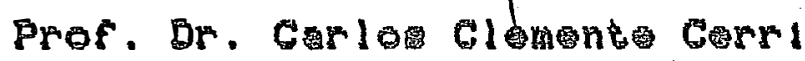
Orjentader 
A meus pais Camilo e Geminiana; à Graça, Fabiola - Kamilla,

Dedico 


\section{ACRADECI}

- Ao Instituto Nacional de Fesquisas da Amazon 1 (INPA), pelo suporte financeiro e bolsa oferec1da:

- Ao Instituto de Tecnologia da Amazonia (UTAM/CETIC), pela oportunidade e bolsa oferecida:

- Ao Centro de Energia Nuclear na Agricultura (CENA/USP), pelas facllidadez oferecidas:

- Ao Conselho Nacional de Desenvolvimento Cientifico e Tecnológlco, pela bolsa oferecida: .

- Ao Prof. Dr. Enelas Salati e Carlos Clemente Cerr1, pela or lentaçă

- Aos colegas Dr. Umberto de Menezes Santos: Marla de Nazaré G. Ribelro e Antonio dos Santos, do INPA, Jefferson Mortatti do CENA/USP e Prof. Arari Marcon 1 da ESALQ/USP, pelas sugestöes:

- Aos técnicos Lor 1 mar Santos: Emerson Barcelar: José Marla Cesarro e Ralmundo Lages do ITTAM, e Joś Marla dos Santos do INPA, pela dedlcą̧ro com que nos assessoraram nas andl 1 ses químlcas e fílcas: 
- Aos Técnicos do Departamento de Química do Solo (Brigitte Eduardo: Jener de Moraes: Mara Piacentin1: Sandra Nicolette: José Martins e Darci Bortoletto) e da Biblioteca (Criatina Pereira: Silvia Zinsly: Liamar Antonioli e Lidioneti Brajäol do CENA/USP, que multo nos ausil1aram:

- A Sra. In dedicaçổo com que nos assessorou na revisăo gramatical;

A todos que, direta ou indiretamente, nos deram apolo espiriual täo necessarlo na realizagaro deste trabalho. 
SUMARIO

psgina

LISTA DE FIGURAS

$x$

LISTA DE TABELAS $\times 10$

RESUMO

x०11

SUMMARY

$31 x$

1. INTRODUÇAO

01

2. REVISAOO BIBLIOGRAFICA

03

2.1.MEIO FISICO DA BACIA AMAZONICA: ASPECTOS GERAIS O3

2.1.1. Geografia

03

2.1.1.1. Relevo

OG

2.1.2. Clima e Hidrologia

O9

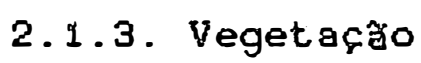

13

2.1.3.1. Tı́pos Fisıonômıcos

14

2.1.3.2. Floresta de Terra Firme

14

2.1.3.3. Floresta de Várzeas

2.1.3.4. Floresta de Igapo

19

2.1.4. Geolog1a

21

2.1.4.1. Orı́gem da Bacıa Amazônica

24

2.1.4.2. Origem doe Sedimentos

25

2.1.4.3. Sedimentaço

27

2.1.5. Solos

2.2. CONSEIDERACOES LIMNOLOGICAS

35

2.2.1. Orıgem das Várzeas 
2.2.2. Estratificaço e Condị̆es do Oxigânio nos Lagos de. Varzeas

2.2.3. Os Lagos Amazônicos

$\$ 1$

2.2.4. Produça Primaria 44

3. MATERIAL E METODOS 49

3.1. MATERIAL 49

3.1.1. CARACTERISTICAS GEOCLIMATICAS DA AREA ESTUDADA $\quad 49$

3.1.1.1. Geografia 49

3.1.1.2. Geologia 52

3.1.1.2.1. Solo 53

3.1.1.3. Clima 55

3.1.1.4. Caracterizaço dos Lagos 58

3.1.2. LAGOS ESTUDADOS 59

3.1.2.1. Local izaçăo das Amostras .59

3.1.2.2. Sedimentos dos Lagos do rio Branco 62

3.1.2.3. Sedimentos dos Lagos do rio Negro Influenciados pelo rio Branco · 62

3.1.2.4. Sedimentos dos Lagos do rio Negro 65

3.1.2.5. Sedimentos dos lagos do rio 
3.3.1. T6cnica de Amostragem

3.3.2. Preparo da Amostra

3.3.3. Análise FÍsica e Fĺsico-Qúnica

3.3.3.3. AnGlise Mineral6gica

3.3.4.2. Complexo Sortivo: Elementos

Tocáveis

3.3.4.2.1: Calcio e Magnesio

3.3.4.2.2. S6dio e Potsssio

3.3.4.2.3. Alumínio

3.3.4.2.4. Soma de Base (S)

3.3.4.2.5. Razão Carbono/

$$
\text { Nitrogenio } \mathrm{C} / \mathrm{N}
$$

3.3.4.2.6. Materia Orgânica

3.3.4.3. Determinaç̃o dos Elementos

Totais: Digest ช̆o Sulfúrica

3.3.4.3.1. Nitrogênio

3.3.4.3.2. Fosforo

3.3.4.3.3. Aluminio

3.3.4.3.4. Ferro 
4. APRESENTAÇAO DOS RESULTADOS

4.1. SEDIMENTOS DOS LAGOS DO RIO NEGRO

4.1.1. Análise FÍsica e FIsico-Qurmica

85

4.1.1.1. Analise Granulometrica

4.1.1.2. $\mathrm{pH}$

85

4.1.2. Análise Químiça

86

4.1.2.1. Complexo Sortivo

86

4.1.2.2. Analise Qurmica Total

87

4.1.2.3. Fraço Orgânica

4.2. SEDIMENTOS DOS LAGOS DO RIO BRANCO

4.2.1. Analise Física e FIsico-Química

89

4.2.1.1. Analise Granulométrica

89

4.2.1.2. $\mathrm{pH}$

89

4.2.2. Analise Qurmica

4.2.2.1. Compleso Sortiyo

90

4.2.2.2. Análise Qurmica Total

91

4.2.2.3. Fraça Orgânica

92

4.3. SEDIMENTOS DOS LAGOS DO RIO NEGRO INFLUENCIADO PELO RIO BRANCO

4.3.1. Analise Física e Físico-Qurmica

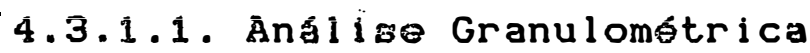

$4.3 .1 .2 . \mathrm{pH}$ 
4.3.2.1. Complesso Sortivo

4.3.2.2. Anslise Química Total

4.3.2.3. Fraçæo Orgânica

4.4. SEDIMENTOS DOS LAGOS DO RIO SOLIMOES/AMAZONAS

4.4.1. Anslise Frsica e Ffsico-Qưmica

4.4.1.1. Analise Granulomøtrica

4.4.1.2. $\mathrm{pH}$

4.4.2. Anslise QuImica

4.4.2.1. Complexo Sortivo ;

100

4.4.2.2. Análise Qứmica Total

102

4.4.2.3. Fraçăo Orgânica

104

5. DISCUSSAO DOS RESULTADOS

106

5.1. SEDIMENTOS DOS LAGOS DO RIO NEGRO

5.1.1. Complexo Sortivo

106

5.1.2. Elementos Totais

5.2. SEDIMENTOS DOS LAGOS DO RIO NEGRO INFLUUENCIADO PELO RIO BRANCO

5.2.1. Complexo Sortivo

5.2.2. Elementos Totais

5.2.3. Influância do rio Branco sobre o rio Negro

5.3. SEDIMENTOS DOS LAGOS DO RIO SOLIMOES/AMAZONAS

5.3.1. Complexo Sortivo 
5.4. INTERPRETAÇOES DA ANALISE DO CONJUNTO DOS

LAGOS ESTUDADOS

5.4.1. Complexo Sortivo

148

5.4.2. Elementoa Totaia

5.4.2.1. N1trogenio

157

5.4.2.2. Fóforo

162

5.4.3. Fraçăo Orgân1ca

164

5.4.3.1. Matér1a Orgân1ca

165

5.4.3.2. Plgmento Total

168

6. CONCLUSOES

174

7. BIBLIOGRAFIA

178 


\section{IHDYCE DE FIGUAA}

FIGURA 1. Bacı a Amazônıca. (1) Rio Amazonas; (2) R10 Sol1moes: (3) R10 Negro: (4) Rio Branco: (5) Rio Made1ra: (6) Rlo Purus; (7) Rio Jurua e (8) Rio Japurǵ. A Linha Pont1lhada Representa os Limites da Bac1a Amazon 1ca.

Figura 2. Eventos de Deposiço e Erosåa na Bacia Amazônica e Formas do Relevo Atual. 08

FiguRA 3. Distribulço Anual das Precipltaçơes na Reg1 ăo Amazôn 1ca.

FIGURA 4. T1pos de Vegetaçăo da Regl ło Norte (Amazônia). (A) Floresta de Terra Firme: (B) Floresta de Varzeas: (C) Filoresta Subducifblia e (D) Campo (Kuhlmann, 1977).

FIgURA 5. Principals Unidades Geolbgicas e Geomorfologlcas da Bacia Amazônica: (T) Terciár10: (Q) Quaternár10: (C) Pré - cambríano e (P) Paleozôlco. Unidades Geomorfolbgicas: (1) Bac1a 
Aamazônica: (2) Escudos Cristalinos;

(3) Depess ב̋o Sub - andina (4)

Cordilheiras dos Andes.

FIGURA 6. Regiăo Norte do Brasil . Area Amostrada:

(I) Rio Negro: (II) Rio Branco; (III)

Rio Sol imð̋es/Amazonas.

FIGURA 7. Flutuaços de Nível de Agua do rio Negro (Dados: Capitania dos Portos, Manaus) e Precipitaça perto de Manaus (Dados: Ciŝncias do Ambiente/ INPA, Manaus) (Junk, 1980).

FIGURA 8. Mapa Esquematico das Areas estudada, Mostrando-se os principais rios amostrados.

FIGURA 9. Mapa mais detalhado da regiåo em estudo: Rio Branco: Rio Negro e Rio Solimßes.

FIGURA 10. Bacia do Rio Negro. Localiząão dos Lagos do Rio Branco e Rio Negro.

FIGURA 11. Bacia do Rio Negro. Localizaçăo dos Lagos do rio Negro solore Influencia do rio Branco. 
FIGURA 12. Bacia do Rio Solimores / Amazonas.

Localizaço dos Lagos do rio Solimð̃es/

Amazonas. Regiăo do Janauacá.

FIGURA 13. Bacia do Rio Solimoes / Amazonas.

Localizaçăo dos Lagos do rio Solimỡes/

Amazonas. Regi åo do Careiro.

FIgURA 14. Teores de Argila, Silte, Areia Fina

- Areia Media nos Sedimentos do

Rio Branco.

FIGURA 15. Teores de Argila, Silte, Areia Fina e Areia Media nos Sedimentos do Rio Negro.

FIGURA 16. Teores de Argila, Silte, Areia Fina

e Areia Media nos Sedimentos do Rio Negro sobre Influância do Rio Branco.

FIGURA 17. Relą̧ăo Percentual de Argila Coloidal nos Sedimentos do Rio Negro, Bio Branco

e Rio Negro sobre Influência do Rio Branco.

FIgURA 18. Relaçăo Percentual de Argila, nos Sedimentos do Rio Negro, Rio Branco e Rio Negro sobre Influência do Rio Branco. 
FIGURA 19. Relacao percentual de silte nos Sedimentos do Rio Negro, Rio Branco e Rio Negro sobre Influância do Rlo Branco.

FIGURA 20. Difratogramas de Ra10-X. (A) Sedimentos do R10 Negro: (B) Sedimentos do Rio Branco e (C) Sedimentos do Rio Negro sobre Influâncla do Rio Branco.

FIGURA 21. Teores de Argila, Silte Arela Fina e Areia Hedia nos sedimentos do Rio Sol 1 mờes/Amazonas.

FIGURA 22. Difratograma de Raio-X. Sedimentos do Rio Sol 1 möer/Amaxonaz. (A) Reglato do Janauaćs e (B) Reg1 ão do Careiro. 


\section{INDICE DE TABELAS}

TABela 1. Conteúdo de $\mathrm{Ca}, \mathrm{Mg}, \mathrm{Na}, \mathrm{K}, \mathrm{N}$ e $\mathrm{P}$ nas Florestas Inundaveis de Varzeas (Klinge et alii, 1983).

TABEla 2. Conteúdo de $\mathrm{Ca}, \mathrm{Mg}, \mathrm{Na}, \mathrm{K}, \mathrm{N}$ e $\mathrm{P}$ nas Floresta Inundsveis de lgapó (Klinge et alii, 1983)

TABELA 3. Analise Qurmica dos Elementos Trocaveis dos Sedimentos dos Lagos pertencentes ao ecossistema do rio Negro.

TABELA 4. Anglises Qurmicas dos Elementos Totais dos Sedimentos dos Lagos pertencentes ao Ecossistema do rio Negro.

TABELA 5. Anglise Químicados dos Elementos da Fraçăo Orgânica C, N, M.O., N/P e Pigmento Total dos Sedimentes dos Lagos do rio Negro.

TABELA 6. Anglise Química dos Elementos Trocgveis dos Sedimentos dos Lagos do $\mathrm{rio} \mathrm{Branco}$

TABELA 7. Anslise Qurmica dos Elementos Totais e $\mathrm{pH}$ dos Sedimentos dos Lagos do rio Branco. 
TABELA 8. Analise Qurmica dos Elementos da Fraçăo Orgânica C, N, C/N, M.O., N/P e Pigmento Total dos Sedimentos dos Lagos do rio Branco.

TABELA 9. Anal ise Química dos Elementos Trocáveis dos Sedimentos dos Lagos do rio Negro que sofrem Influência do rio Branco.

TABELA 10. Analise Quimica dos Elementos Totals Sedimentos dos Lagos do rio Negro Influenciado pelo rio Branco.

TABELA 11. Analise Química da Fraçăo Orgânica C, $\mathrm{N}, \mathrm{C} / \mathrm{N}, \mathrm{M} . \mathrm{O} ., \mathrm{N} / \mathrm{P}$ e Pigmento Total nos Sedimentos dos Lagos do rio Negro Influenciado pelo rio Branco.

TABELA 12. Analise Qurmica dos Elementos Trocáveis nos Sedimentos dos Lagos do rio Sol imores/Amazonas .

TABELA 13. Anglise Química dos Elementos Totais nos Sedimentos dos Lagos do rio Sol imores/Amazonas . 
TABELA 14. Analise Qurmica dos Elementos da Frą̧̃o Orgånica C, N, C/N, M.O., N/P e Pigmento Total nos Sedimentos dos Lagos do rio Sol imores/Amazonas.

TABela 15. Conteúdo de $\mathrm{P}, \mathrm{K}, \mathrm{Mg}, \mathrm{Ca}$ e $\mathrm{Na}(\mathrm{g} / \mathrm{mg})$ nas Folhagens das Florestas Inundaveis de Igapó e nas águas do rio Negro, e o Fator de Concentrąão ( $K l$ inge et alii, 1983).

TABELA 16. Analise Qurmica e Físico-Qurmica dos Sedimentos do rio Negro, rio Branco e Confluância do rio Negro com rio Branco.

TABELA 17. Conteúdo de $\mathrm{P}, \mathrm{K}$, Hg, $\mathrm{Ca}$ e $\mathrm{Na}(\mathrm{g} / \mathrm{kg}) \mathrm{na}$ Folhagem das Florestas de Inundaçăo e nas aguas do rio Solimões e o Fator de Concentraça (Klinge et alii, 1983).

TABELA 18. Cátios Básicos Trocaveis da Frąåo Argila do Material em Suspensão do rio Solimges/Amazonas (Irion, 1976)

TABELA 19. RazÕes Ca/Mg, $\mathrm{K} / \mathrm{Na}, \mathrm{Ca} / \mathrm{S}, \mathrm{Mg} / \mathrm{S}, \mathrm{Na} / \mathrm{S}$ - K/S, no Complexo Sortivos dos Sedimentos dos Lagos Estudados. 
CARACTERIZAÇO QUYMICA DOS SEDIMENTOS DE LAGOS DE VARZEAS DA AMAZONIA CENTRAL

Serglo Roberto Bulcro Bringel

Carlos clemente Cerri

or lentador

RESUMO

Foram analisados os sedimentos de vinte e nove lagos de varaeas, que constituen uma bra significativa da bacia Amazônica: Lagos do Rio Branco: Lagos do rlo Negro: Lagos do rlo Negro sobre influencia do rio Branco e Lagos do rio Solimốs/Amazonas. Determinouse, os cátions troçuels (Calcio, Magnésio, Sódio, Potassio e Aluminio), os elementos.na forma total (N1trogenio, Fbeforo, 56d10, Potáalo, Manganas e Ferro), bem como o Carbomo orgânico, Plgmento total e o pH. Fezse ainda, a determinaço da granulometria e a difraç̃o aos ra10-X, da fracăo argila. 
Anteg da confluânela com o rio Branco, oe selimentos do rlo Negro, apresentam teores de zoma de basea de 3,0 a 7,5 e.mg/100g: pH 4,1 a 5,1 e teor de arglla de 1 \%. Apoe a confluencla, o rlo kegro aprezenta teorea de soma de bases de 5,9 a 10,1 e.mg/1009: pH 5,1 a.6,8 e teor de argila de $45 \%$, o que compreva a fertilizacáo eobretula, de eua margem eequerds, pelas influanclaz dag águag e sedimentos do rio Branco. 
CHEMICAL CHARACTERIZATION OF . VARZEA LAKES SEDIMENTS OF CENTRAL AMAZONIA

Sôrglo Rọberto Bulcâo Bringel

Carlog Clemente Cerrl

Advizor

\section{EUMMARY}

Sedimente from twenty-nine varzea lakeg, reprezenting a algnificant area of the Amazon bagin, were analyzed - lakeg of the Branco river: lakez of the Negro river: lakes of the river Negro influenced by the Branco river and lakez of riverz Sol 1 möeg/Amazonaz. Exchangeable cations CCalcium, Magnesium, Sodium, Potassium and Aluminiums were determined. Also total- Nitrogen, Fhozphoruz, Sodium, Potagzlum, Manganeze and Irlon, bezidez organ $1 c^{\circ}$ Carbon, total-pigment, and pH were determined. Granislometry and $\mathrm{X}$-ray diffraction of the clay fraction were al zo determined. 
Before the confluence with Branco river, sediments from river Negro showed average contents of sum of basis of 3.0 to 7.5 e.mg/100g: $\mathrm{pH} 4.1$ to 5.1 and $10 \%$ clay content. After the confluence the Negro river showed average contents of sum of besis of 5.9 to 10.1 e.mg/100g; pH 5.1 to 6.8 and $45 \%$ clay content, which proves the fertilization of the margin due to the influence of the waters and sediments from river Branco. 


\section{I ITRODUCAO}

Muito se tem escrito sobre a limnologia e hidrogeoquímica da regi ฮ̃o Amazónica, particularmente da Amazónia Central. A literatura existente esta mais concentrada na quimica das águas dos principais ecossistemas aquaticos da regiăo, sem contudo relacions-la com os sedimentos dos lagos que constituem esses ambientes. Ha portanto um flagrante desconhecimento sobre as caracteristicas e propriedades desses sedimentos.

A carôncia de informaçðes sobre os sedimentos deve-se, provavelmente, a intrincada rede hidrografica da bacia e as inerentes dificuldades nas operaçoes de amostragens, espeḉficas para a regiăo.

O objetivo primordial deste trabalho 60 de fornecer informaçoes basicas sobre as principais caracteristicas dos sedimentos dos lagos de uma área significativamente importante da bacia Amazônica: Lagos do Rio Branco, Lagos do Rio Negro, Lagos do Rio Negro sobre influência do Rio Branco e Lagos do Rio Solimøes/Amazonas. 
Os resultados aqui apresentados, certamente, serão de utilidade para os programas de pesquisas em andamento e futuros, que visam a compreensão da hidrogeoquímica do meio natural amazônico e sobretudo poderåo servir de referoncias para os programas de monitoramento das alteracóes do meio, devido ao desmatamento que ora se intensifica na região.

Para atingir os objetivos propostos foram realizadas excursöes em barco laboratório, e coletados sedimento do fundo de vinte e nove principais lagos de várzeas que compõem as confluências dos rios Negro e Branco e, ainda do rio Solimöes/Amazonas. As amostras coletadas foram analisadas quanto as principais caracteristicas físicas, químicas, físico-químicas e mineralogicas. 


\section{REVISTOO BIBLIOGRAFICA}

Neste item, såo mostrados os aspectos gerais da bacia Amazônica relativos a Geologia, Geografia, Clima, Vegetąão, Solo e as características Limnológicas.

\subsection{MEIO FISICO DA BACIA AMAZONICA: ASPECTOS GERAIS}

\subsubsection{GEOGBAFIA}

A exata defini ̧̧ăo dos limites geográficos da bacia Amazônica $\theta$ bastante diffcil, uma vez que o termo Amazônia $\epsilon$ empregado num sentido bastante amplo. Assim, por vezes, o termo Amazônia a regiåo Norte do Brasil, muito embora, como regiăo natural, ela estenda-se por vários outros paises da Américado Sul (FIGURA 1): ao Norte pelas duas Guianas e 0 Suriname, e a Leste pela Venezuela, Colómbia, Equador, Peru e Bol ŕvia. Por outro lado a Amazonia tambem $\Leftrightarrow$ identificada como uma área que compreende a bacia de drenagem do rio 


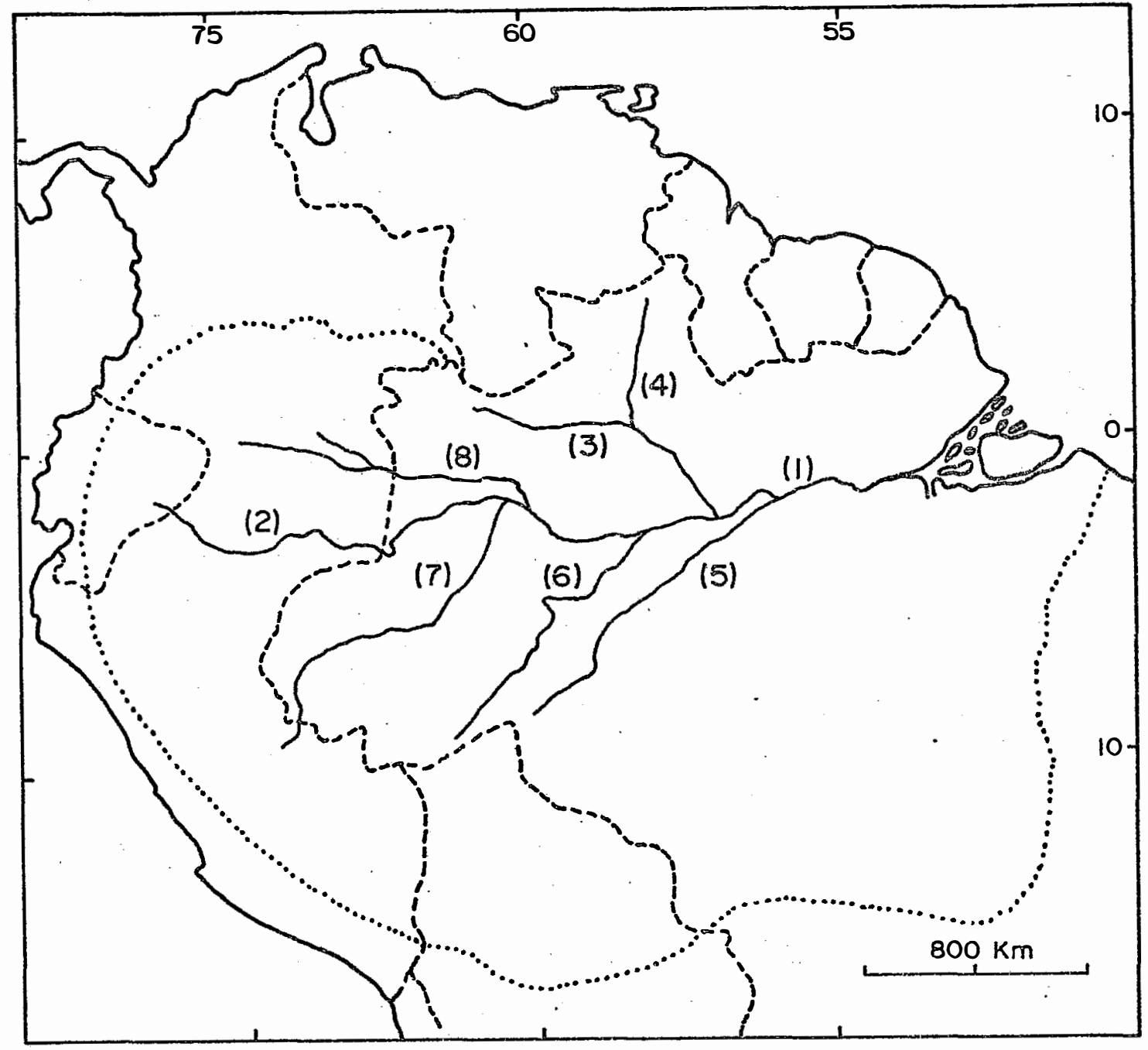

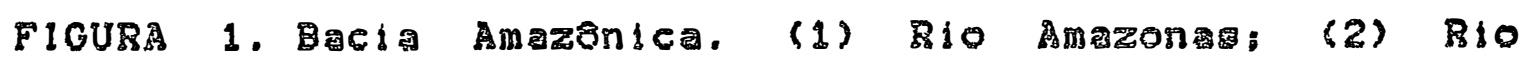

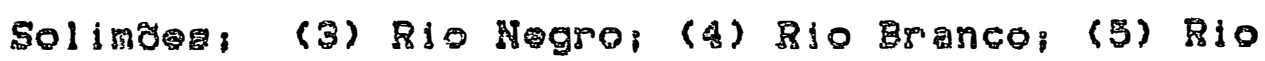
Madoira; (6) Rio Purus; (7) Rio jurua (8) Rio

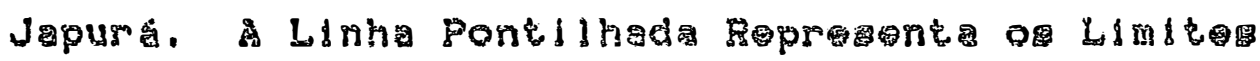
da Bacia 
Amazonas. No entanto, em algumas regiơs, a Amazônia ultrapassa os divisores de agua desta bacia e dos seus principais tributarios (Xingu, Tapajos e Tocantins), os quais tôm suas cabeceiras situadas no cerrado brasileiro. Existem divergôncias quanto aos seus limites. SlOLl (1994), considera o rio Tocantins como afluente do rio Amazonas, enquanto GIBBS (1975), næ̧o considera esse rio como tributario do Amazonas.

Visando uma ocupaçăo e o desenvolvimento por parte do Governo Federal, a bacia Amazônica passou a ser chamada de Amazônia Legal. Esta área de $5.030 .000 \mathrm{~km}^{2}$, a qual ocupa aproximadamente $59 \%$ do territorio brasileiro, esta contida entre os paralelos de $16^{\circ} \mathrm{S}$ no Estado do Hato Grosso, pelo paralelo de 135 no Estado de Goŕas e ainda, pelos meridianos de 44 W e 79 W Gr.

A bacia Amazônica tem uma configuraçăo clássica $\theta$ formada de extensas planf́cies e ladeada por terras elevadas. Ao Deste encontra-se as cordilheiras dos Andes, com altitudes de 3.000 a $7.000 \mathrm{~m}$. Ao Korte destacamse o escudo das Guianas com altitudes variando de 200 a 500 . m e ao Sul, o escudo Brasileiro, também com altitudes de 200 a 500 m. 
- principal rio de descarga dessa bacia o rio Amazonas, que tem como formadores os rios Ucayali $\theta$ Marañon, no Peru e seus principais tributários no lado brasileiro, såo os rios Jurua, Purus, Madeira, Tapajos e Xingu, pela margem direita; enquanto que os da margem esquerda, săo os rios Iq̧a, Japurá, Negro e Trombetas. Tem um sentido direcional Deste - Leste totalizando $6.771 \mathrm{~km}$, paralela j̀ linha do Equador, desaguando no Oceano Atlântico (STALLARD, 1983).

\subsubsection{RELEVO}

O relôvo atual da bacia Amazônica acha-se intimamente relacionado a processos geológicos da era Quaternaria, principalmente às variaşós no nfvel do oceano devido às glaciacões (IRION, 1984. YLAHRER, 1984).

As principais unidades de relêvo da bacia amazônica foram enumeradas por KLA decrescente de suas idades: - o "plateau" de deposiqăo conhecido como argila Belterra; b-um relevo de suave erosaro descendo o plato ató uma altitude de, aproximadamente, $80 \mathrm{~m}$ acima do nivel atual dos rios e e um grupo de 9 a 10 varzeas fosseis estendendo-se da altura de $80 \mathrm{~m}$ at 6 o presente nível do $\mathrm{mar}$ (FIGURA 2). 
A argila Belterra tem altitudes aproximadas de $100 \mathrm{~m}$ a $250 \mathrm{~m}$ acima do nivel do mar na regiăo central da Amazônia. Ao se distanciar do rio Amazonas este "plateau" pode atingir $300 \mathrm{~m}$ de altitude. SOMBROECK (1966), ao estudar essas argilas, atribuiu a origem marinha-lacustre, sendo depositada durante a formacão de um grande lago, que foi formado pelo represamento dos rios, devido à subida do nivel do mar durante o persodo de transicão entre a era Terciaria e a Quaternaria. Já IRION (1984a), atribui a formaça da argila Belterra aos produtos de intemperismo da formaço Barreiras, cujos sedimentos foram depositados durante 0 Tercisrio.

Grande parte dos terrenos que na Amazônia são conhecidos como terra-firme constituem, segundo RLAMPER (1984), as várzeas fósseis, que atualmente se encontram modeladas em funç⿰丿丶⿸⿴巳一丶 de sua litologia e estrutura e que 0 grau de dissecąåo 6 um reflexo de sua idade. 


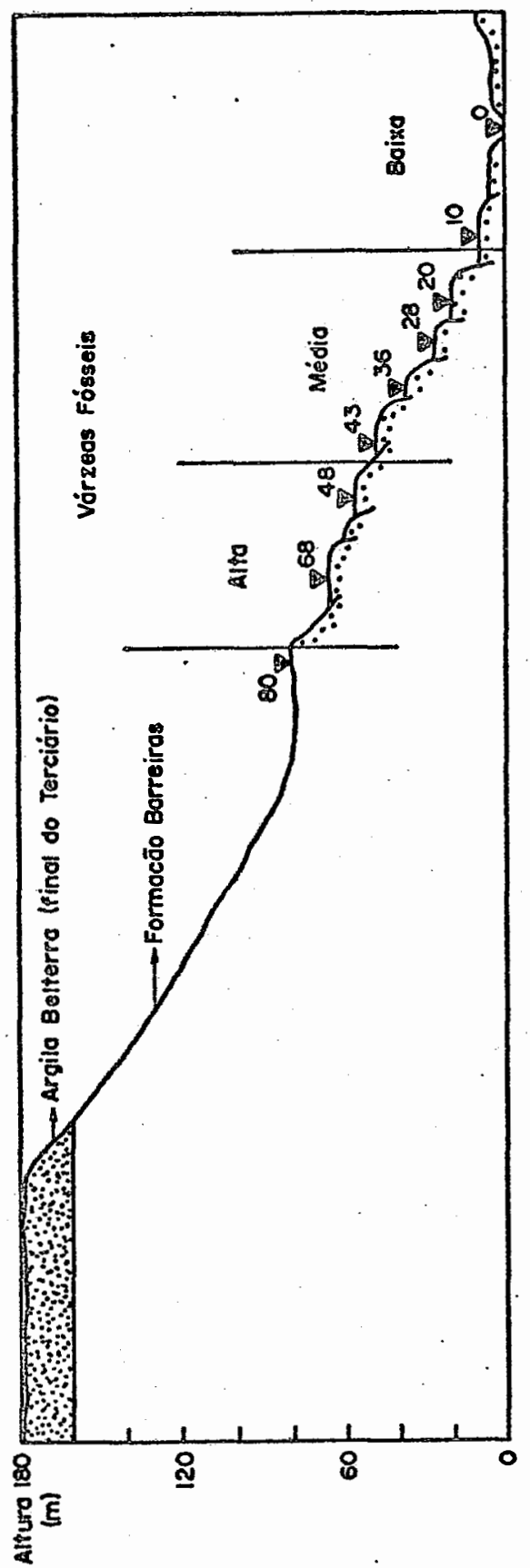

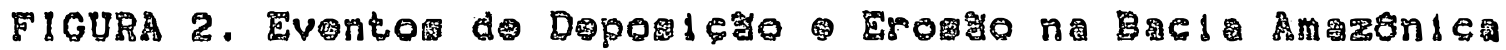

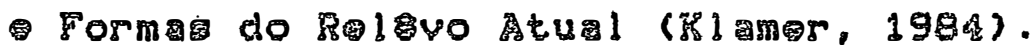


As varzeas mais jovens da Amazônia, que se situam próximas aos canais dos grandes rios, têm sua origem no Holoceno (JUNK, 1984 e IBION, 1984). Durante a glaci aça de Wurmian (18.000 anos), houve consequentemente um abaixamento do nível do mar de cerca de $130 \mathrm{~m}$. Desta forma, os vales do canal principal e o baixo curso de seus tributarios foram intensivamente erodidos, ou seja, os sedimentos foram depositados durante o final do Terciario e durante o Pleistoceno. Com o fim dessa glaciąå, houve um rapido aumento no nível do mar até $125 \mathrm{~m}$, havendo a formaça de um grande lago devido ao represamento dos rios, onde hoje est子o localizadas as varzeas atuais. (5IOLl, 1975b: IRION, 1984: KLAMHER, 1984).

\subsubsection{CLIBA E HIDBOLOGIA}

Estudos realizados por SALATI (1988), indicam que a Amazonia, recebe no limite superior da atmosfera um maximo de $875 \mathrm{cal} . \mathrm{cm}^{-2} \cdot \mathrm{d}^{-1}$, entre janeiro a dezembro e um mínimo de $730 \mathrm{cal.cm} \cdot \mathrm{d}^{-1}$ em junho e julho, sendo que $50 \%$ dessa quantidade chegam à superfície.

WI MER (1977), relata que devido ao regime de temperatura, toda a regi đo Norte do Brasil, na qual esta contida 70 \% da bacia Amazônica, possui domínió climstico quente, sendo os principais subdomínios climsticos: 
- super úmido e o úmido. 0 super úmido domina a porço Oeste da bacia, grosseiramente a parte de Manaus, onde o tipo climstico 6 o equatorial, j与 na posiço Leste da bacia a partir de Manaus, domina o ŕmido, com tipo climstico tropical:

A distribuiça de precipitaçăo na bacia 6 sensivelmente, menos uniforme (FIGURA 3 ). 0 movimento meridional do sol entre os paralelos $23^{\circ} 27^{\prime}$, cruzando a linha do Equador duas vezes por ano em intervalos de seis meses, conjuntamente, com a fonte de agua $e$ ar quente que 6 - Oceano Atlantico, são os principais fatores que determinam os padrźes de clima e consequentemente a pluviosidade da região Amazônica (\$ALATI, 1984 1986).

HARQUES Ot 11 (1979), estimaram que a quantidade media de vapor dagua armazenado na atmosfera (sgua precipitavel) a da ordem de $35 \mathrm{~mm}$; enquanto $a \mathrm{~m} \varphi d i a$ mundial 6 de $28 \mathrm{~mm}$, conferindo $\vec{a}$ regiăo condi६̧̃es isotérmicas, com alta pluviosidade. Relatam ainda, que a pluviosidade anual 6 maior na costa Norte, com valores acima de $3.250 \mathrm{~mm}$, sendo que esse valor decresce em dirę ج̊ a Amazônia Central atingindo um mínimo de $1.750 \mathrm{~mm}$. A a partir da Amazonia Central, a quantidade anual de precipitaço comeca a aumentar, desta feita, em direç̃os Nordeste e Sudeste. Na direço Nordeste, encontraram-se os 
maiores indices, ficando em torno de $3.500 \mathrm{~mm}$ e a Sudeste, esses valores sao menores alcancando 2.250 a $2.500 \mathrm{~mm}$ (SALATI ot alii, 1978 NIHER, 1977). Por6m, SALATI (1986), mostra que esses Indices podem chegar z $5.000 \mathrm{~mm}$. ano ${ }^{-1}$, na regi ăo Andina.

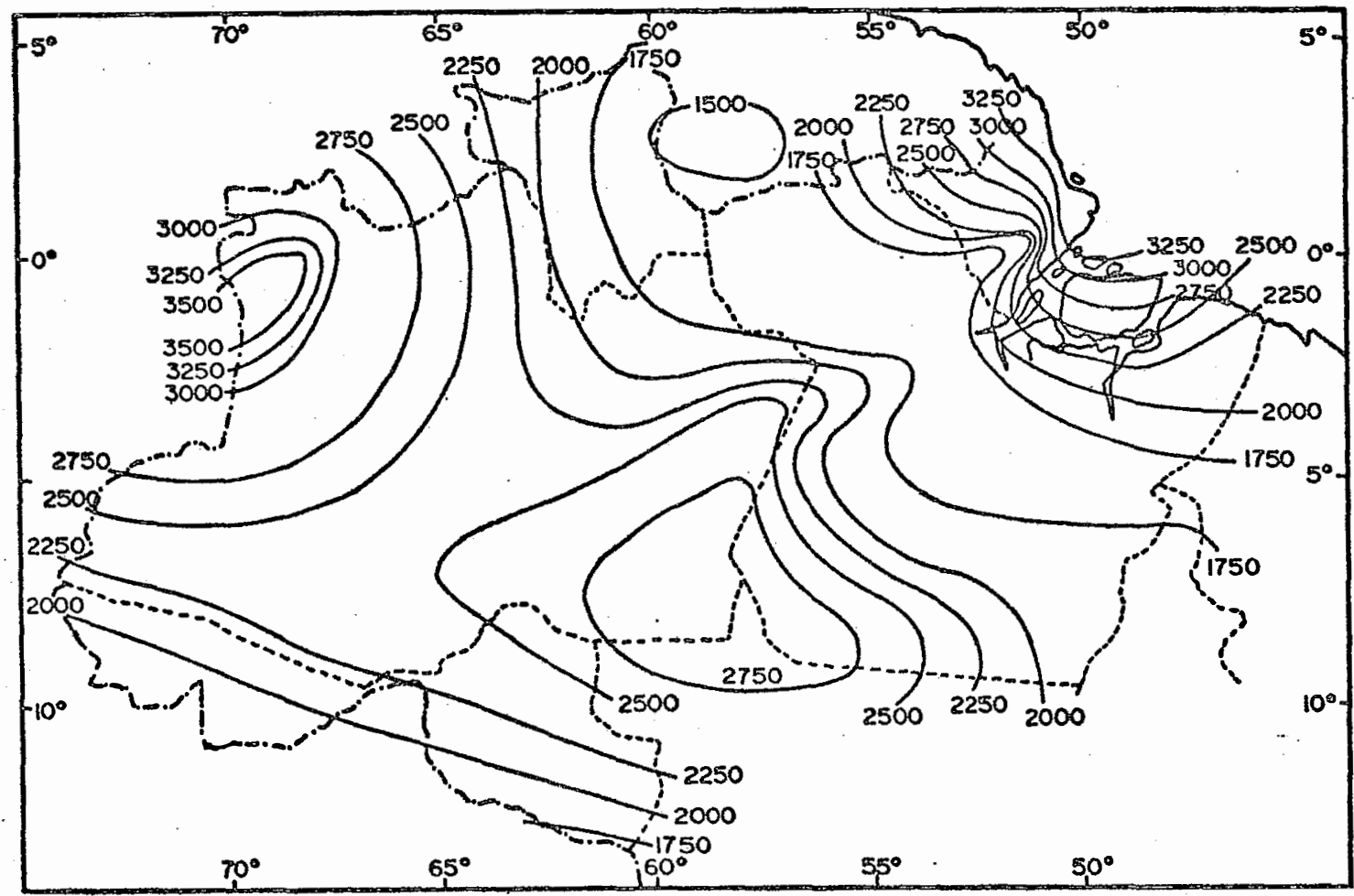

FIGURA 3. Distribuiço Anual das Precipitaçơs na Regiăo Amazônica (Salati, 1984). 
Trabalho realizado por RIBEIBO \& VILA NOVA (1979), numa reserva florestal perto de Manaus (Reserva Florestal Ducke, a $26 \mathrm{~km}$ de Manaus), durante o perfodo de 1965 a 1973, observaram um valor médio da precipitaço de $2.478 \mathrm{~mm}$ e de $1.536 \mathrm{~mm}$ para a evapotranspirąå, sugerindo que 62 \% da agua precipitada volta à atmosfera e 38 \% fica no sistema ou saiu do mesmo por escoamento superficial.

\section{LEOPOLDO 't aldi (1982b), tambGm}

trabalhando em uma reserva florestal tropical proximo a Manaus (Bacia Modelo, à $80 \mathrm{~km}$ de Manaus), estimaram que $74 \%$ da precipitacão que atinge o dossel da floresta foi evapotranspirado e 0 restante $26 \%$ foi perdido por escoamento; sendo que o valor absoluto da precipitacaro foi de $2.088,9 \mathrm{~mm}$ e da evapotranspiracão,e $1.548,2 \mathrm{~mm}$.

Estudos realizados no alto rio Negro, Venezuela, em São Carlos do Rio Negro, por JORDAN ald (1981), onde estimaram que $52 \%$ da precipitacão foi evapotranspirada e $48 \%$ deizsou a bacia pelo escoamento superficial. Determinaram ainda, que a precipitaço foi bem mais elevada nesta regiăo, na ordem de $3.664 \mathrm{~mm}^{-a^{-1}}{ }^{-1}$, enquanto nas outras greas da Amazônia Central foram estimadas em $2.214 \mathrm{~mm}$. ano 
Considerando-se a bacia como um todo, MOLION (1979), observou que $48 \%$ da precipitą̧̃o $(2.379$ -1 .

mm.ano, era evapotranspirado e 52 \% era escoado pelo rio Amazonas. MARQUES of alil (1980), chegaram a resultados semelhantes: $2.328 \mathrm{~mm}$. ano foram precipitados e $54 \%$ foram evapotranspirados. Estimaram ainda, que atraves da precipitaça, a bacia recebe $11,87.10^{12} \mathrm{~m}^{3}$.ano $0^{-1} \mathrm{e}$, através da descarga do rio Amazonas, deixa o sistema $5,44.10^{\mathrm{m}}$. ano

Pelos trabalhos climatológicos at agora realizados na regi ăo Amazônica, podemos caracterizála por altas temperaturas com baixas amplitudes térmicas onde predomina o clima quente e úmido; precipitą̧a bastante elevada durante 0 ano, em média $2.200 \mathrm{~mm}$ (5ALAt 1, 1986).

\subsubsection{VEGETAGKO}

Apesar da Amazônica constituir-se na mais vasta regi ăo de floresta tropical, sua flora 6 muito pouca conhecida. Destacam-se os trabalhos de (SPBUCE, 1900; GATES, 1927; GUNTHER, 1931; ULE, 1947; SOARES, 1948C; KUHIMANA, 1959; VELOSO, 1962 ○ 1966; PIBES, 1957, 1966 1973; BIZZINE, 1967 SIOLI, 1967). SIOLI (1968a), foi quem caracterizou, ecologicamente, essa região. 


\subsubsection{TIPOS. FI5IOROMICOS}

Grande parte de area coberta pela floresta Amazônica tem uma fisionomia extremamente uniforme, mas no seu interior ha uma riqueza de diversificaço botânica que varia com as condiçoses locais, as precipitaç̃es pulviom6tricas, as alteracóes anuais nos níveis dos rios e outros fatores ecologicos.

Segundo PIRES (1966 1973), a floresta Amazônica 6 coberta por 90 \% de floresta de terra-firme (terras nశo inundadas), de determinados tipos, nå tendo uma distribuiç⿰ uniforme. Essa diferenca $\sigma$ devida em parte, à grande variedade de especies de arvores, e mais ainda à diversidade das caracteristicas. de solo, profundidade e facilidade de drenagem, profundidade e flutuaço do lencol freatico e dos microclimas. Na Figura 4. Mostra-se os varios tipos de vegetaço existente na

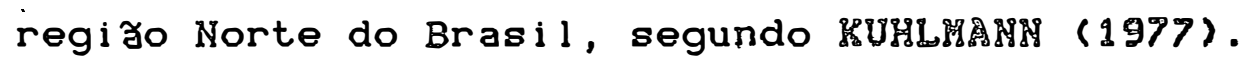

\subsubsection{FLORESTA DE TERBA FIRYE}

Cobrindo $90 \%$ da filoresta Amazônica, situa-se nas terras altas e nåo alagadas. Fisionomicamente, * uniforme em toda a sua extensão, mas ha uma grande variedade na composicăo das especies de uma área para 
outra. Por $6 m$, podem ser subdivididas em:

a. Floresta elevada com grande biomassa, cobertura relativamente esparsa do terreno. Arvores altas, copas fechadas, lianas grossas e lenhosas e pouco numerosas :

b. Floresta

ba ixa

com

biomassa reduzida, relacionada com a altura, solo, declividade do terreno: cobertura espessa, árvores baixas e um maior número de plantas endêmicas:

c. Floresta de cipó, com biomassa mødia e totalmente entrelaçada de lianas, situada entre os rios Xingu e Tocantins: tende à formaçăo de bambuzais e possui muito pouco epifitas:

d. Floresta de campina (caatinga amazônica), um tipo de floresta baixa $\theta$ cerrada, um solo de areia branca, intermediário entre a floresta alta e a campina; possui uma flora caracter Istica, na qual se incluem muitas 


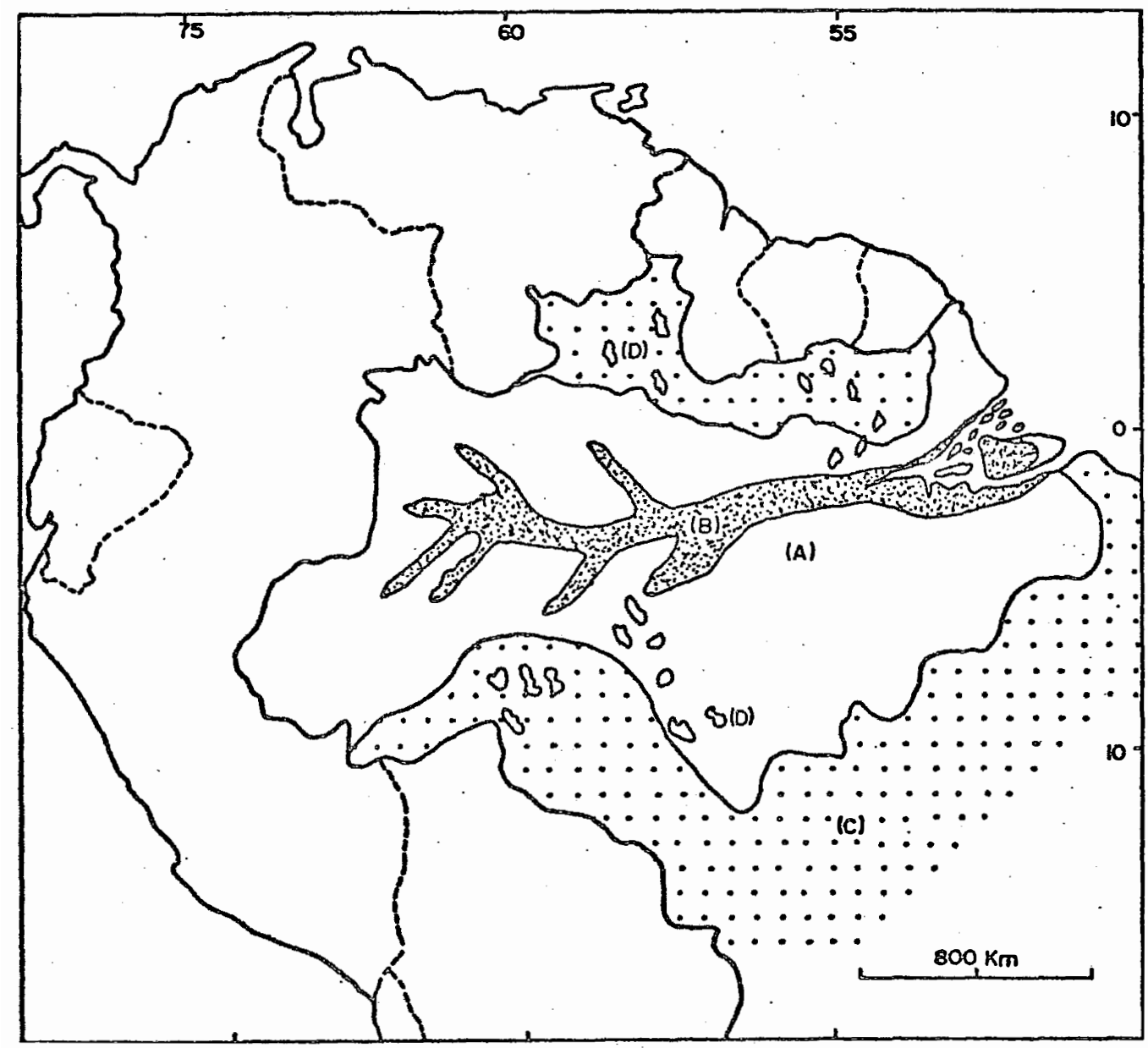

FIGURA 4. Tipos de Vegetaģ⿰丿⺄⿱二小) da Região Norte (Amazônia). (A) Floresta de Terra Firme; (B) Floresta de. Varzeas: (C) Floresta Subcaducisblia e (D). Campo. (Kuhlmann, 1977). 
plantas endônicas. A floresta de campina (caatinga) do alto rio Negro tem um endemismo e uma diversificą̧̃o vegetal muito superior às de outros do mesmo tipo situada no Baixo rio Negro, pr6ximo a Manaus:

e. Floresta seca, com biomassa média, alta penetraço de luz no terreno, abundância de cipo e grande número de arvores, cujas folhagens caem periodica mente. Esse tipo de vegetaço representa uma transiço entre a floresta alta amazónica e as variacōes de cerrados cerradäo do Brasil Central, sendo comum no Mato Grosso (SOARES, 1988C; PIRES, 1957; 1966 1973; RIZZINI, 1967; SIOLI, 1967 1968a. KUHLXNAN, 1977).

\subsubsection{FLORESTA DE VRRZEAS}

Esses tipos de vegetaço são encontrados em solos, periodicamente alagados. A durąåo do período de al agamento varia de acordo com a altura em que ela se situa acima do nível do rio. 
A floresta que 6 alagada anualmente apresenta uma considerável diferença na composiç̃o das especies em comparaço à floresta de terra firme, achando-se a maioria de suas especies adaptadas tanto a um tipo quanto ao outro. A floresta de varzeas apresenta menor diversidade de especies do que a de terra-firme (PIRES, 1966 - 1973 SIOLI, 1968a).

Nas florestas de várzeas altas, o terreno tem cobertura esparsa, sendo comum a presenfa de raizes respiratorias (ponoumatoforo). Esse tipo de floresta 6 geralmente mais baixo do que a de terra-firme, apresentando algumas arvores gigantescas como a samaúna (C) pontandra) (PIRES, 1966 . 1973 SIOLI; 1968a).

Nas florestas inundáveis de varzeas (TABELA 1), o conteúdo dos elementos nutritivos $\mathrm{N}, \mathrm{P}, \mathrm{Ca}$, Mg e K são mais altos que os verificados na floresta de igapo (KLINGE ot alii, 1983). Essas concentraçes são variaveis de acordo com as especies que constituem -essa vegetą̧̃o. 
TABELA 1. CONTEODO DE Ca, HG, Na, IAUNDAVEIS DE VRRZEAS (BIIIng ot ali1, 1983).

\section{E L E M E N T O S N U T R I T I V O S}

ESPECIES

Ca $\quad \mathrm{Mg} \quad \mathrm{Na} \quad \mathrm{K} \quad \mathrm{N} \quad \mathrm{P}$

\begin{tabular}{|c|c|c|c|c|c|c|}
\hline \multirow[b]{2}{*}{$\begin{array}{c}\text { Boraginacea } \\
\text { (Munguba) }\end{array}$} & \multicolumn{2}{|c|}{ ーーーーーーーーーーーーーーー } & \multirow{2}{*}{$\begin{array}{l}\text { ppm } \\
156\end{array}$} & & \multirow[b]{2}{*}{2.260} \\
\hline & 15.887 & 3.992 & & 31.286 & 35.000 & \\
\hline $\begin{array}{l}\text { Legum inosae } \\
\text { (Inga) }\end{array}$ & $\begin{array}{l}\text { I.sp. } \\
23.702\end{array}$ & 2.876 & 107 & 8.463 & 35.500 & 1.600 \\
\hline $\begin{array}{c}\text { Miliaceae } P \\
\text { sp }\end{array}$ & $\begin{array}{l}\text { ichilia } \\
26.417\end{array}$ & 6.716 & 35 & 6.683 & 17.800 & 1.720 \\
\hline $\begin{array}{c}\text { Gutt iferae } \\
\text { Pl.et.Tr. }\end{array}$ & $\begin{array}{c}\text { brasil iense } \\
13.930\end{array}$ & $\begin{array}{l}(\text { Mart.) } \\
2.433\end{array}$ & 58 & 13.732 & 14.600 & 1.510 \\
\hline
\end{tabular}

E o tipo de vegetaça encontrada em solos permanentemente alagado, com água estagnada durante, pelo menos, uma parte do ano. Geralmente, o solo e a agua såo bastante acidos (5I0Ll, 1956b 510LI \& 89L188G, 1962). Sua . vegetąå altamente especifica e apresenta menor. diversidade de espacies, ocorrendo, porǿm, endemismo em muitos igapos isolados (PIRES, 1966 1973). 
As rafzes de escoras e as respiratólas sło mals numerosas. Alguns lgapós tornam-se secos e se transformam em pratas durante uma pequena parte do ano, mas, o terreno nz̧o é adequado para sustentar uma floresta

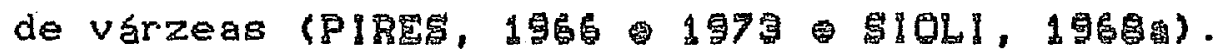

Nas florestas inundaveis de 1gapo, 0 conteúdo de elementos nutritivos tais como, Ca: Mg: Na e K,

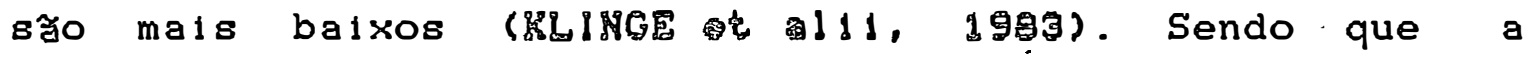
concentraç̧es săo variácis e dependem das espécies existentes nessas areas (TABELA 2).

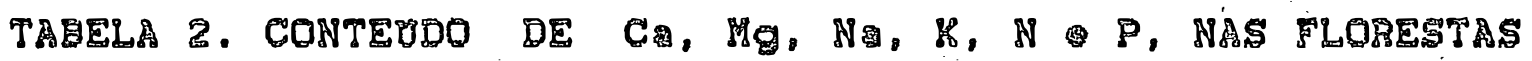
INU⿴囗大

ESPECIES

E L E M M E N $\mathrm{N}$ O

$\begin{array}{llllll}\mathrm{Ca} & \mathrm{Mg} & \mathrm{Na} & \mathrm{H} & \mathrm{N} & \mathrm{P}\end{array}$

\section{ppm}

Leguminosae Macrolobium (DC).
Benth.
5.497
2.009
105
$9.943 \quad 25.500$
1.100

Leguminosae Aldina latifol da var. latifolia Spruce
ex Benth.
1.3301 .236
$20 \quad 3.565 \quad 24.300$
400

Sapotaceae Franchetella crassifoli a wawra (Radik)
J.M.Pires
660
372
41
5.794
12.700
360

Theaceae Ternstrocem 1 a

$\begin{array}{lllllll}\text { andolliana } & 1.583 & 1.310 & 65 & 13.129 & 12.200 & 160\end{array}$




\subsection{G. GOLOQIA}

Com base nos estudos realizados por PUTZER, (1984): 5CHUBART, (1983) FI0L8, (19756), podemos definir, geologicamente, a bacia Amazônica como uma bacia sedimentar intercratônica, formada entre os escudos Brasileiro e das Guianas. Ja zonas mọfoestruturais bem definidas: escudo Pré-Cambríano (Brasileiro e das Guianas): bacia Amazônica; a Cordilheira dor Andes e a depressâ Sub-Andina (FIGURA 5).

A base de toda bacia 6 formada por rochas cristalinas da era Pró-Cambriana. Essas rochas encontram-se nos limites Norte e Sul da bacia, sendo que ao Norte, formam o escudos das Gulanas, constituldos de rochas ígneas

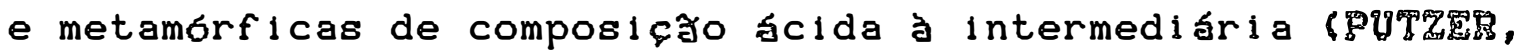

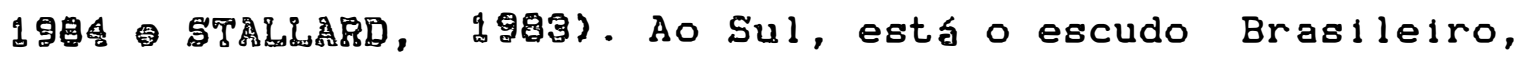
que 6 bastante similar ao das Guianas. Estas plataformas cristalinas avançam do Norte e do sul em direço zे depressào Amazônica, cobertas de sedimentos recentes

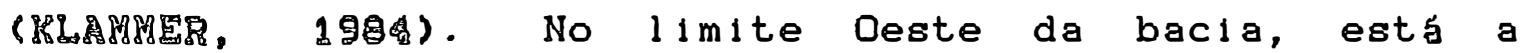
Cordilheira dos Andes, que surgiu na era Cenozốlca, sendo mals recente que os escudos cristalinos. Apresenta uma 11 tologia bastante complexa, sendo composta por argelitos, carbonatos, arenitos e sedimentos flúvio-lacustres (รTTLLARD, 1989 ). 


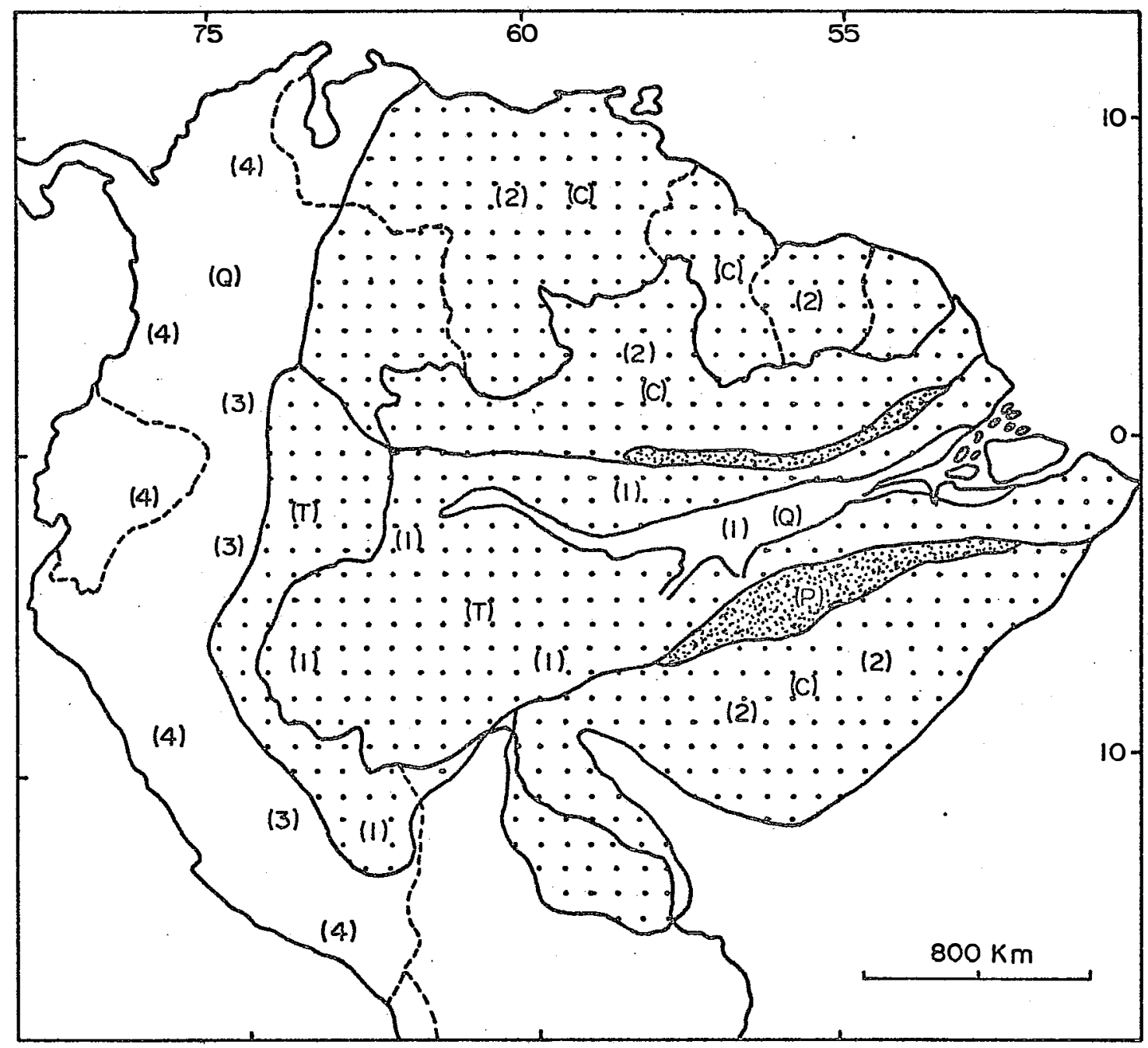

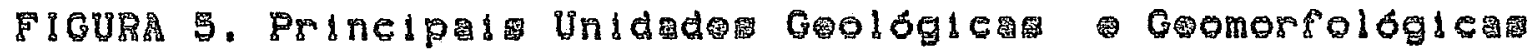
d Bø (т) Trereis (Q)

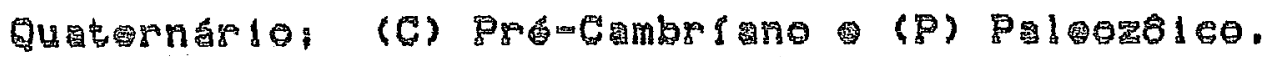

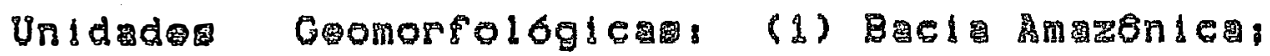

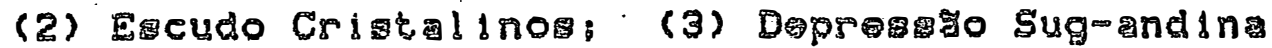

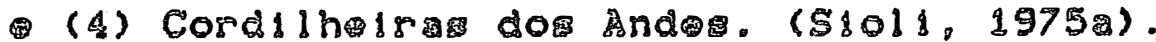


Historicamente, a formą̧̃o da bacia Amazônica 6 bastante antiga. Data da era Paleoz6ica $(420$ milhơes de anos), quando nåo havia ainda surgido a cordilheira dos Andes, a Africa e a Ambrica do Sul formavam um único contimente. A depressaro situada entre os dois escudos cristalinos foi invadida pelo mar, através de transgressð̋es no sentido Oeste para Leste, pelo menos trôs vezes durante os 2300 milhăes de anos que duraram esta era. Desta forma, alternaram-se período de sedimentacão e eroşว (PUTZER, 1984 5IOLI, 19756). Atualmente estes sedimentos só nå foram cobertos em duas estreitas faixas que margeiam os escudos cristalinos na regiăo do Baixo Amazonas. Na era kiesozóica foi um período de desnudaço, tendo no Cretácio, ocorrido intrusores de diabásico, através de fraturas da crosta, quando da formaço do Oceano

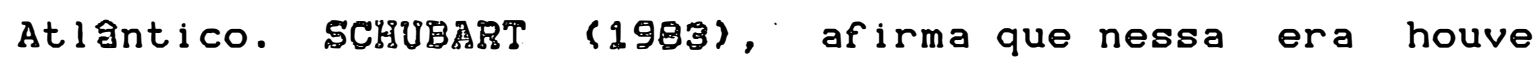
deposi ̨aro de sedimentos flúvio-lacustre.

Nesta fase, havia duas bacias distintas; uma onde o padrão de drenagem era semelhante ao que ocorre atualmente, ou seja, os rios percorriam, predominantemente,

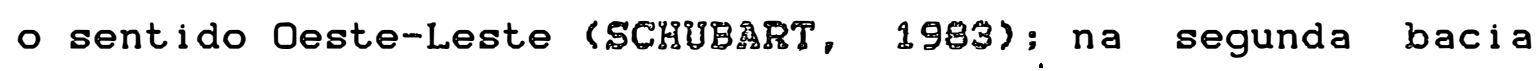
situada na regiăo de lquitos (Peru), os rios drenavam para - Pacífico, no sentido Leste-Oeste. No final da era Terciária, no período Mioceno, houve a elevą̧̆o dos Andes. 
Consequentemente, os rios que corriam em sua direç̃o foram bloqueados, passando a fluir em sentido contrario, ou seja, de Oeste para Leste (GIBBS, 1965; 510LI, 1975b PUTZER, 1984).

Seguiu-se um período de deposiçăo de sedimentos de origem flúvio-lacustre, constiturdo principalmente de silte-argila, originando a formaço Barreiras (Alter do Chão). Durante o perfodo Plioceno e toda a era Quaternsria, devido a oscilaçōes do nivel do mar ocasionadas pelas glaciaçes, os rios da bacia Amazónica

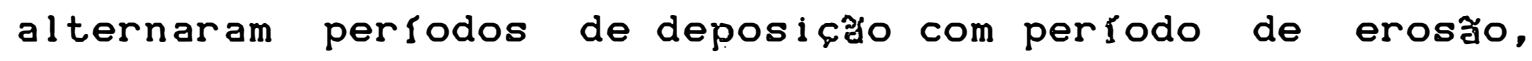
formando extensas planícies de inundacăo e estabelecendo o atual padråo de drenadem (Jußk, 1984; S10LI, 197\&b;

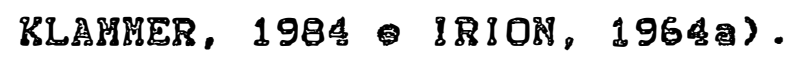

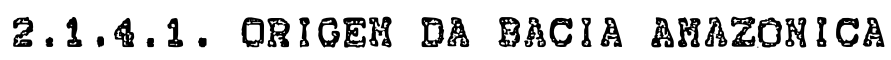

Segundo RATZER (1903): OLIVEIRA \& LEONABDO (1983) 510LI (1965), as Sguas da regiăo Amazonica tiveram um papel preponderante na formą̧̆o geol6gica da regi ăo. A "bacia amazônica" era coberta por um golfo dọ mar do oceano Paḉfico, o qual era aberto para Este, e limitado ao. Norte e ao. Sul pelos macicos das Guianas e do Brasil. Central, e fechado a Leste. Esse golfo, possivelmente tenha durado todo o Paleozóico. 
Os movimentos verticais que af astaram o continente, durante o Mesozbico, fizeram com que o mar se retirasse desse golfo e, consequentemente o seu secamento. Os rios que drenavam nessa zona, tiveram o seu movimento seguido em direçăo ao Pacífico, isto, somente com o levantamento dos Andes, isto 6 , no fim do Mioceno. Desse levantamento, resultou um lago de agua doce, pois se encontrava fechado por todos os lados, tendo somente uma pequena ligaç̧o com o mar das Antilhas.

No Pleistoceno, a margem do "lago amazônico" da época do Tercierio, teve inscio a um rebaixamento, fazendo com que as águas iniciassem os seus movimentos de descida, desta feita, para o lado do At lântico. Isto ocoreu, devido ao grande peso da massa de Sgua e de sedimento em cima do bloco contimental.

Com a movimentaçăo das gquas para o At lântico. 0 peso da massa de água foi diminuindo e a crosta terrestre teve um levantamento leve, ficando acima do nível do mar, dando origem as "terras firmes" a "floresta amazônica".

\subsubsection{ORIGER DOS SEDIMENTOS}

Os sedimentos tâm sua or 1 gem na eroş̧o de 
rochas pro-existentes, que podem situar-se a varias distâncias do lugar onde haverá a acumulą̧a, como também da própria şrea de deposiç̃o.

Os sedimentos carreados pelo rio Sol imøes/Amazonas săo provenientes dos Andes. Sua vazåo observada em Obidos 6 de, aproximadamente, $170 \mathrm{milhơes} \mathrm{de}$ toneladas em soluço e 425 milhres de toneladas em suspenså, que passam anualmente neste ponto (LEIHZ AMABAL, 1978; MEADE OC al11, 1979 BRASIL, 1984).

A composiç̃o desse sedimento, $\theta$ ○ Fluxo da . composįăo das rochas que estăo sofrendo erosăo na fonte de produço e da natureza dos precipitados orgânicos e inorgânicos susceptíveis de se somarem no. sítio dé deposi६ăo. Essa composi६ăo depende, também, da relą̧̃o entre o intemperismo na fonte de deposicăo e a deposicão na bacía sedimentar.

Se as rochas erosivas eståo profundamente intemperizadas, seus constituintes minerais eståo quimicamente desintegrados. Quando a velocidade de erosaro $\epsilon$ rápida, entåo os minerais săo transportados e soterrados antes que possam ocorrer muitas alteraç̋es e desintegraço

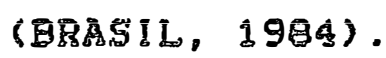




\subsubsection{5EDI MEXTHCAO}

Na bacia Amazônica, camadas denominadas Alter do Chåo săo atribuŕas, pelo menos em parte ao Cretacio. A evidôncia paleontológica de maior peso săo dentes identificados como pertencentes a dinossauros teropodes (88R5id, 1989).

Localizam-se na Amazônia as mais importantes areas de sedimentą̧๐o Quaternaria. Sశ๐o as argilas aflorantes nas margens do rio Jurua, com bivalidos de agua doce, folha e vertebrados, que permitem sua dataço com o Quaternário. A planf́cie de inundąåo do Amazonas $\sigma$ sede de intensa sedimentaço.' Nas varzeas e lagos, acumula-se grande quantidade de sedịmentos, depositados pelas cheias. As regiơes que nåo sof́rem influência da enchente săo formadas por sedimentos Quaterngrios mais antigos (BRASIL, 1988).

Nas cabeceiras do rio Branco, ocorrem os sedimentos Quaternarios denominados formaço Boa Vista. Toda a sedimentação Pleistoç̂nica que cobre a bacià do Amazonas extravasa-se, cobrindo o embasamento. Que a Deste do meridiano de Manaus, 6 denominada formaçăo ļa, na qual se assinala a presenca de turfa (98月sil. 1984).

DAVIS (1964), estimou que a descarga do 
rio Amazonas era de $212.000 \mathrm{~m}^{3} \cdot \mathrm{s}^{-1}$, entretanto OLTHAMN (1968), calculou em $175.000 \mathrm{~m}$. s, isto perto de obidos. Para esse mesmo local, RICHEY dil (g.d.), estimaram em $177.000 \mathrm{~m}_{3}^{3} \cdot \mathrm{s}_{-1}^{-1}$ na 6copa do início da subida das bguas e de $202.000 \mathrm{~m}$. s , no inicio da descida das aguas.

GIBBS (1965), calculou o total de descarga de sedimentos do rio Amazonas em $3,5.10^{8} \mathrm{t} \cdot$ ano $^{-1}$, representando $80 \%$ do total que 6 descarregado no Oceano Atlântico na regi zo equatorial. Enquanto que, MEDE

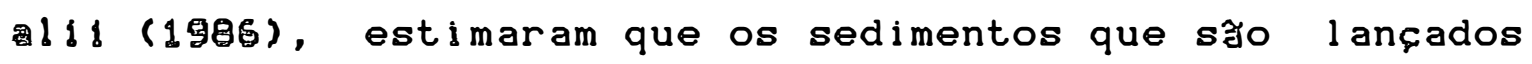
ao Atlântico pelo rio Amazonas, 6 da ordem de 1,1 a $1,3.10^{9}$ t. ano $^{-1}$.

Segundo झORDI8 है। (1981), a distribuiço de tamanho de partículas do leito do rio Amazonas, næo sofre varią̧วo apreciável desde de Iquitos, no Peru, at́ llacapa, no Brasil, isto uma distância de $3.200 \mathrm{~km}$.

Entretanto, LAHD\&B \& registraram que as areias do rio Amazonas, proximas de Iquitos, ou seja, nos primeiros $1.300 \mathrm{~km}$ săo ilcas em minerais instaveis, tais como "hyporgthon", augita e anfibolio, o que indica uma fonte predominantemente andina e que as areias nos $2.000 \mathrm{~km}$ inferiores contêm menos 
minerais instaveis e maiores proporqão de zircăo e turmalina.

Estudos de sedimentos em suspensẩo realizados por MAEDE et. alij (1979), mostraram que as concentraçßes em seçôes transversais do rio Amazonas e de seus tributăios năo apresentam distribuiçăo uniforme. Entretanto, os que eståo entre 0,01 a $0,5 \mathrm{~mm}$ acham-se em maior concentraqăo junto do fundo, e que a maior parte das variaçбes transversais são devidas as diferenças nas concentraçôs de silte e argila em suspensåo. Mostraram ainda que o material do fundo, recolhido na sua major parte por draga de suçáo de areia fina a mélia em quase todas as seçôes transversais, desde Iquitos até a foz do rio Amazonas. Mostraram tambóm que a distribuifăo granulométrica do material do fundo nå varia sensivelmente em $3.300 \mathrm{~km}$ do curso dọ rio.

Em estudos sedimentológicos realizados na ilha da Marchanteria, rio Solimoes/Amazonas, foi verificado a uniformidade tanto na mineralogia como da composifäo geoquimica. As areias dessa ilha consistem principalmente de quartzo, o feldspato ests presente em pequena proporç⿰ (18108 ot 181, 1983).

Esses autores, observaram que as fraçôes 
dos grăos finos dos sedimentos consistiam principalmente de montmorilonita, ilita, caulinita e clorita, em adiça ao quartzo e ao feldspato. Mjostraram também que a química da f̣̣ą̧o em suspensăo no rio Amazonas 6 casualmente muito similar às fraços de argilas do sedimentos da ilha. Esses sedimentos são ricos em nutrientes inorgânicos, e săo essenciais para o bom conhecimento da fertilidade das várzeas do Amazonas.

IRION (1982), ao perscrutar os lagos localizados na parte Central da Amazônia Ocidental, sugeriu, que o comęo da sedimentą̧̃o durante o período Holocônico coincidiu com o levantamento mundial do nível do mar, devido as informaçes obtidas por meio do uso do carbono radioativo encontrado nesses sedimentos.

Quanto a composi६̧̃o iônica dos minerais de argilas e a ausância de minerais autogônicos descarta a possibilidade da existência de um clima árido,e que a continuidade do bosque chuvoso tropical na Amazônia Ocidental nåo está somente relacionada com o período Pleistoç̂nico médio a tardio, mas também, com o Holoceno. Sendo que suas conclusâes năo excluem a possibilidade de. que nas areas baixas mais ao Norte e Sul do rio Amazonas,. nas flutuaçes do Quaternario haviam sido suficientemente severas como para trocar o caracter da vegetaça. 
Estimativas dos sedimentos em suspensão no rio Amazonas foram feitas por MEDE ot alds (1979), onde em Obidos, este rio apresenta uma descarga de 230.000 3. -1

m .s e uma concentraço de sedimentos suspensos na ardem -1 - $3-1$ de $235 \mathrm{mg} .1$ e em Manacapuru, $130.000 \mathrm{~m} \mathrm{.s} \mathrm{e} 200 \mathrm{mg} .1$ enquanto o rio Negro apresenta um descarga de $50.000 \mathrm{~m}$. $-1$

s e uma concentraça de sedimentos suspensos na ordem de $5 \mathrm{mg}^{-1}$.

\subsubsection{SOLOS}

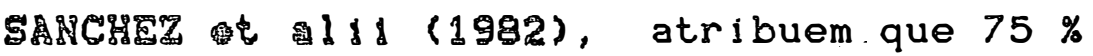
dos solos da Amazônia såo ácidos e inferteis, principalmente os Oxisols e Ultisols segundo a classificąão americana, ou Podzolicos e Latossolos pela classificacaro brasileira; 15 \% da Grea é dominada por solos aluviais pouco drenados, que pela classificaça americana são os Aquepts, Aquents e Gleysols. Os solos moderadamente férteis e bem drenados constituem $8 \%$ da area, e såo classificados como Alfisois, Molisois, Vertisois, Tropopst e Fluvents. Os 3 \% restantes, såo os arenosos de baixissima fertilidade, classificados como Spodosols, Psamments e Podsols.

Com base nos estudos de sAnCh (1982), podemos atribuir que $90 \%$ såo deficientes em 
fósforo; $73 \%$ apresentam toxidade de aluminio; $56 \%$ sofrem inundaçes periodica e drenagem deficiente; $16 \%$ apresentam baixa Capacidade de Troca de Cations; $15 \%$ evidenciam alta erodibilidade; $67 \%$ tem capacidade de formaçăo de laterita, caso haja exposiça do subsolo. Com isso, evidencia-se que as maiores limitaços dos solos da Amazônia såo de origem química e físiça, e somente 6 \% da área (32 milhores de ha), sło constituídas de solos sem maiores limitaços para a agricultura.

STALLARD (1983), relaciona os trôs maiores tipos de solos com áreas de diferentes climas e vegetaço: as Savanas que ocorrem na regi åo Nordeste e Sul, onde os solos tendem a ser caulinfticos com níveis variaveis de sesquibxidos de alumínio, e um maior período seco em relaça às outras regiðes; na parte Central da bacia eståo localizados os solos predominantemente cauliniticos com teores mǿdios de quartzo e a regiăo de Campina-Caatinga, com um menor período seco, onde os solos são bastantes ricos em quartzo, com ocorrancia de caulinita $\theta$ sesquíridos de alumínio.

IBION (1978), relaciona os solos da bacia Amazônica, às formaçoes geol bgicas dos escudos Cristalinos e da formaço Barreiras, mostrando que săo solos formados por rochas cristalinas de textura grosseira, com alta 
permeabilidade originalmente ricos em feldspatos e que devido a alta pluviosidade, os perfís encontram-se altamente intemperizados com formaço de caulinita apartir dos feldspatos. Sðo solos ácidos e de baixa fertilidade, onde a soma de cátions (Ca, Mg, Na e K), apresenta-se normalmente baixa. I8IO\$ (1976), atribui a esses solos uma constituiça de $90 \%$ de caulinita e que os solos dos escudos cristalinos săo geralmente mais ricos que os da formaça Barreiras.

Estudos realizados na parte Oeste da bacia sedimentar da Amazônia por S083808g (1984), evidenciam que os solos ali existentes såo menos intemperizados que os da parte Leste, uma vez que săo predominantemente formados de materiais andinos, sedimentos marinhos e cinzas vulcânicas. Esse autor faz uma classificacăo dos solos dessa regiăo, baseando-se na existância ou não de diferencią̧a textural. Afirma que essa diferencią̧o, ocorrem mais para a parte Sudeste do Brasil e na Colômbia, Peru e Bolívia. São solos ácidos, constituídos de minerais de argilas como a ilita em adį̧̃o à caulinita e sesqui 6xidos. Apresenta ainda uma Capacidade de Troca de Cátions relativamente alta, onde o horizonte B-textural ou arg§lico apresenta baisa atividade de argila (Podzolico Vermelho-Amarelo, alico, atividade de argila baixa ou Paleudults de acordo com a classificaça 
americana), ou alta atividade de argila (Podz6lico Vermelho-Amarelo, alico, atividade alta ou Tropudults segundo a classificą̧̃o americana).

Nos escudos Cristalinos Pro-Cambrianos situados na parte Norte $e$ sul da bacia Amazônica, encontram-se os solos cujas características são bastantes variadas. Alguns desses solos såo bastantes semelhantes àqueles encontrados na planicie Amazônica (formą̧̃o Barreiras), como os Latossolos Vermelho-Amarelo alico (Haplortx, pela classificąå americana). Outros, são os solos fisicamente semelhantes, onde a fracăo argila apresenta uma grande percentagem de 6xido de ferro, devido a rocha-mãe (basaltos e rochas sedimentar de ferromagn(́sio). Esses solos são conhecidos como Terra-Roxa Estruturada (Paleudalfs, na classificaça americana) SORBROER (1988).

1810\$ (1976), atribui que os solos das areas Paleozbicas săo menos intemperizados se comparados com os solos formados sobre a formaç̧o Barreiras, devido à menor impermeabilidade das rochas sedimentares do Paleoź́ico. Ressalta que a mica nesse solos apresentam-se ainda, relativamente bem preservadas, enquantio que os. feldspatos Já foram totalmente intemperizados, levando a formaço de caulinita. I810\$ (1979), observa que, nas primeiras camadas, esses solos eståo compativeis com os 
solos que ocorrem na formą̧๐o Barreiras e nos escudos cristalinos, e que entre 1,5 a 5 metros ocorrem um intemperismo parcial da ilita, aumentando o conteúdo de magnésio e potássio.

5OFBROEß (1984), relaciona os solos que se encontram sobre os depósitos Cretgceo-Terciarios, como pertencentes a parte Deste e năo apresentam gradiente textural. significante. Sđo solos mais ricos em minerais $\theta$ menos uniformes, se comparados com os da formą̧̃o Barreiras, sendo constituśdos por sedimentos de textura fina resistente à infiltraça da água e pouco drenados (IRIOH, 1976 1978). O resultado final da intemperizaço desses solos é, geralmente, a montmorilonita de baixa. at ividade (1810N 1988 ).

\subsection{CONE IOERACORE L8RHOLOG Y CAS}

Nos ambientes terrestres, existem varios sistemas aquosos, como lacustrico (lagos, lagoas) e fluvial (cursos de ggua, rios). Muitas vezes, encontramos também os pantanos e brejos. Existem dois fatores ecologicos que julgamos de especial importância nesses ambientes aquosos:

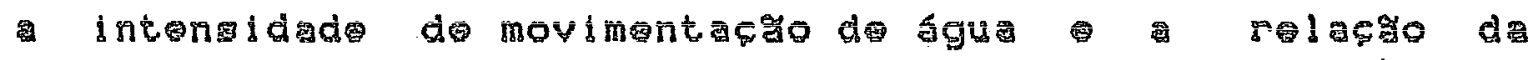
muprof 
Sgua ou correntes torna-se importante pela influência que causa na circulaçăo de oxigênio dissolvido e dos nutrientes (SOARES, 1951 1959; MARL 1ER, 1967; SCHWOERBEL, 1971; SCHMIDT, 1973; JUM\%, 1980 SARTOS, 1980).

MARLIER (1967), estudando trôs lagos da regi ăo Amazônica, um de sgua clara, um de sgua branca e um de sgua preta, diz que somente os lagos de sgua branca possuem uma produção autbctona razosvel de matøria orgânica. E, que devido a falta de sais minerais, a produçăo primsria 6 muito baixa nos outros lagos.

Quanto a biomassa desses lagos, MARLIER (1967), afirma que a alta nos lagos de sgua branca e que a produça aumenta somente com a enchente. Esses fenômenos podem ter razôes em processos diferentes. Um deles, $\theta$ a chuva que traz alguma quantidade de nitrogenio. Outro, 6 a penetração de sgua frestica atraves do fundo do lago quando sobe o nível das aguas ao redor do lago. Sendo que, o lago quando recebe sgua diretamente de um afluênte de sgua branca (rio Amazonas/Solimơes), tambøm ganha um novo suplemento de matéria mineral.

Nas Sguas claras e pretas de lagos florestais, a produço organinica albctona. 0 estoque de matǿria orgânica, no lago, aumenta progressivamente com a 
evolu६ão ecologica da água e com a ą̧̃o dos organismos os quais acumulam nutrientes dentro da propria substância. A producão aut6ctona mostra, também, um pequeno aumento quando sobe o nível da agua, porem a biomassa total sempre permanece pequena (MARLIER, 1967).

Segundo MARLIER ( 1967 ), um dos fatores da produtividade o qual, desta maneira, parece importante, 6 o número de animais. Primeiro, eles armazenam nutrientes os quais, em outro caso, seriam perdidos aos cursos de agua, afluentes dos lagos; segundo, eles aumentam a velocidade de mineralizaçåo do material fornecido pelas plantas do litoral, o que cai para dentro da agua e torna-se acessível ao ciclo do lago. o primeiro processo 6 dependente da densidade da populąão animal e o segundo $\sigma$ dependente da densidade e da diversidade da mesma. E que a ąăo favoráal do rio Solimães/Amazonas e das águas brancas sôbre a produtividade demonstra a importância de um levantamento hipsométrico acurado da região para o rim de uma delimitąåo de zonas de produtividade na bacia.

510la\& (1968), mostra uma relą̧̧o entre a química das sguas (sgua frestica e sgua corrente) e a. geologia das areas de influência sobre as mesmas sð̋ notsvelmente nitidas, principalmente na amazónia brasileira. 
Sendo que, os macicos do arqueano ao Korte e ao Sul do Amazonas produzem águas que são, químicamente, bastante pobres e puras e que possuem valores de $\mathrm{pH}$ bem mais baixos. Mais pobres e mais acidas, são as aguas das

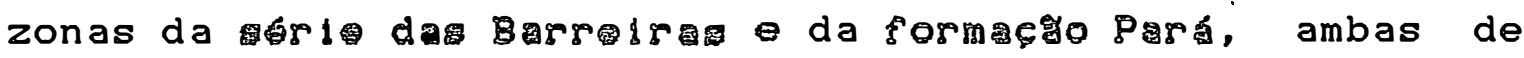
origem plioceno-pleistoceno; enquanto que no Deste da

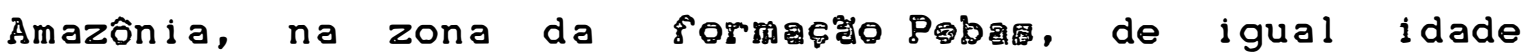
geologica, ocorrem aguas mais ricas e menos acidas.

Segundo \$80L\&, em. todas estás areas geológicas săo encontradas manchas de areia esbranquicadas (podzolø), cobertas de um tipo especial de vegetaç⿰丿, as quais produzem aguas profor dos latossolos amarelos que suportam a floresta alta, provém sguas cristalinas. As. aguas pretas contâm grande quantidade de substâncias corantes, de humus, enquanto que os teores de sons ınorgânicos e os valores de $\mathrm{pH}$ são os mais baixos da amazônia.

A concentraç̧o de material suspenso e. os teores de diversas substâncias dissolvidas no rio Negro, s శo relativamente baixas, contudo sofrem variaços durante - ano. Os materiais suspensos, as fraçoes suspensas de ferro e de fosfato, e o teor total de sais dissolvidos, apresentam um mgssimo de concentração, coincidindo com o prinḉpio da estą̧o chuvosa, quando o rio ainda esţ muito 
baixo, mas ja comecando a subir scmgrdot (1972a).

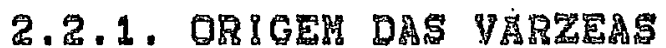

Segundo SƯNK (1980), as várzeas do Amazonas estende-se dos Andes aţ O Oceano Atlântico com uma largura de 20 a $100 \mathrm{~km}$. Sua area foi calculada por SOARES (1956) em $64.000 \mathrm{~km}^{2}$.

A exp]іса६ð̃o sugerida para a formąão desta regĩo 6 de que ha 75.000 anos atrás, o nível do mar esteve de cerca de 100 metros abaixo do nivel atual, durante um período de aproximadamente 50.000 anos (A18881DGE, 1961). Em consequância de balxada do nivel do mar, o rio Amazonas e seus tributarios formaram lagos de fundo de vales. A subsequente subida do mar até o nivel atual, provocou um represamento dos rios nos seus proprios vales. Com isso, mais de $1.000 .000 \mathrm{~km}^{2}$ da bacia Amazônica estão situadas abaixo da ischipse de 100 metros, este represamento teve efeito no vale do Amazonas até ao sopé dos Andes (J48s\%, 1980).

Consequentemente, os rios comecaram a encher os seus vales afogados com sedimentos recentes. conforme sua. carga sedimentária. No caso do rio Amazonas, que transporta grande quantidades de sedimentos dos Andes e da zona prø-Andina, este processo de sedimentação, 
aparentemente, foi completado. Foi alcancado um novo equilśbrio que inclui amplos processos de sedimentaça e erosăo na própria varzeas, que estáa sendo modificada permanentemente pela atividade do rio (JUßK, 1980).

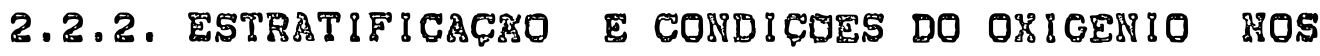 LAGOS DE VARZEAS}

\section{HUTCHINSON $\triangle$ LOFFER (1956) JUMK (1980),}

classificaram os lagos de acordo com o tipo de circulaça de agua, incluindo também uma discusså sobre lagos tropicais. De acordo com esta classificaço, lagos de várzeas devem ser considerados como oligomíticos, durante a cheia e polimioticos, durante a agua baixa. A circulaço da agua durante a seca, năo se realiza tanto por causa da temperatura mas por causa do vento. Durante este per ıodo, os lagos rasos săo normalmente túrbidos porque as camadas superiores dos sedimentos săo levantadas, sendo eles, em parte, retransportados aos. rios. Por causa disso, os sedimentos de lagos classicos podem ser encontrados às

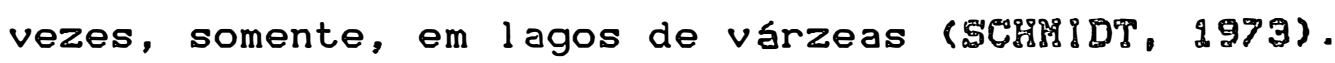

Intimamente ligados à estratificą̧̊

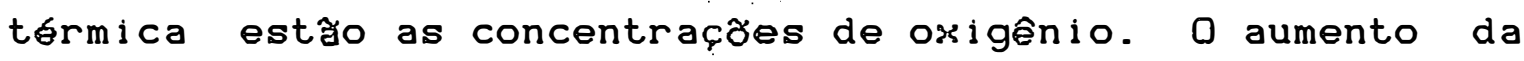
temperatura năo somente diminui a solubilidade do oxigênio na agua mas, aumenta, al6m disso, o consumo do oxigênio por 
causa de taxas de decomposicão e respiraço crescente. Por isso, muitos lagos tropicais, frequentemente, tâm baixa concentraça de oxigânio, logo abaixo da camada eurótica e - sulfeto de hidrogânio 6 comum nas zonas mais fundas. Em lagos de varzeas, esta situaça 6 ainda mais pronunciada porque durante a enchente grande quantidade de materia orgânica proveniente da vegetaço terrestre inundada estão

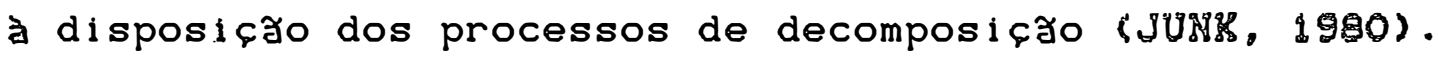

\subsubsection{OS LAGOS ARAZON COS}

Segundo SOARES (1948\% Di: 2951 - 1959), 6 comum distinguir dois tipos de lagos para a regi ăo

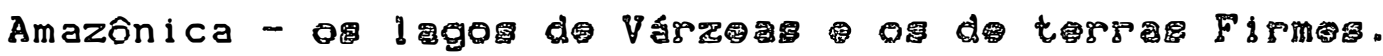

Os primeiros ocupam as depressßes da planicie aluvial, isto 6 , as areas nao colmatadas pelo limo das enchentes, no processo normal da construqăo das varzeas amazônicas. Frequentemente să meandros abandonados loHbow dak@) ou porçes de longos trechos de paranás e mesmo de antigos leitos do Amazonas e seus afluentes, na planicle de inundą̧o. Sצo geralmente rasos, alguns mesmos temporários, transformando-se em brejos, na época da vazante, quando o seu aluviamento ja vai bastante adiantado. Comumente, ocupam parte central das ilhas aluviais, como o lago dos Reis, na ilha do Careiro. 
CARVALHO (1942), resume as características gerais dos lagos de varzeas, apresentadas por L. COd\&TE (1903), da seguinte maneira:

- Ş๐ apenas depressðes, sem profundidade que, na planície de aluvið̋o, ao longo do rio principal, se enchem de sgua de inundą̧๐o, retendo-as em parte na vazante ;

- Suas margens são baixas, planas e geralmente se prestam a campo e pastagens.

Para SOARES (1948a b; 1951 1959), os chamados lagos de terra firme, săo as massas de águas que se encontram dentro de grande trincheiras com dezenas de quilômetros de largura cavadas pela erosão no planalto terciario. Alguns encontram-se no contacto da terra-firme com a varzea, ou melhor, por se achar encaixados na terrafirme, tendo também, margens na varzeas.

As caracteristicas típicas desses lagos

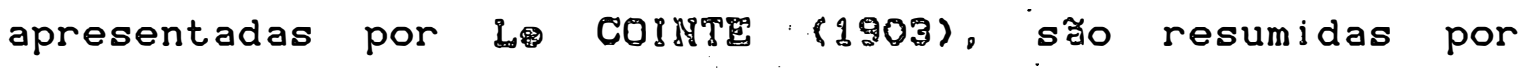
CARYAHO (1942), da seguinte maneira:

- São massa de agua represadas pelas restingas de aluvi Bes; 
- Suas margens săo mais elevadas, em rega, matosas e os lados de praias de areias brancas, recebem pequenos rios cujas bocas se alargam consideravelmente.

Existem varios tipos de lagos de terrafirme. SOARES (1959), faz uma pequena descri६ão desses

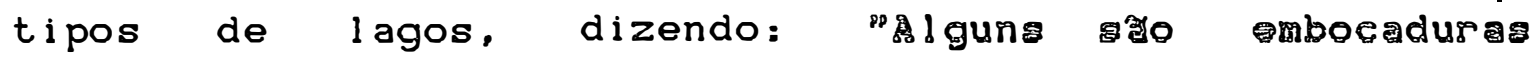

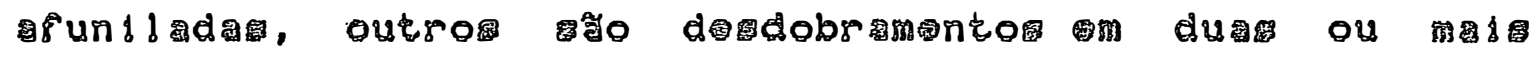

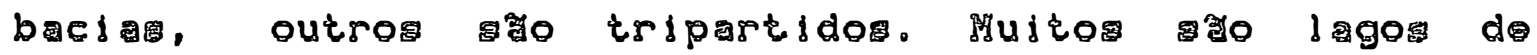

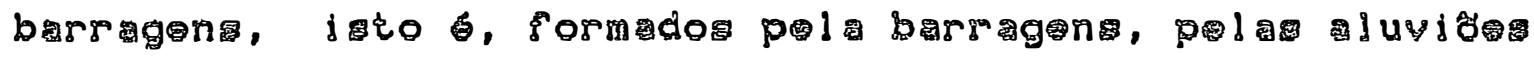

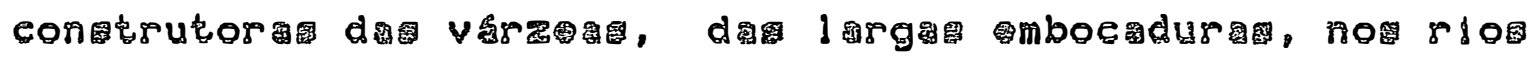

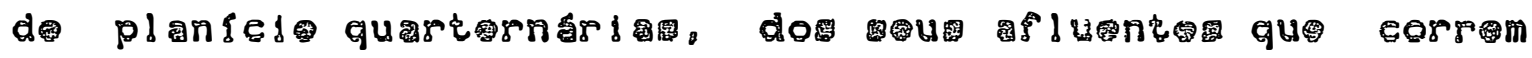

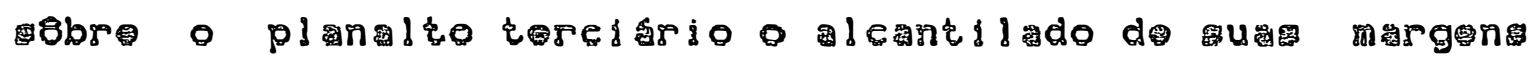

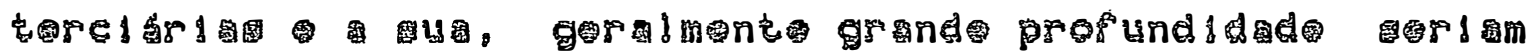

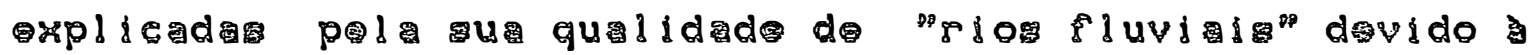

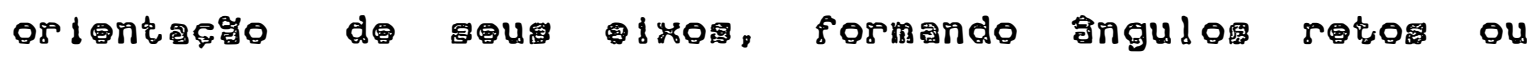

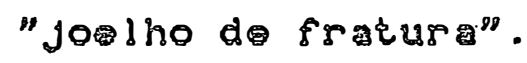

Entretanto, STEBNBEBC (1953 1958), ao comentar esses tipos de lagos, levanta a hipotese de que a

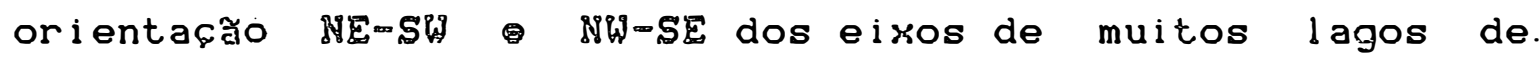
terra-firme, formando esses tipos de ângulos retos ou joelhos de fratura, seria a adaptacăo dos mesmos à rêde de fraturas que teria fendido o pacote terciario amazônico. 
Assim, os lagos de terra-firme teriam uma origem tectônica, ocupando linhas de falhas ou vales tectonicos, posteriormente, alargados e aprofundados pela erosăo, e finalmente, invadidos ou afogados pelas aguas do Amazonas na última elevação do nfvel de base atlântico.

\subsubsection{PRODUCFO PRSBSERIA}

A partir de 1967. foram desenvolvidos os primeiros trabalhos sobre produçăo primaria na regiăo Amazônica, através de scymg gr (1973: b).

Uma comparạ̧o enţ่อ os ecossistemas Amazônicos dos rios de "ggua branca"; "ggua preta" e "ggua clara", como também das aguas que drenam a floresta de terra - firme e os lagos de varzeas. Estes últimos săo

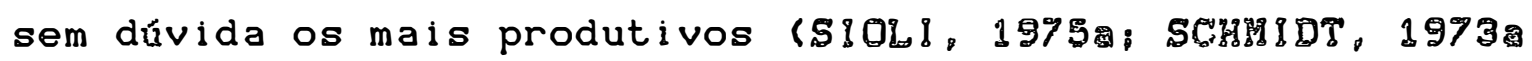

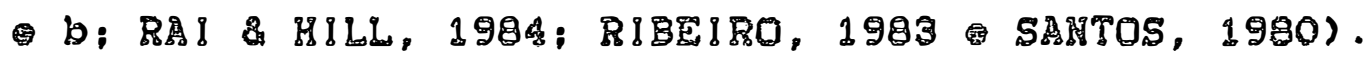

Uma das principais características dos lagos de varzeas, $\theta$ o bal anco energia-biomassa, no qual a entrada dos rios nos lagos fornece a energia e o lago responde com uma produçăo razosvel de biomassa RA \& $(1984)$.

Năo resta dúvidas que sưo nas várzeas que se ds inicio ż cadeia trofica na Amazônia. 
Como consequencia, a produço pesqueira $\&$ bastante dependente desse sistema. JUßK (1988) por exemplo, salienta que, muito embora exista uma relativa quantidade de nutrientes nas aguas do rio Madeira, ele $\sigma$ bem menos piscoso, devido à escassa formaça de varzeas em sua margens. Essa produça primaria anual, que existe nos lagos

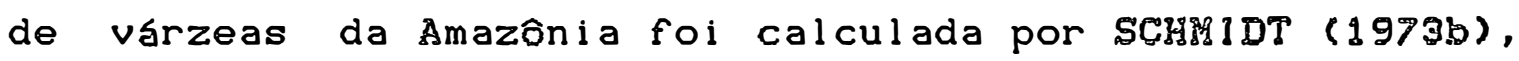
em torno de 100 a $150 \mathrm{~kg} / \mathrm{ha}$ em um lago.

Existem dois fatores que limitam à produça primaria nas águas dos lagos da regiăo Amazônica; um de ordem física (luz) e um outro de ordem química (falta de nutrientes). Para os pequenos igarapes que drenam na Amazônia Central, estes dois fatores eståo conjungados. Como as florestas que envolvem esses igaraṕs săo de difícil penetrąro da luz, estes permanecem sombreados. Segundo 580L! (1975), somente 1 a 2 \% da radiaçăo solar chega at 6 a superficie. Por outro lado, esses igarapes e rios apresentam baixa concentraça de nutrientes s\$gld,

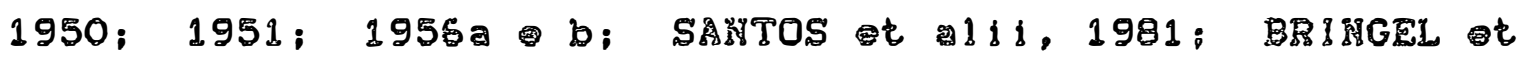
alii, 1984; SANTOS aldi, 1984). Com issto, os animais que habitam os diferentes niveis troficos são dependentes de material al6ctones para a sobrevivôncia (\$I0L\}, 1975æ).

Para os grandes rios, o problema de iluminaçวo externa nå ocorre. Entretanto, para os rios de 
aguas-bancas, a grande quantidade de material em suspensấo limita a entrada da luz, chegando a alguns centsmetros de uma coluna de agua. Como não existe falta de nutrientes nesses rios, a falta de luz a correnteza contribuem para uma redução na produção primaria ( 8 \& $1975 a$ BIBEIBO, 1983).

Para os rios de agua-preta, o maior fator que limita a produça primaria $\sigma$ de ordem nutritiva, resalvando-se que nessas aguas, a penetraço da luz năo atinge níveis ideias para promover uma produço primsria (5CHมIDT, 1973b a 5IOLI, 1975a). Por outro lado, BIBEIBO (1978), ao perscrutar a produção primaria em lagos do rio Solimbes/Amazonas e do rio Negro, conclui que a produça primaria 6 maior para os lagos do ecossistema do rio Sol i môes/Amazonas .

Nos lagos de várzeas do rio Solimốes/

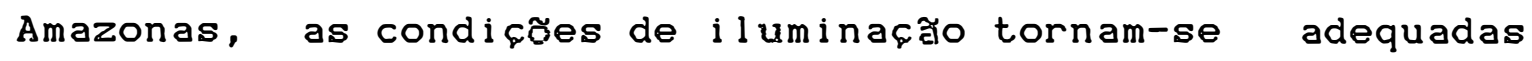
para a produção primaria,' quando ha sedimentąão das partículas em suspensão trazidas pelo rio que inunda as varzeas no período de cheia. Esse rio, aprensenta ainda, uma quantidade apreciácel de nutrientes dissolvidos (SRMTOS, 1980 TMNTOS at al1, 1985). Estes fatores, associados zे alta temperatura fazen com que a produço primaria seja maior nas aguas desse ecossistema do que em 


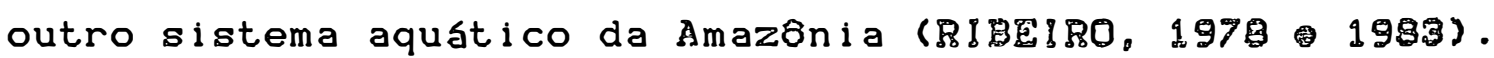

SIOLI (1975a), encontrou no lago Cabalina, que esta ligado diretamente ao rio Solimäes, valores elevados de temperatura da agua $\left(33,4^{\circ} \mathrm{C}\right)$ e $\mathrm{pH}$ (8.8). Concluindo, que todo o CO livre foi consumido e que a concentrą̧a de $0_{2}$ atingiu $150 \%$ de saturą̧̃o.

Para o lago do Castanho, que ligado

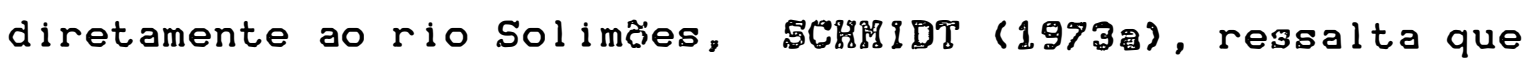
a producão primaria 6 caracterizada por duas peculiaridades: a produça tem lugar numa camada relativamente pouco profunda na coluna d'agua, variando sua espessura sazonalmente em funçẩo da profundidade do lago (6 m na época da cheía e $0,5 \mathrm{~m}$ ma epoca seca); a outra peculiaridade $\theta$ a elevada produçă por unidade de volume, sendo os maiores valores encontrados durante 0 período de seca, $1,8 \mathrm{~g}$ de C.m ${ }^{-3} \mathrm{~d}^{-1}$ isto em $15 / 11 / 67$ e $2,15 \mathrm{~g}$ de $C \cdot \mathrm{m}^{-3} \cdot \mathrm{d}^{-1}$ verificada em 23/10/69. Observa ainda, que os valores mínimos foram encontrados durante a entrada da Sgua do rio, devido à diluigro da massa de fitoplanctônica pela agua invasora e pela ciesfavoravel condi६̧̧o de luz, nesta Epoca.

Para o lago do Cristalino que se encontra

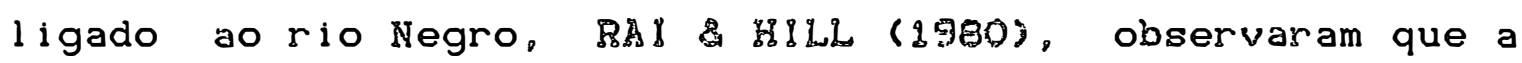


produçăo primaria 6 limitada aos primeiros $2 \mathrm{~m}$ da columa de sgua. Concluem que a escassez de luz 6 de ocorrância generalizada nas aguas dos lagos de varzeas da Amazônia. Por outro lado, FORFBERG ( $198 \%$ ), atrayés de bioensaios experimentais realizados nas sguas desse lago, observou que a produça primgria era limitada pela baixa concentracăo de fosforo.

Com relą̧̃o a produço primsria, para 0 lago do Cristalimo. BA I HILL (1980), observaram que as maiores produçes ocorreram na bpoca seca. Ressaltam ainda, que a produça desse sistema é muito mais respiratória que rotossintética, sendo que a producăo de fitoplancton corresponde a 18 \% da massa bacteriana produzida. Concluem que a produça primária de fitoplancton por unidade de área no lago do Castanho foi menor em comparaça ao lago do Cristalino, sendo $0.8 \mathrm{~g}$ de $\mathrm{C}_{\mathrm{m}} \mathrm{m}^{-3} \cdot \mathrm{d}^{-1}$ para 0 lago do Castanho e $\$ .3 \mathrm{~g}$ de C. $\mathrm{m}$.d para o lago do Cristalino. 


\section{MATERIAL M METODOS}

\subsection{MATERIAL}

\subsubsection{CARACTERISTICAS GEOCLIMATICAS DA AREA ESTUDADA}

Neste item, serão apresentadas as características gerais da regiăo investigada, com relaça aos aspectos Geográficos, Geologicos e Climáticos.

\subsubsection{GEOGBAFIA}

As sreas perscrutadas constituem parte da bacia do rio Branco, Negro e Solimões/Amazonas (FIGURA 6). A srea investigada da bacia do rio Negro, forma uma linha inclinada, na diresão $N-O$, partindo de Manaus (Log. $60^{\circ} \mathrm{W}$ e Lat. $3 \mathrm{~S}$ ) estendendomse ate o rio Caures (Log. 63 W e Lat. 1 S), abrangendo parte da bacia do rio Branco.

$\mathrm{Na}$ bacia do rio Solimaes/Amazonas, foram estudadas as áreas do compleso do Careiro e Janauaca, que estå compreendidas entre as Jongitude de 59 a $61^{\circ}$ i e as 
latitudes de 3 a 4 S. Na Figura 6 , mostra-se a regiło Norte do Brasil e as áreas estudadas.

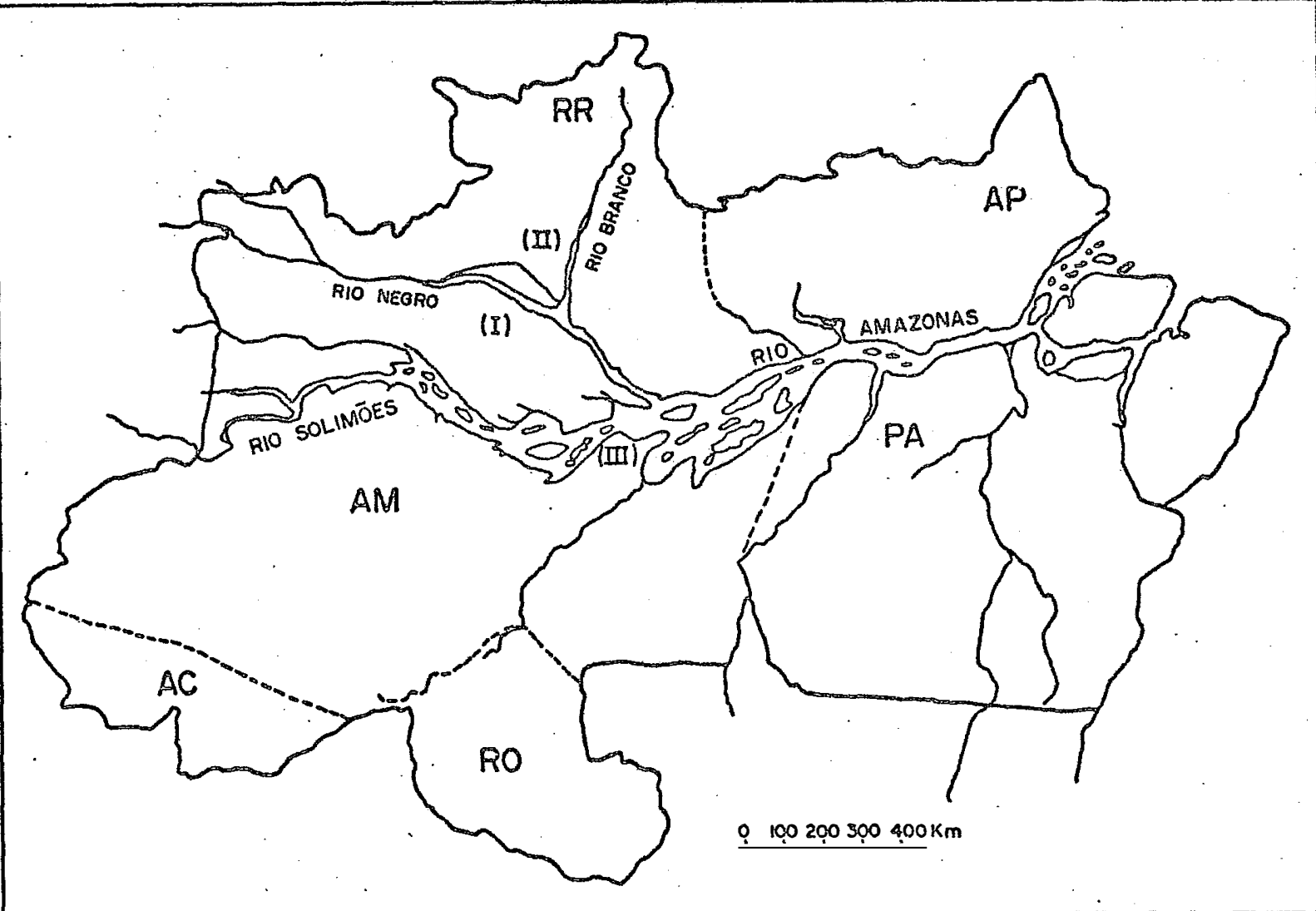

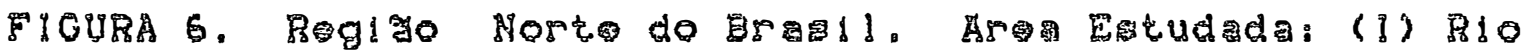
\$ogro: (II) Bio Branco (III) Bio So1 1 mô. 
Em sintese, o relø̄vo da regiăo perscrutada 6, representativo da Amazônia. E formado por rochas sedimentares originadas no Terciario e Quarternario, de estratificaço horizontal, arenosa e argilo-arenosa, constituindo o baixo platô, chamado de terras-firmes e a planfcie de inudaço (\$OYคA, 1951).

Os Latossolos Amarelos de textura muito pesada så encontrados em chapadas mais elevadas, nas altitudes entre 100 a $160 \mathrm{~m}$ acima do nivel do mar. Os Latossolos Amarelos de textura pesada såo encontrados nas altitudes de 80 a $100 \mathrm{~m}$, e entre 60 e $80 \mathrm{~m}$, săo encontrados os Latosolos de textura média e as Arejas Quartzosas Latossolrcas. Já o Podzol Hidromórfico e Regosol situam-se nas camadas de 40 a 60 meteros e, em torno de 40 metros os Hi dromórficos Indiscriminados ( 99006,1971$)$.

Geralmente, os terrenos que se encontram entre 15 a 50 metros acima dos cursos dos rios sao denominados de Terra-Firme. Săo representados por chapadas entremeadas de pequenas colinas e vales estreitos. As terras localizadas as margens dos rios e com cerca de poucos metros acima do nivel dos rios, e que periodicamente, sofrem inundaçôe, săo chamados de Várzeas, e seu relêvo é plano (IPESOOC, 1971). 
De acôrdo com a localização, estas várzeas podem receber tambøm o nome de igapo, havendo controvørsia com relaço a estas denominaçes (510L1, 1951; 1956a 1959). Săo terras com relôvo pouco acima do nível normal dos rios, com vegetaça tópica, de acordo com o período e a altura da submersăo, tipos de solos, e também, de acordo com o tipo de aguas que as inundam. Nota-sa porém, uma grande diferença entre a Varzea e o lgapo, no que diz respeito à fertilidade.

\subsubsection{GEOLOGIA}

A formaçฐ Solimões 6 representada por extensa cobertura pelítica das bacias do Alto Amazonas que recebem diversas designações (Puca, Baixada, Quixito, rio Acre, Aquiri, Conteman e Purus), havendo controversia quanto à sua relaça com a formaço Alter do Chão (CApUTo (t)

SANTOS (1978), relacionou diversos criterios litológicos, geomorfologicos e geocronológicos como guia para distribuir essas duas formaçós, delineando a area regional de ocorrência da formaçăo Solimø̃es, em aproximadamente $1.000 .000 \mathrm{~km}^{2}$ em territ6rio brasileiro.

ARASIL (2984), determinou a existência de duas zonas bioestatigraficas na formaç̃o Solimões, sendo 
uma pliocônica e a outra miocônica, caracterizando-as litologicamente pela presenca de arenitos cinzas, cinzasesverdeados, intercalados com banco de arenitos, camadas de linhitos e gipsita.

Sob a designą̧̃o genørica de PleistocenoHoloceno, eståo reunidos os depósitos fluviais que acompanham muitos cursos de sgua que constituem a atual rêde de drenagem, sendo noţveis por sua extensão e volume, principalmente, acompanhando o rio Solimões/ Amazonas e seus afluentes da Amazônia Ocidental (Madeira, Purus, Jurua, I qa e Japurá).

Os sedimentos Holocênicos estão representados pelos aluvioes fluviais e flúvio-marinhos.

Os aluvióes fluviais såo constiturdos de cascalho, areias, siltes e argilas. Preenchem as planicies dos rios e as áreas lacustres em processos de assoreamento. Os aluviơes flúvio- marinhos săo constituidos de areias, siltes, argilas e vasas e compơem as planícies costeiras de sedimentaça mista (BRASIL, 1984).

\section{$3.1 .1 .2 .1 .50 L 05$}

Os solos dessa regiăo têm sua origem a partir de material de rochas sedimentares, possivelmente 
vindas do Terciário e Quaternario.

- Terciario 6 representado pela Sorie das Barreiras do período Plioceno, sendo um dos mais extensos depósitos terciários do mundo, situado em terra firme (OLJVREIRA \& LEONARDO, 19A3). A S6rie das Barreiras 6 constituida de um arenito purpura avermelhado claro, cimentado com caulinita, folhelho caulinítico e caulinita maciça mosqueada. Este arenito, quando intemperizado, forma normalmente os solos argilosos, argilo-arenosos como os latossolos de classes texturais diferentes (SAMAMOTO, 1957).

Do Quaternario, podemos encontrar o Pleistoceno e o Holoceno ou Atual. o Pleistoceno 6 geralmente, formado pela deposicão de sedimentos constituidos de areia, argila e silte. Estes sedimentos quando associados a matéria orgânica na superfície dzo origem aos solos Podzol Hidrombrficos e Regosol (OLIVE!PA \& LEONARDO, 1943).

O Holoceno săo encontrados nas margens dos cursos de agua e nas areas que periodicamente sofrem inundaç̃es, e $a$ constiturdo de sedimentos compostos de areia fina, silte e argila, de coloraço escura devido a matéria orgânica que ds origem ao solos Hidromorficos Indiscriminados (OLIVEIBA \& LEONARDO, 1943). 
SIOLI \& KLINGE (1962), mostraram que a formaç⿰ dos podsols, estå relacionados com problemas fitogeograficos e geograficos, que condicionam a ocorrência e o alastramento de campos e florestas ralas ifloresta pluvial equatorial) que predomina tôda a regiåo Amazônica. Fazem indicaçes sôbre os quimismo $e$ as cargas em suspensơes nos diversos tipos de agua para demonstrar a existôncia de relaçós entre as águas e os solos da Amazônia. Sendo que os diferentes tipos de sguas explicamse por diferencas nas condiçes edfficas nas respectivas regioes de cabeceiras.

\subsubsection{CLIPA}

Na regi ăo perscrutada, a pluviosidade na bacia de drenagem dos rjos apresentam precipitaç̃os entre 2.000 a $3.000 \mathrm{~mm}$. ano ${ }^{-1}$. Dados referentes a cidade Manaus, mostram uma precipitaço na ordem de $2.100 \mathrm{~mm}$. ano. $^{-1}$.

A precipitaç̃o pluviométrica na regiăo, năo 6 igualmente distribuida durante $\circ$ ano, existindo uma época menos chuvosa com precipitaçós esparsas e de pouca duraço e uma época chuvosa onde as chuvas såo intensas. Entretanto hó uma nítida diferenca entre as duas estaçōes (FIGURA 7). 
Essas estaç̃es (menos chuvosa e chuvosa), provoca flutuaços no nível de agua, nos rios, que na cidade de Manaus, no rio Negro, ha uma oscil aço entre 10 a 15 metros (FIGURA 7). Quando os rios encontram-se no seu nível maximo, tôda a vărzea 6 inundada, e quando esta no seu nível mínimo, essa varzea fica descoberta, formando os campos de varzeas da Amazônia (JuNk, 1980).

Os lagos de varzeas, predominantemente na regi ðo Amazônica, sðo submetidos à grande oscillaçðes tanto de área como de profundidade, que dependendo do nłvel do rio pode alcançar mais de 13 metros de profundidade, em uma area de aproximadamente $6 \mathrm{~km}^{2}$, durante a estacão chuvosa ou seja, no período das enchentes. (inverno). Entretanto, esses lagos podem ser drasticamente reduzidos, durante a estaço menos chuvosa (verăo), onde suas areas podem alcancar menos de $2 \mathrm{~km}^{2}$ e sua profundidade maxima estimada em, aproximadamente, 2 metros ( $30 \mathrm{NH}_{4}, 1980$. SANTOS, 1980).

Tais condiçes podem ser alteradas em funça do nível da Sgua do rio, sendo que na epoca onde as precipitaçes sæo consideradas baixas para a regi ăo ou quando a estą̧วo chuvosa tem seu inicio atrasado podem apresentar uma menor şea e profundidade. 


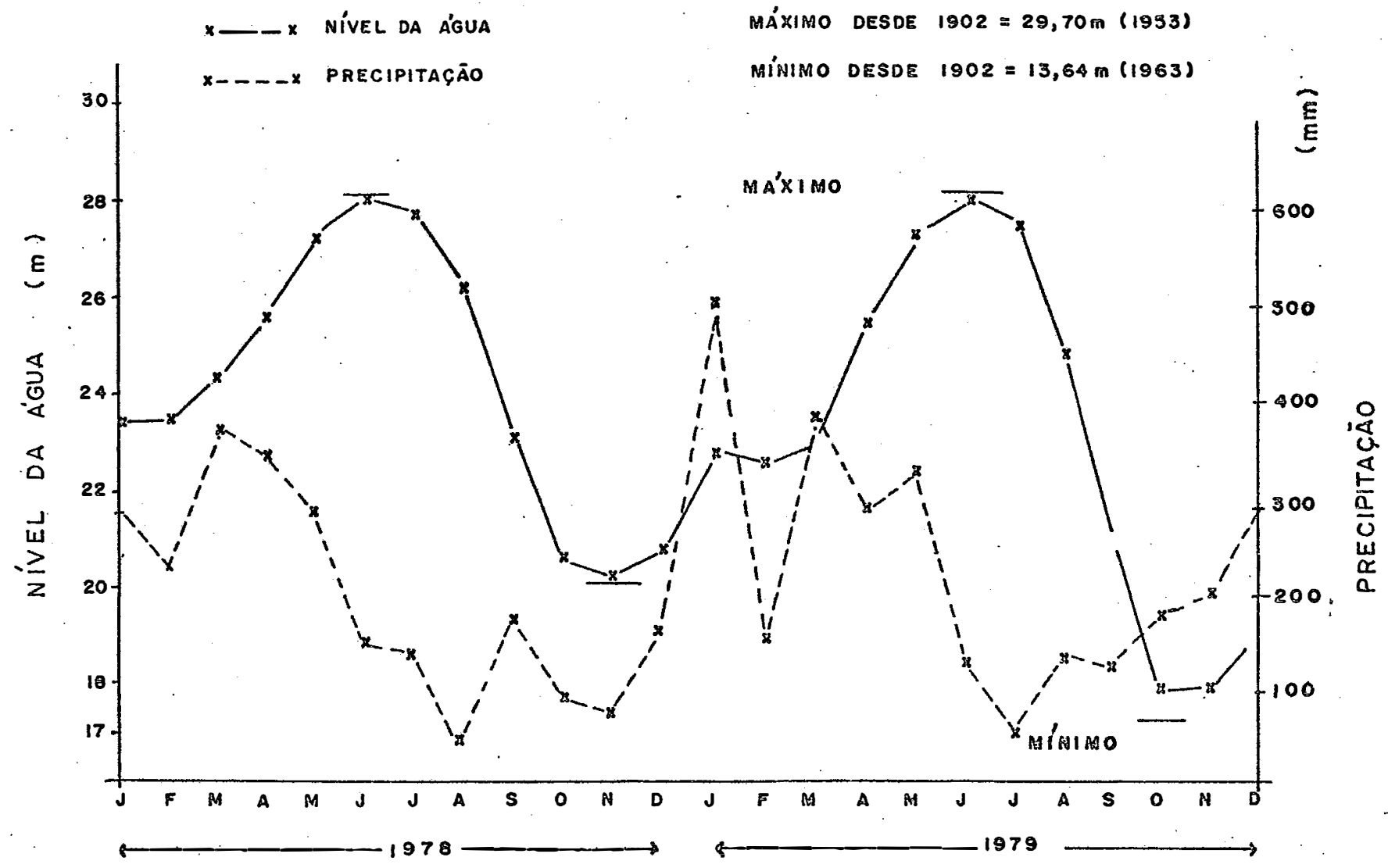

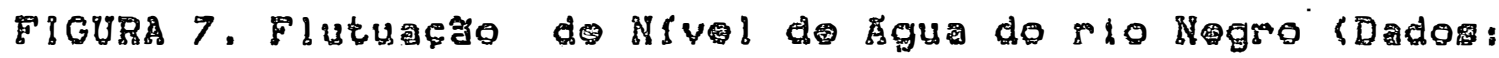
Capitan! do

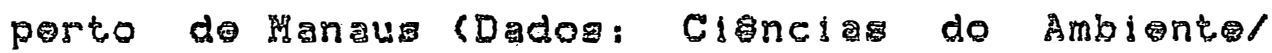
INPA, Mอกลนร) (Junk, 1990). 
Quando a estą̧วo menos chuvosa não chega em 6poca adequada, ou seja, a estacão chuvosa 6 prolongada, esses lagos sofrem processos inversos, sua area $\theta$ de diff́cil determinaço, uma vez que esse lagos eståo em contacto com outros, dando a formaço de um único lago, como 6 o caso dos lagos da ilha do Careiro e da regia a do Janauaca, ambos no rio Solimðes/Amazonas. O rio principal influenciam os lagos da regiăo Amazônica, de diferentes maneiras, que dependendo da oscillą̧o do nrvel de água nessas bacias e da conexåo direta existente entre o rio e o lago (JUNK, 1980 SANTOS, 1980).

\subsubsection{A. CARACTERIZAGA DOS LAGOS}

Praticamente, nåo existe em termos limnológicos, uma diferenca na definicăo entre lagos e rios. Lagos săo considerados aguas paradas sem ligaço direta para o mar, distribusdas como ilhas, na terra, contém geralmente agua doce, pobre em eletrojito, com excę̧о de lagos salobres (JUKK, 1980). Geologicamente e com poucas exceçes, săo relativamente jovens, de pouca duraço, pois apresentam caráter acumulativo, ou seja, sistema majs ou menos fechados (SCHWOERBEL, 1971).

Sua classificaço podera ser feita pela sua gênese e ou através do seu nivel trofico, sendo este a 
de maior interesse (BUTTHER, 1952 ELSTER, 1958). Podemos considerar os lagos como limites definidos, onde a superfície e a profundidade dever学o ser consideradas relativamente constantes, no momento de coleta das amostras dos sedimentos.

Entretanto, tanto os lagos como os rios na regi ăo Amazônica estão sujeitos as flutuaçōes de nivel. Que juntamente com o clima e o relâvo, influenciam areas que ţ̂m sua duraça de acordo com a ́́poca; podem variar de largura e profundidade.

\subsubsection{LAGOS ESTUDADOS}

Foram perscrutados sedimentos do fundo de 29 lagos da região Amazônica, sendo 2 (dois) pertencentes a bacia do rio Branco; 13 (treze) localizados no ecossistema do rio Negro e 14 (quatorze) situados na bacia do rio Sol imôes/Amazonas. Na Figura 8 , mostram-se esquematicamente a localizaçăo dos principais rios, onde foram coletadas as amostras e na Figura 9, Mapa mais detalhado da area em estudo.

0.1.2.1. LOCAL 3 2ACKO DAS AMOSTRA

Para melhor investigar as influências do rio Branco sobre o rio Negro. Este, foi subdividido em 
dols outros ecossistemas, ou seja: um, do rio Negro que sofre influência do rio Branco e um outro, diretamente do rio Negro. Alem dos outros dois ecossistemas, o do rio Branco e o do rio Soljmơes/Amazonas, cujas as amostras estaัo assim local izadas:

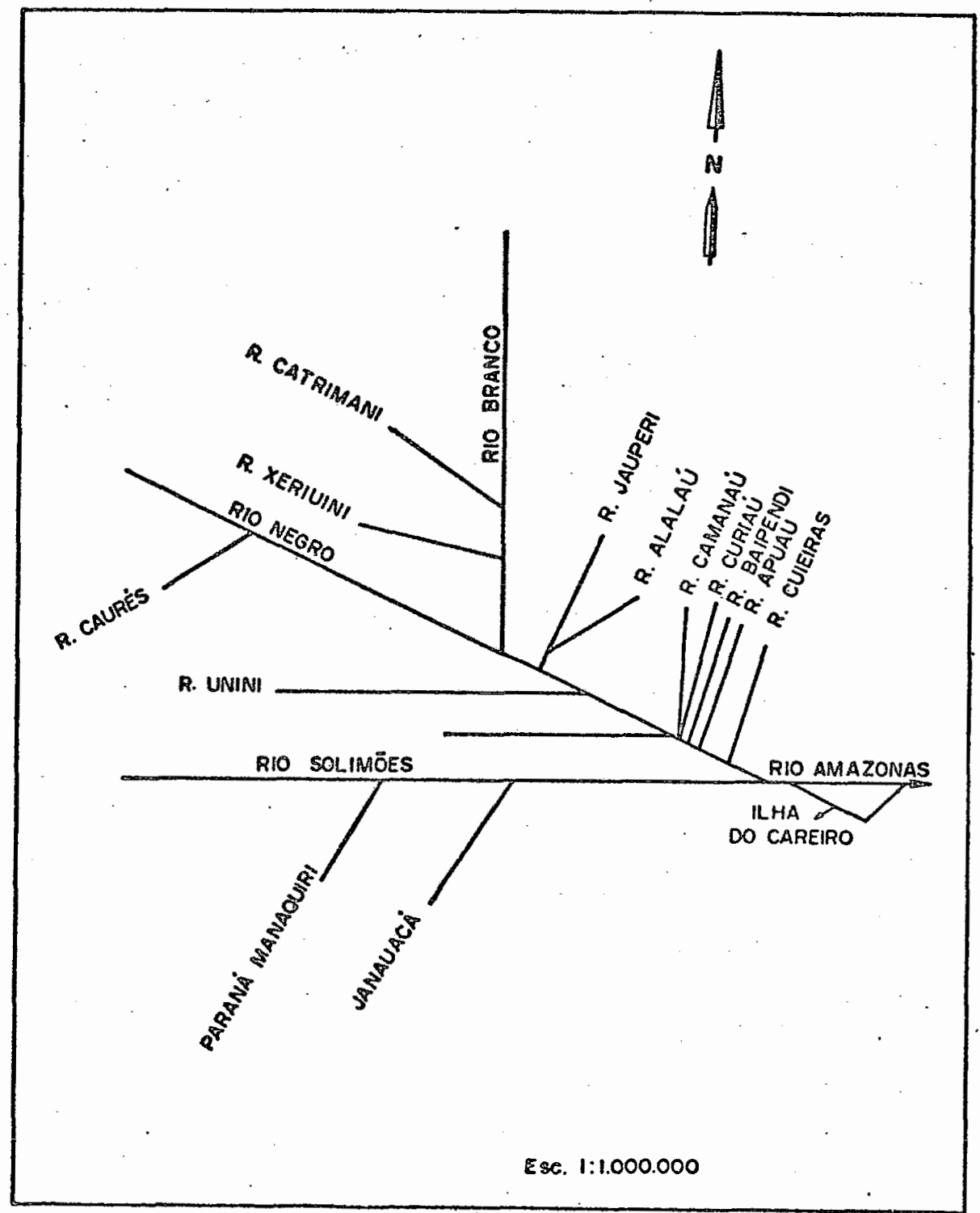

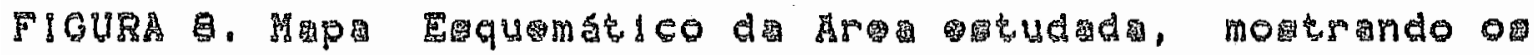
principald rios amostrados. 


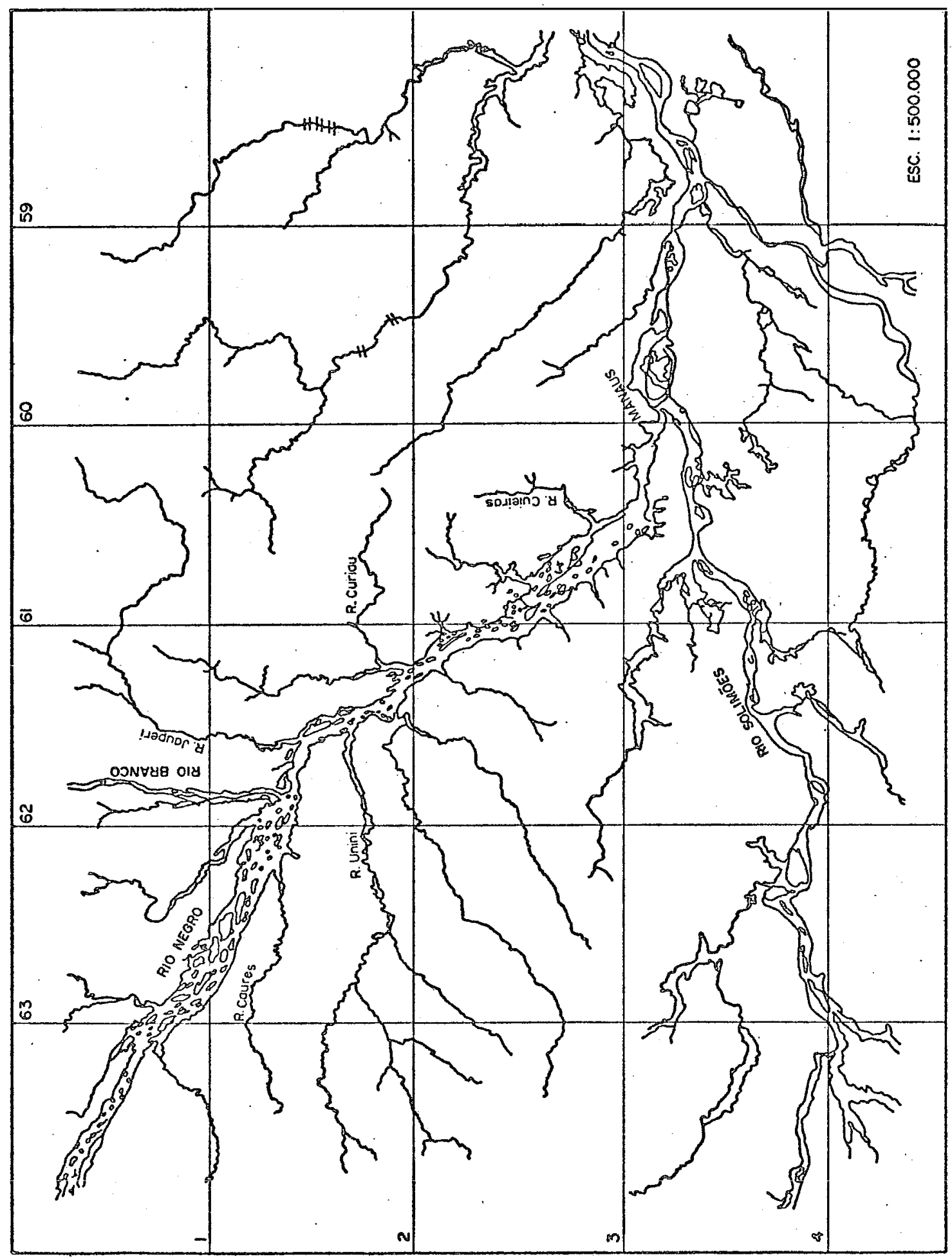

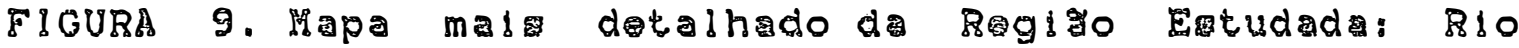

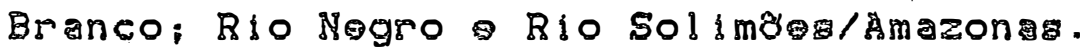




\subsubsection{SEDIMENTOS DOS LAGOS DO RIO BRARCO}

Sצ̆o considerados lagos de várzeas, do ecossistema do rio Branco, devido a movimentaçăo de subida e descida do nível do rio (Figura 10):

- Lago do Curubaú, localizado na margem esquerda do rio Branco, log. $61^{\circ} 51^{\prime}$ we Lat. $1^{\circ} 4^{\prime}$ s, ponto de coleta de $\mathrm{n}^{0} 1$;

- Lago do Maguari, situado na margem esquerda do rio Branco, Long. $61^{\circ} 51^{\prime} \mathrm{w}$ e Lat. $1^{\circ} 11^{\prime} \mathrm{s}$, ponto de coleta de $\mathrm{n} 2$.

3.1.3.3. SEDIHENTOS DOS LAGOS DO RIO MERTO INFLUENCIADO PELO BIO BRANCO

Săo lagos de várzeas pertencentes à bacia do rio Negro que sofrem influência do rio Branco, como também devido a movimentação da subida e descida do nível de agua do rio Negro (Figuras 11):

- Lago do susupuru, localizado no parańa da Floresta, na margem esqueda do rio Negro, Long. $61{ }^{\circ} 46^{\prime}$ W e Lat. $1^{\circ} 21^{\prime} \mathrm{S}$, ponto de coleta de $n^{\circ} 3$;

- Lago do Calango; situado no rio Jauperi, próximo a confluância do rio Negro, Long.. $61^{\circ} 39^{\prime} \mathrm{w}$ e Lat. ${ }^{\circ} 17^{\prime}$ s, ponto de coleta de $n^{\circ} 4$; 


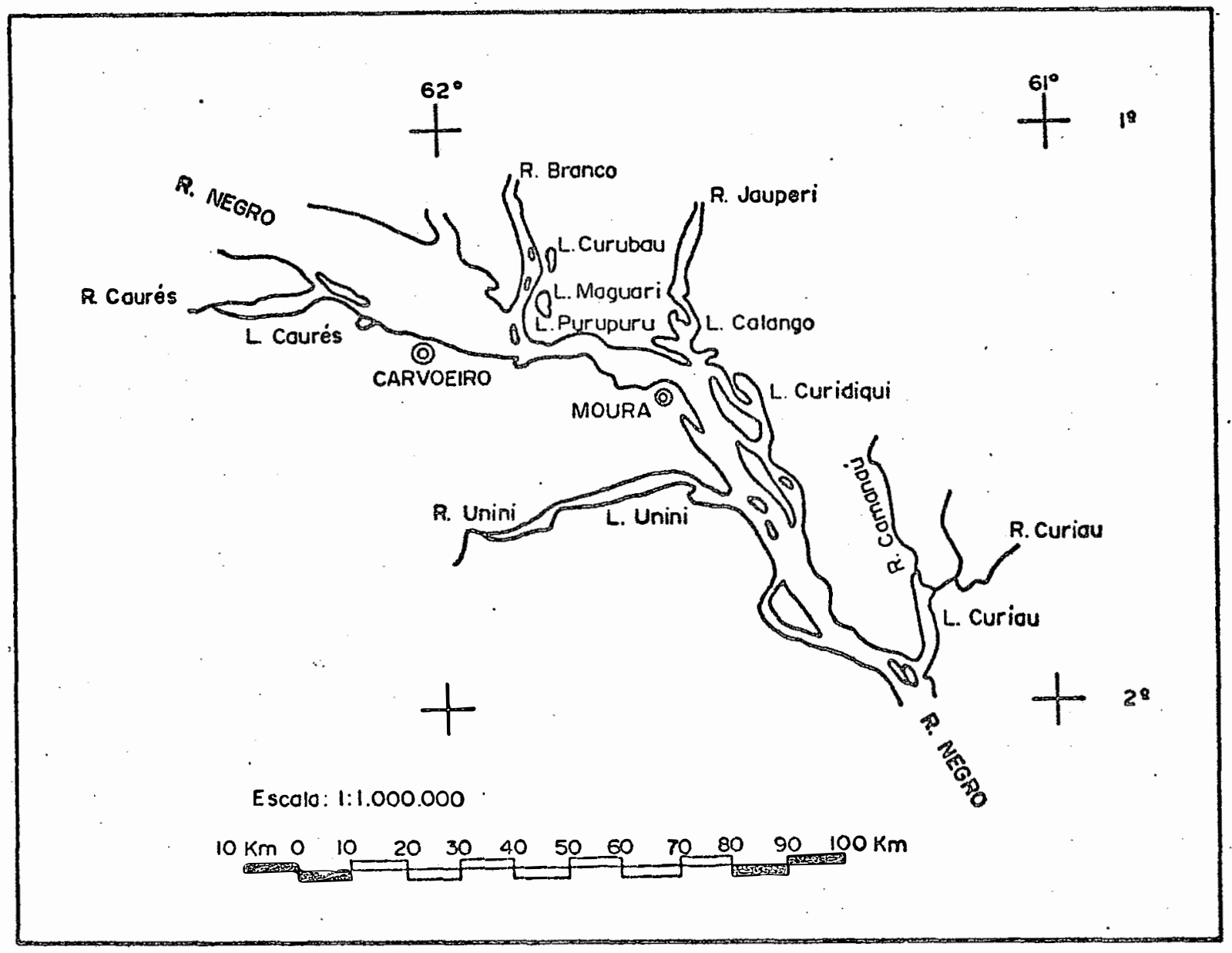

Rio Branco Bio Negro. 
- Lago do Curieliquj, localizado no Parana do Jacar $\theta$, margem esquerda do rio Negro, Long. $61^{\circ} 20^{\circ}$ we Lat. $1^{\circ} 52^{\prime} \mathrm{S}$, ponto de coleta de $\mathrm{n}^{\circ} 5$;

- L8go do Bandi, situado no rlo Baipendi, próximo a confluência do rio Negro, Long. $61^{\circ}$ $4^{\prime} W$ e Lat. $2^{\circ} 9^{\prime} S$, ponto de coleta de $n^{\circ} 6$ :

- Lago do Tauatu, localiza-se na margem esquerda do rio Negro, Long. $60^{\circ} \mathrm{w}$ e Lat. $2^{\circ} 28^{\prime} \mathrm{S}$, ponto de coleta de $n$ 7;

- La do Co casxi, localizado na margem esquerda do rio Negro, Long. $60^{\circ} 58^{\prime}$ we Lat. $2^{\circ} 29^{\prime} \mathrm{S}$, ponto de colota de $\mathrm{n} 8$;

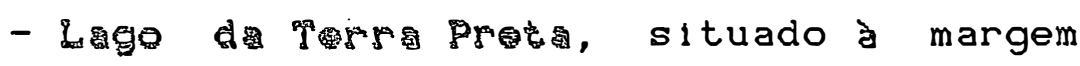
esquerda do rio Negro, no local denominado de Terra Preta, Long. $60^{\circ} 58^{\prime} w$ e Lat. $2^{\circ} 30^{\prime} \mathrm{S}$; ponto de coleta de $\mathrm{n}^{\circ} 9$;

- Lago do Ariau, localizado na margem esquerda do rio Negro, Long. $60^{\circ} 47^{\prime}$ we Lat. $2^{\circ} 35^{\prime} \mathrm{s}$, ponto de coleta de $n$ 10;

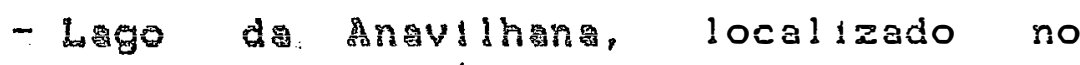
arquiprlago das Anavilhanas, no rio Negro, Long. $60^{\circ} 37^{\prime} \mathrm{w}$ e Lat. $2^{\circ} 47^{\prime} \mathrm{S}$, ponto de coleta de $n^{\circ} 11$. 


\subsubsection{SEDIPENTOS DOS LAGOS DO RIO NEGRO}

Săo lagos considerados de várzeas, que sofrem influência das águas do rio Negro; aumentando de volume, devido ao represamento das águas desse rio e de acordo com a subida e decida das águas do rio Negro. As águas dos lagos desse ecossistema şo formadas por rios de agua preta, cujas localiząão podem ser observados nas Figuras 11 .

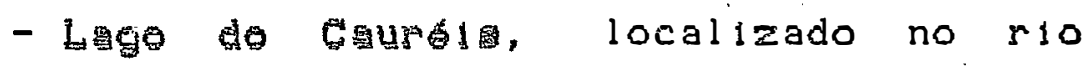
Caurés, prósimo à confluencia do rio Negro, pela margem direita, Log. $62^{\circ} 17^{\prime}$ we Lat. $1^{\circ} 20^{\prime} \mathrm{S}$, ponto de coleta de $\mathrm{n}$ 12;

- Lago do Curiaú, situado no rio Curiaú, próximo a confluência do rio Camanaú, afluente da margem esquerda do rio Negro, Long. $61^{\circ} 12^{\prime}$ we Lat. $1^{\circ} 41^{\prime} \mathrm{S}$, ponto de coleta de $n$ 13;

- Logo do Promed, localiza-se no rio Cuieiras, afluente da margem esquerda do rio Negro, Log. $60^{\circ} 23^{\prime} W e$ Lat. $2^{\circ} 40^{\prime} \mathrm{S}$, ponto de coleta de $\mathrm{n}^{\circ} 14$ :

- Lago do Unigri, localizado no rio Ünini, afluente do rio Negro pela margem direita, Long. $61^{\circ} 40^{\circ} \mathrm{W}$ e Lat. $1^{\circ} 36^{\prime} \mathrm{S}$, ponto de coleta de $\mathrm{n}^{\circ} 15$ : 


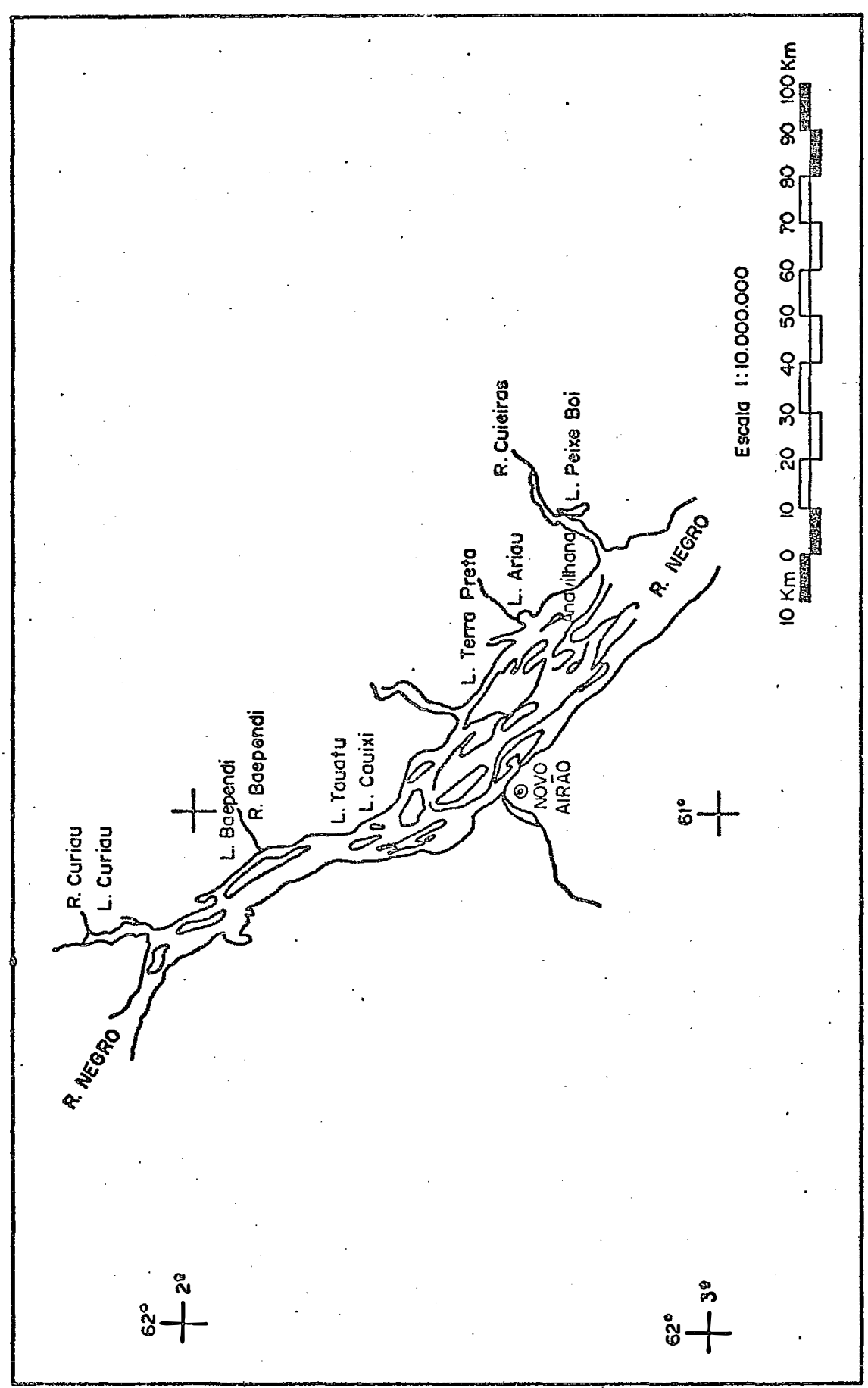

FIGURA 11. Bacia do rio juegro. Localizacão dos Lagos do rio Negro sobre Influência do rio Branco. 
3.1.2.5. SEDIMENTOS DOS LAGOS DO RIO SOLIMOES/AMAZONAS

Săo lagos típicos de várzeas do ecossistema Solimơes/Amzonas, sofrendo influência desse rio, que traz material em suspensão, durante a época cheia, cujo material $\&$ um dos principais fornecedores de nutrientes. Esses lagos possuem extensos tapetes de capim flutuantes (Gramineas do genero Paspalum) e outras macroidrofitas (Victoria, Azolla, Eichornia, Sauvinia, Pigtia) que são caracteristicas de água branca. Na Figuras 11 e 12, observam-se as locallzaçes desses lagos:

- Lage eda Prelonela, localizado na tha da Pacência proximo à cidade de Iranduba, Log. $60^{\circ} 15^{\prime} \mathrm{w} e$ Lat. $3^{\circ} 21^{\prime}$ S, ponto de coleta de ${ }^{\circ} 16$;

- Lago do Jaraqul, situado no Paraná do Manaquiri, Long. $60^{\circ} 38^{\prime} \mathrm{W}$ e Lat. $3^{\circ} 18^{\prime} \mathrm{S}$, ponto de coleta de $n$ 17;

- Lago do Hangulat, localizado no Parana do Manaquiri, Long. $60^{\circ} 10^{\prime}$ we Lat. $3^{\circ} 10^{\prime} \mathrm{s}$, ponto de coleta de $\mathrm{n} 18$;

- Lago do Muratu, situado na Ilha do Muratu, Long. $60^{\circ} 5^{\prime} w$ e Lat. $3^{\circ} 15^{\prime} \mathrm{S}$, pónto de coleta de ${ }^{\circ} 19$ 
- Lago Grand do Jusal, localizado na regi đ̃o do Janauaca, na margem direita do rio Solimøes, Long. $60^{\circ} 18^{\prime} \mathrm{w}$ e Lat. $3^{\circ} 24^{\prime} \mathrm{S}$, ponto de coleta de $\mathrm{n}$ ' 20 ;

- Lago do Formiga, situado na região do Janauaca, Long. $60^{\circ} 12^{\prime}$ we Lat. $3^{\circ} 18^{\prime} \mathrm{s}$, ponto de coleta de n 21;

- Lago do Cagranho, localizado na margem direita do rio Solimzes, tambem $r a z$ parte do complexo sistema do Janauaca, com conexăo permanente com o rio Solimores, pelo Parana do Janauaca, Long. $60^{\circ} 14^{\prime}$ w e Lat. $3^{\circ} 24^{\prime} 5$, ponto de coleta de $n^{\circ} 22$;

- Lago do Reiz, situado na ilha do Careiro, Long. $59^{\circ} 20^{\prime} w$ e Lat. $3^{\circ} 12^{\prime} \mathrm{s}$, ponto de coleta de de $n$ 23;

- Lago do Tarumanduba, situado na ilha do Careiro, Long. $59^{\circ} 45^{\prime}$ w e Lat. $3^{\circ} 14^{\prime}$ s, ponto de coleta de $n^{\circ} 24$;

- Lago do Hagaco, situado na ilha do Careiro, long. $58^{\circ} 50^{\prime}$ we Lat. $3^{\circ} 15^{\prime} \mathrm{s}$, ponto de coleta de $n^{\circ} 25$;

- Lago do Arrog, localizado à margem esquerda do Parana do Careiro (rio Solimâes), ilha do. Careiro, Long. $59^{\circ} 48^{\prime} \mathrm{W}$ e Lat. $3^{\circ} 10^{\prime} \mathrm{s}$, ponto de coleta de $\mathrm{n}^{\circ} 26$; 
- Lago do Jagaretinga, localizado na margem direita do Parans do Careiro (rio Solimøes), Long. $59^{\circ} 50^{\prime}$ e Lat. $3^{\circ} 13^{\prime}$ s, ponto de coleta de ${ }^{\circ}$ 27:

Lago do Passarinho. situado na ilha do Careiro, Long. $59^{\circ} 40^{\prime}$ we Lat. $3^{\circ} 13^{\prime} \mathrm{s}$, ponto de coleta de ${ }^{\circ} 28$;

- Lago do Capitari, situado na margem direita do Parana do Careiro (rio Solimões), Long. $59^{\circ}$ direlta do Parans do Careiro (rio Solimóes), Long. 59 $50^{\prime} w$ e Lat. $3^{\circ} 20^{\prime} \mathrm{S}$, ponto de coleta de $\mathrm{n}^{\circ} 29$. 


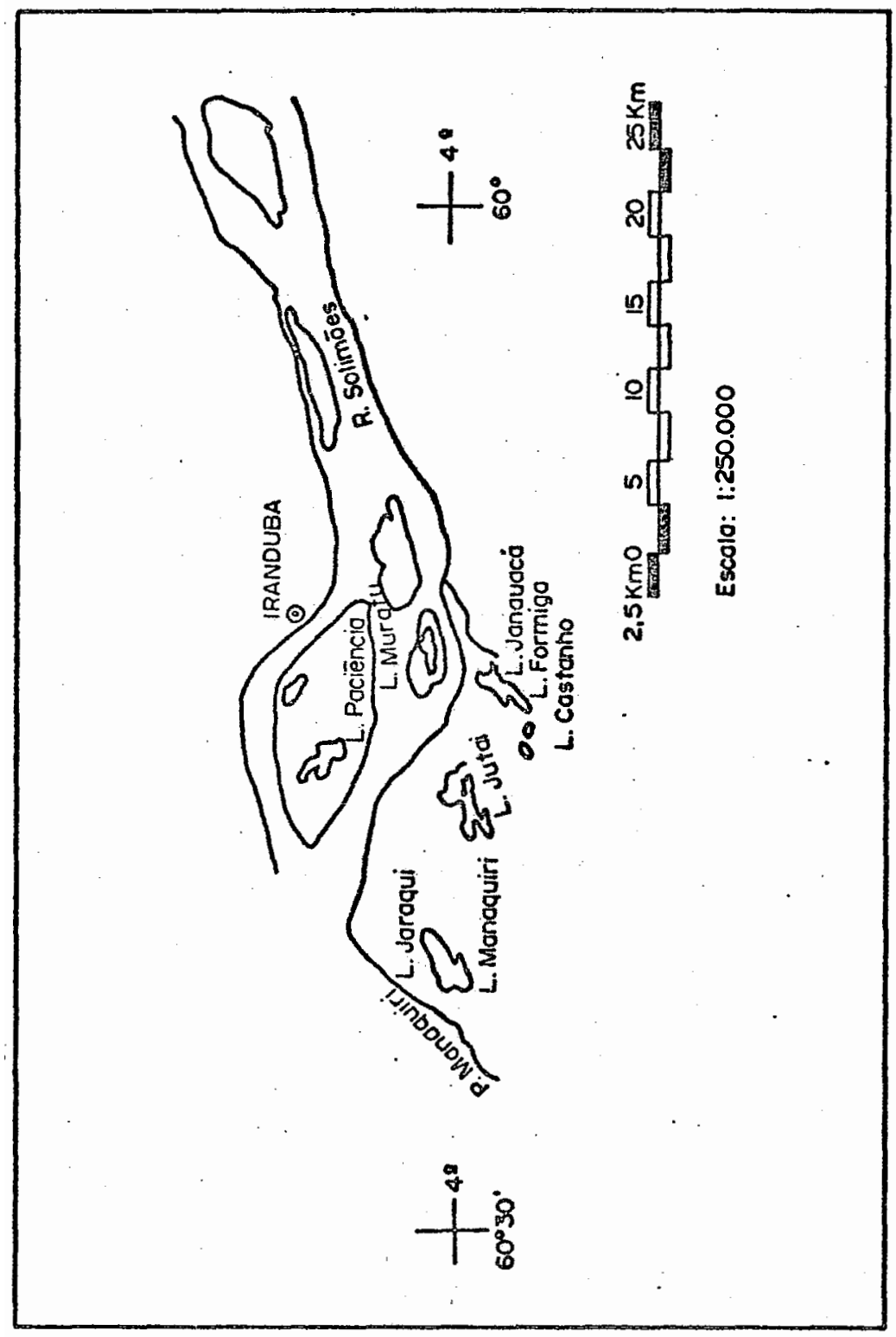

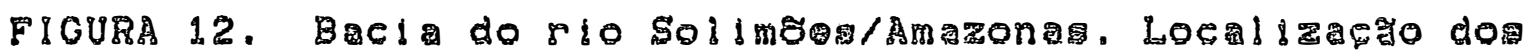
4. 


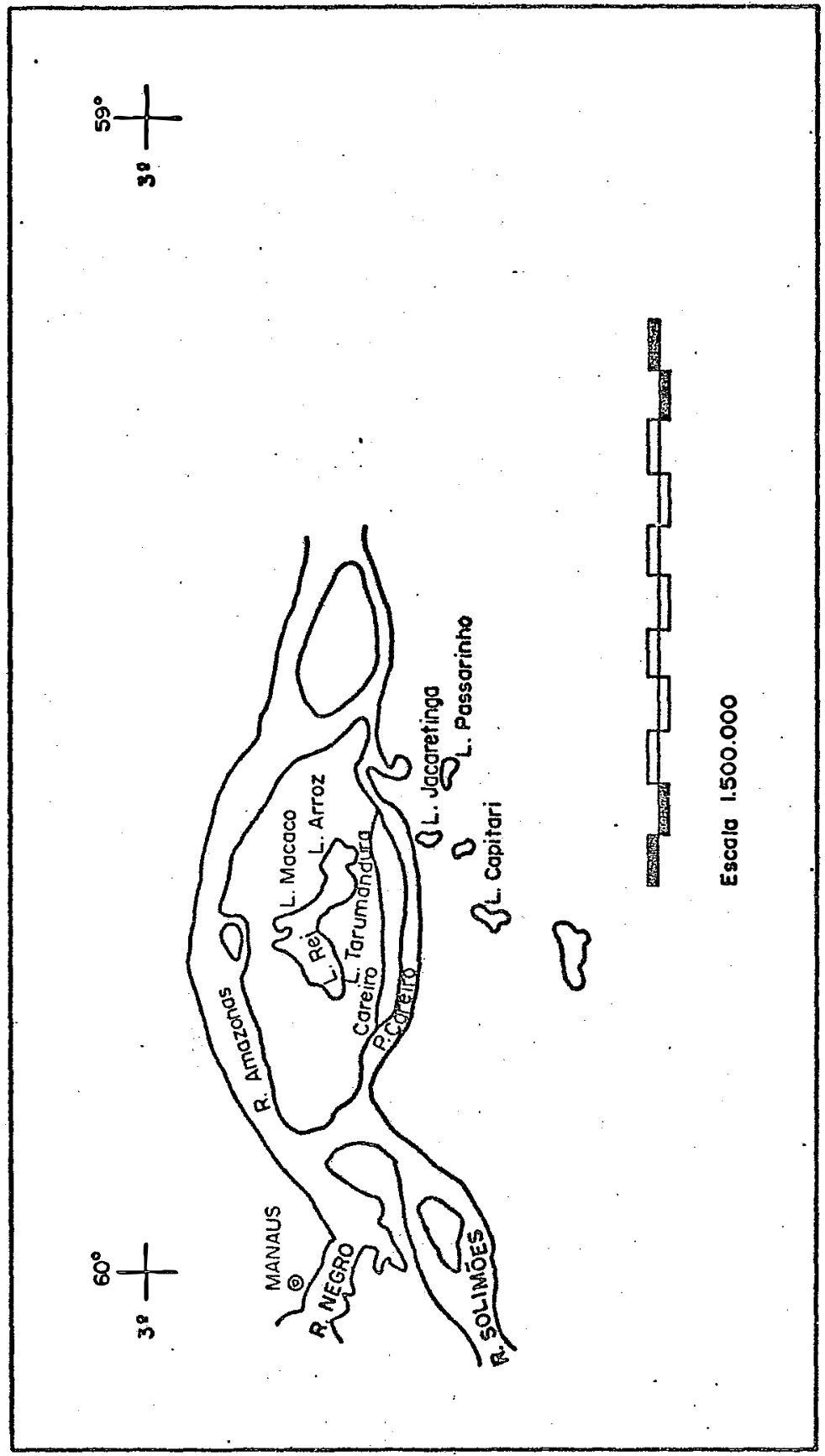

FIGUBA 23. B L 


\subsection{METODOLOGIA}

\subsubsection{TECNICA DE AMOSTRAGEM '}

Em agosto de 1982, foram coletadas amostras de sedimento de fundo dos lagos (camada superficial) pertencentes à bacia do rio Negro, rio Branco e rio Solimoes/Amazonas, com um amostrador tipo draga, medindo $35 \times 20 \times 25 \mathrm{~cm}$.

Todos os esforços foram realizados com o intuito de que, no momento das coletas, permanecessimos o máximo possível no "centro do lago". Medida essa, realizada de uma maneira visual. Entretanto, devido a aça da correnteza e do vendo, torna-se dificil uma melhor $f$ ixacăo do ponto de coleta.

Desta maneira, procurou-se evitar que os sedimentos récem depositados nas várzeas, tivessem alguma influância nos sedimentos do "fundo do lago" do lago, no momento da coleta. Assim, julgamos que os sedimentos coletados, foram os depositados no "fundo do lago", longe das influências que ocorrem nos solos que circundam esses lagos.

$$
\text { Apos as coletas, as amostras foram }
$$

acondicionadas em sacos de polietileno e conduzidas ao 
laboratório, para as análises: física, físico-química e química.

\subsubsection{PREPARO DA AMOSTRA}

As amostras coletadas foram secas ao ar, e peneiradas (2 mm T.F.S.A.) e devidamente armazenadas. Portanto, 6 possível que tenha ocorrido alteraç̋es na composiç̃o química dessas amostras. Porem, os resultados obtidos e a semelhanca no padrão de comportamento das tendências encontradas, permite-nos a acretidar que tais alteraç̧es não ocorreram, ou, se houveram, foram às mínimas possíveis.

\subsubsection{ANALISE FISICA E FIรICO-DUYMICAS}

\subsubsection{ANALISE GRANULOHETRIGA}

A analise Granulométrica dos sedimentos fol realizada pelo método DRER-mE $51-64$, que consiste em uma combinaç̃o de analises por sedimentąão e por peneiramento, usando-se como defloculante, solucão de

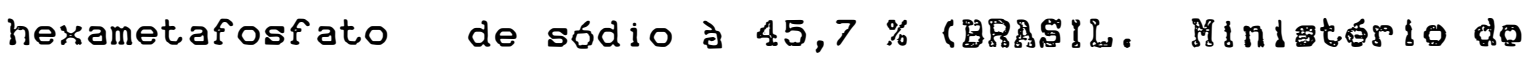
Transporte. Departamento Nacional dø Earradas, 1964). 


\section{$3.3 .3 .2 . \mathrm{PH}$}

Foi determinado usando-se o método potenclometrico, medido em aparelho de $\mathrm{pH}$ meter da WTW, modelo pH meter, 391 com eletrodo de vidro e calibrado com soluç⿰ $\mathrm{pH}$ 4,00 e pH 6,9. Paratal, pesou-se $10 \mathrm{~g}$ de T.F.S.A. e adicionou-se $100 \mathrm{ml}$ de agua destilada, homogenizou-se com agitador magnetico. Apss 30 minutos, fez-se a leitura, mergulhando o eletrodo na fase lsquida;

\subsubsection{ANALISE MIMERALOCIGA}

Realizou-se, a Difraça aos raios-x, na fraça argila das amostras dos sedimentos, que previamente, foram tratados com H O para eliminar a matéria orgânica, e 22

fazendo-se a dispersăo em soda. Para as determinações de minerais do tipo 2:1, fez-se um tratamento com vapores de etileno glicol e aquecimento.

\subsection{B. AMรLISES QUYMICAS}

\subsubsection{CARBONO}

Determinado pelo processo Walkjoy-8lack (JACKSON, 1958), onde o dicromato de potássio, em presenca de $\mathrm{H}$ si a quente transforma em $\mathrm{CO}$ todas as formas oxidaveis de carbono. 


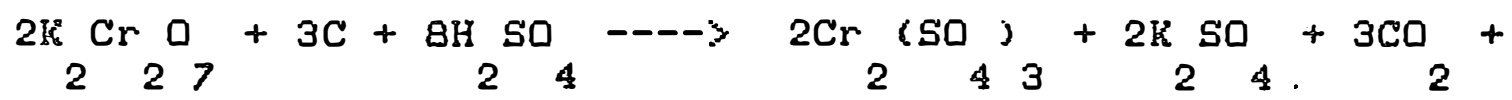

$8 \mathrm{H} 0$

$$
2 \mathrm{Cr} \mathrm{a}_{27}^{-2}+3 \mathrm{C}+16 \mathrm{H}---->4 \mathrm{Cr}^{+3}+3 \mathrm{CO}+8 \mathrm{H}_{2} \mathrm{O}
$$

Sendo que o excesso de dicromato de potasi10. $\theta$ determinado por lodometria. E o número de equivalente-miligramas de $\mathrm{K} \mathrm{Cr} 0$, redualdo pelo carbono multiplicado por 3, fornece o número de miligramas de Carbono em uma al fquota. Para $18 s 0$, usou-se $1,09 \mathrm{da}$ amostra (T.F.S.A.), em um balơo volumbtricode 50 , adlcionando-se $10 \mathrm{ml}$ de $H$ SO $(1+1)$, coloca-se 5 mil de. soluçăo $2 \mathbb{N}$ de $\operatorname{Cr} 0$, Após banho-marla, toma-se uma al qquota de $5 \mathrm{ml}$ do sobrenadante, adiclomando-se $50 \mathrm{ml}$ de squa destllada, $5 \mathrm{ml}$ de H PO $(1+1): 2 \mathrm{ml}$ de soluça a $20 \%$ de $K_{1}$ e titula-se $0 \stackrel{3}{0}^{4}$ l lure com Na25203a $0,05 \mathrm{~N}$.

3.3.

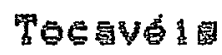

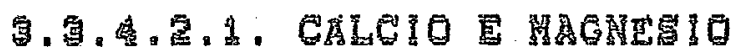
$+2$

A presença de $\mathrm{Ca} \quad 6$ notado quando utıl1za-se indicador metalocrômico calcon em $\mathrm{pH} 7,5$ a 13,5 or Iginando uma coloraçăo rosea-violeta. Ja os lons Ca e Mg em presenga do indicador Es 10 Como Proto $\mathrm{T}$ e em pH entre 
6,5 e 11,5, forma um complexo de coloraço rósea-violeta,

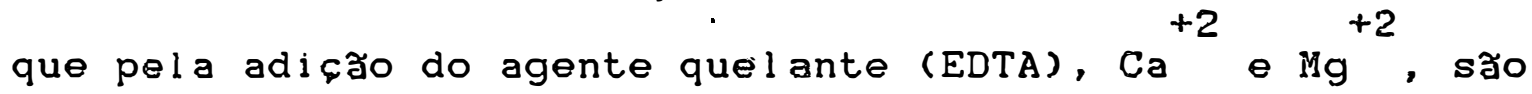
retirados do indicador e formam um quelato que resulta na mudança da coloraçóo rósea-violeta para a cor azul, indicando que todos os rons passaram a integrar as moléculas do quelato.

Utilizou-se, $10 \mathrm{~g}$ de amostra (T.F.S.A.), adicionou-se $100 \mathrm{ml}$ de $\mathrm{KCl} \mathrm{N}$, e filtrou-se.

\section{ANALปSE DO CALCIO TรECAVIL}

Em uma aliquota de $25 \mathrm{ml}$ do extrato anteriormente obtido, adiciona-se $60-70 \mathrm{ml}$ de sgua destilada, $2 \mathrm{ml}$ de $\mathrm{NaOH}$ a $20 \% ; 5$ gotas de Trietanolamina $2 \mathrm{ml}$ de $\mathrm{KCN}$ a $5 \%, 6$ gotas do indicador Calcon e titula-se

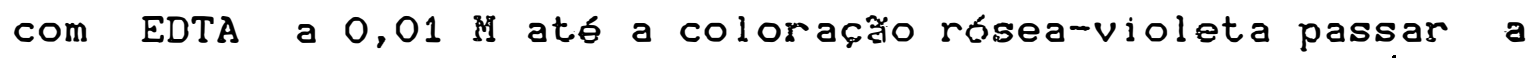
azul (PELLO al s.d.).

AHAL 15E DO HAGNES TO TROCBVEL

Em uma al fquota de $25 \mathrm{mi}$ do extrato obtido com a soluçăo de $\mathrm{KCl} \mathrm{N}$, adiciona-se 60-70 $\mathrm{ml}$ de sgua destilada; 5. gotas de Trietanolamina; $5 \mathrm{ml}$ da soluçăo Tampðo $\mathrm{pH}=10$ e $2 \mathrm{ml}$ de $\mathrm{KCN}$ a $5 \%$ e 6 gotas do indicador Esjo Cromo Proto T e titula-se com EDTA a $0,01 \mathrm{M}$ at coloraço rósea-violeta passe a azul (Mg⿴囗十⺝ 


\subsection{SODIO E POTASSIO}

A extraça do sódio e potassio trocaveis efetua-se, mediante a utilizaçăo de $150 \mathrm{ml}$ da soluçăo extratora $(0,05 \mathrm{~N}$ de $\mathrm{HCl}$ e $0,025 \mathrm{~N}$ de $\mathrm{H}$.5O ). Apos agitaça e repouso, retira-se $50 \mathrm{ml}$ do sobrenadante e efetua-se a leitura em fotometria de Chama cGUמMARAEs ot alii, 197.9), utilizou-se o modelo B 262 da Micronal.

\subsection{ALUBINIO}

0 alumínio trocável foi determinado utilizando-se a metodologia espectrofotometrica do Aluminon, cuja absorção máxima 6 obtida em 485 - 555 nm. Para isso, tomou-se uma al lquota de $5 \mathrm{ml}$ do extrato obtido com a soluça åo de $\mathrm{KCl} \mathrm{N}$ e adicionou-se $10 \mathrm{ml}$ de $\mathrm{HCl} 0,1 \mathrm{~N} ; 5$ $\mathrm{ml}$ de $\mathrm{CaCl}$ a $0,1 \mathrm{M}$; $2 \cdot \mathrm{ml}$ de scido ascórbico a $1 \%$ e $15 \mathrm{ml}$ do reagente composto (partes iguais de aluminon a $0,1 \%$ e soluça Tampåo pH 5,2 - 5,4; gelatina a $1 \%$ ). Apbs banhomaria por 10 minutos, completa-se o volume a $50 \mathrm{ml}$ com agua destilada e faz-se a leitura da absorbância.

\subsection{SOMA DE BASE}

E calculada pela expressão abaixo, sendo os resultados expressos em e.mg/100 g de T.F.S.A.

$$
\mathrm{S}=\mathrm{Ca}^{++}+\mathrm{Mg}^{++}+\mathrm{Na}^{+}+\mathrm{K}^{+}
$$


E obtida por meio da razåo entre as percentagens de Carbono e Nitrogênio e fornece uma idéia relativa sobre o estágio de mineralizaça da matéria.

\subsection{MATERIA ORGAN IEA (M.O.)}

A matéria orgânica ó obtida, multiplicando-se o teor de Carbono Orgânico, pelo fator 1,724

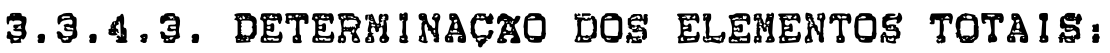

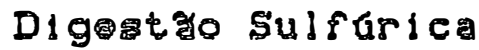

Usou-se 0,1 g da amostra de sedimento

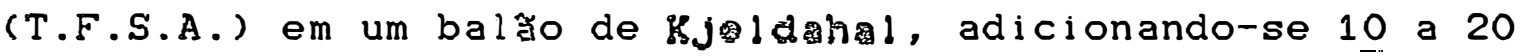
$\mathrm{ml}$ de agua destillada e aquecer por alguns minutos. Coloca-

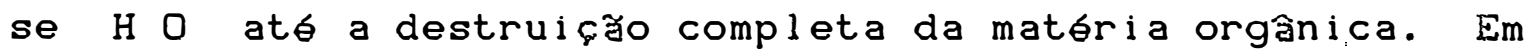
22 seguida, adiciona-se $2 \mathrm{ml}$ de $\mathrm{H}$ so $(d=1,84)$ e deixar "secar", at 6 aparecer os primeiros sinais de fumaca branca (20 a 30 minutos); filtra-se e completa-se o volume para $100 \mathrm{ml}$ com agua destilada. "Esse filtrado (extrato) pode ser utilizado nas deternimaçōes dos teores totais dos elementos na porcåo do sedimento. 


\section{3 .4 .3 .1$. NITROGENIO}

As formas nitrogenadas que se encontram no sedimento (solo), são transformadas em sulfato de amônio, quando este 6 digerido com H so em presença de catalisador. Desta maneira, o nitrogênio 6 destilado por arrastamento de vapor em um destilador tipo Markham, que em presença do $\mathrm{NaOH}$ a $40 \%$ desprende o $\mathrm{NH}$ que 6 recebido.em um balå volumఠtrico contendo $\mathrm{H}$ SO $\mathrm{a}^{3} 0,1 \mathrm{~N}$ afim de fixar - NH desprendido na destilaç⿰丿⺄⿱ $e^{\circ}$ determinado por.

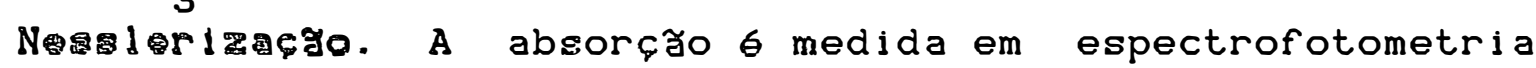
com absorఢ̧ชัo mรxima em $617 \mathrm{~nm}$ (GOLTERMAN, 1970).

Em $10 \mathrm{ml}$ da al fquota obtida pela digeståo. sulfúrica, adiciona-se $10-12 \mathrm{ml}$ de $\mathrm{NaOH}$ a $40 \%$ no destilador tipo Markham e em um balão volumøtrico ( $100 \mathrm{ml}$ ) contendo $5 \mathrm{ml}$ de H SO a $0,1 \mathrm{~N}$, recolhe-se $100 \mathrm{ml}$ do destilado, a seguir, adiciona-se $2 \mathrm{ml}$ de reagente Nessler e detemina-se a absorৎ̧ัo no espectrofotômetro modôlo B 382 da Micronal.

\section{9. 슨.3.}

0 fosforo 6 encontrado em varjas formas de fosfatos complexos: ligado ao ferro, alumínio e çlcio. dependendo do $\mathrm{pH}$ e de outras caracterssticas, ocorre ainda na forma orgânica como fosfolipidios, ou tambím na forma iônica, adsorvido aos colojdes do solo ou ainda, na solu६̧a 
do solo. o fósforo foi determinado em uma aliquota do extrato obtido pela digestão sulfúrica, usando o método do azul de molibdônio. A absorbância das amostras foram medidas em espectrofotometria, cuja absorça máxima se verifica em 712 - $720 \mathrm{~nm}$ (GOLTERMAN, 1970).

Em uma al squota de $50 \mathrm{ml}$ do extrato obtido pela digestão sulfúrica, faz-se a acidificaça com H so a $1 \mathrm{~N}$, até coloraço amarela e em seguida, a neutralizaça com NH OH conc. até a descoloraça total. A seguir, 4

adiciona-se $0,5 \mathrm{ml}$ de Scido cítrico a $2 \% ; 1 \mathrm{ml}$ de mobibdato de wolfranio $[5 \mathrm{~g}$ de ( $\mathrm{NH}$ ) Mo.4H $0 ; 0,1 \mathrm{~g}$ de $\mathrm{Na}$ wo $.2 \mathrm{H} O$ e $85 \mathrm{ml}$ de $\mathrm{H}$ SO $(1+1)$, completa-se a $225 \mathrm{ml}$ de 24224 sgua destiladaj e $0,5 \mathrm{ml}$ de $\mathrm{KCN}$ a $0,1 \%$.

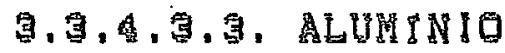

- alumínio total foi determinado, tomando-se uma aliquota de $1 \mathrm{ml}$ do extrato obtido pela digeståo sulfúrica, utilizando o método espectrofotométrico do aluminon. Cuja absorq̧o máxima G obtida em $484-550 \mathrm{~nm}$. o procedimento analítico, segue o adotado para o alumínio trocável.

\subsection{FERRO}

o Serro total a determinado em uma 
alíquota obtida pela digestăo sulfúrica, que em presença de um agente oxidante como o HNO conc. e a quente, transforma

$\circ \mathrm{Fe}^{+2} \mathrm{em} \mathrm{Fe}^{+3}$ 3

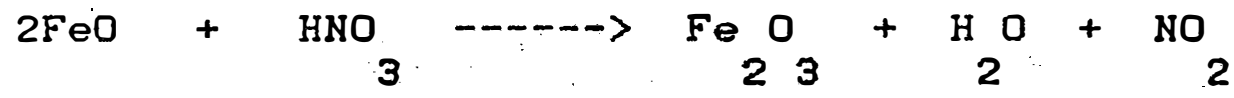

Que 6 determinado por espectrofotometria, cuja absorção mรxima é obtida em $480 \mathrm{~nm}$.

Em $5 \mathrm{ml}$ do esstrato obtido pela digestão sulfurica, adiciona-se $1 \mathrm{ml}$ de HNO conc., e aquecer para que ocorra a transformaça do $F e^{+2}$ para $^{3}{ }^{+3}$. A seguir, adiciona-se $1 \mathrm{ml}$ de $\mathrm{HCl}$ a $32 \%$ e 2,5 $\mathrm{ml}$ de KSCN 1:3.

\subsection{MANGANES}

0 manganßs total pode ocorrer no sedimento $+2$

(solo) na forma de fons divalentes (Mn), troḉvel e não trocável, que fazem parte da rede cristalina de certos minerais e como óxidos hidratados, onde pode ocorrer uma inter-conversão das suas formas.

Para a determinaçăo do manganês total, utilizou-se uma alsquota do extrato sulfúrico, e, fôz-se a converşo do mangaņَs divalente em heptavalente, por meio do persulfato de amônio em presença do íon prata. 


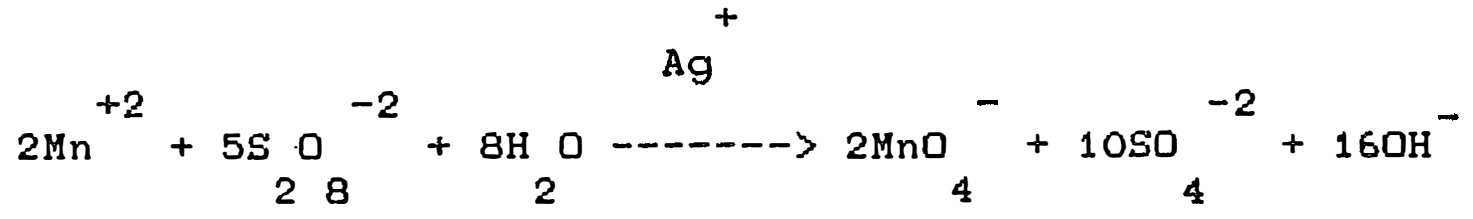

A absorç̧o máxima das amostras 6 obtida em 525-530 $\mathrm{nm}$, cuja determinaç̧o $\dot{\theta}$ realizada por espectrofotometr 1 a.

Em una al \{quota de $25 \mathrm{ml}$, adiciona-se $5 \mathrm{ml}$ de HNO $65 \%$, e aquecer para que ocorra a conversaro do $\mathrm{Mn}^{+2}$ para $\mathrm{Mn}^{+7}$. A seguir, adlciona-se $2 \mathrm{ml}$ de $[1,5 \mathrm{~g}$ de $\mathrm{Hg}(\mathrm{NO})+4 \mathrm{ml}$ de HNO a $65 \%$ completar para $100 \mathrm{ml}$ de 323 Sguaj; $2 \mathrm{ml}$ de $\mathrm{Ag}(\mathrm{NO}) \mathrm{N} / 35,5 ; 5 \mathrm{ml}$ de $\left(\mathrm{NH}_{4}\right)_{2} \mathrm{~S} \mathrm{O}_{8}$ a $10 \% \mathrm{e}$ completa-se o volume a $100 \mathrm{ml}$ de ggua dest $1 \mathrm{lada}$.

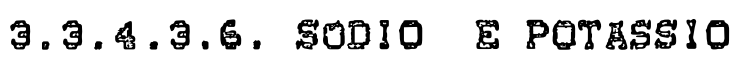

Quando esses elementos esţ̊ presentes em uma soluç̧o, e, se esta 6 atomizada e as partículas da soluç⿰彳 săo projetadas sobre uma chama, haverb́ a excłtaç̃o dos stomos, ou seja, ocorrera um deslocamento de elatrons para nívels energéticos mals slevados.

Os eletrons ao retornarem ao seu nivel energet ico normal, haver emiss âdo da energla absorvida, sob a forma de radiaçăo. A intensıdade das radiaçóes emitidas, - comprimento de onda e a concentraç̧o dos elementos săo assim relacionados. Esta, 6 a base fundamental da 
Espectrometria de Chama, que 6 .utillzada na determiną̧o do Sódio e Potássio.

Em uma aliquota do extrato obtido da digestão sulfúrica procede-se a determinaça do $\mathrm{Na}$ e $\mathrm{K}$ por Espectrometria de Chama usando-se o Fotometro de Chama da Micronal, modelo B 262.

\subsubsection{PIGPENTO TOTAL (Clorof11 A)}

A extraça da Clorofila 6 feita utilizando-se acetona à $90 \%$, seguido de maceraçăo e centrifugaça à $3.000 \mathrm{rpm}$, durante $10 \mathrm{minutos.} \mathrm{A} \mathrm{leitura} \mathrm{da}$ absorvância do sobremadante 6 realizada em 663 e $750 \mathrm{~nm}$, em cubeta de $1,0 \mathrm{~cm}$, contra acetona ja $90 \%$ GQLTERRAN (1970). 


\section{APRESEATACXO DQS RESULTADOS}

Para uma melhor caracterizaça, dos sedimentos de fundo dos lagos, os resultados analiticos for am agrupados, em 4 (quatro) ecossistemas abaixo relacionados e localizGveis nas Figuras 10; 11; 12 e 13:

- Sedimento dos lagos do rio Megro:

- Sedimento dos lagos do rio Branco;

- Sedimento dos lagos do rio Negro influenciados pelo rio Branco e

- Sedimento dos lagos do. rio Solimões/ Amazonas.

Serăo apresentados inicialmente, os resultados das an dos dados químicos do complexo sortivos, dos elementos totais e da fraça orgânica. Os resultados da anglise física, seråo apresentados em forma grgfica, com o intuito de se fazer uma anglise comparativa dos ecossistemas em estudo, bem como a comprovaça da fertilizą̧o das sreas do rio Negro que sofrem influência do rio Branco. 


\subsection{SEDIMENTO DOS LAGOS DO RIO NEGBO}

São lagos considerados de varzeas, que sofrem influência das águas do rio Negro; aumentando de volume, devido ao represamento das aguas desse rio e de acordo com a subida e descida das aguas do rio Negro. As aguas dos lagos desse ecossistema, são formadas por rios de agua preta (Figura 10):

\subsubsection{ANALISE FISICA E FISICO-QYYHICA}

\subsubsection{ANALISE GRANULOMETRICA}

Os resultados da anslise granulometrica desses sedimentos, são constituŕdos de Areia fina siltosa, contendo de $6,0 \%$ de argial coloidal $(<0,001 \mathrm{~mm}) ; 10,0 \%$ de argila; $42,0 \%$ de silte e $38,0 \%$ de areia fina. Podem ainda apresentar granulometria do tipo Areia fina argilo siltosa, contendo, $12 \%$ de argila coloidal $(<0,001 \mathrm{~mm}) ; 28$ $\%$ de argila: $24 \%$ de silte; $47,0 \%$ de areia fina e 1,0\% de areia média.

\subsubsection{PH8}

Os sedimentos dos lagos do rio Negro, apresentam caracteristicas acidas, cuja variacao do pH esta entre 4,1 a 5,1 (Tabela 3 ). 


\subsubsection{ANELI5E QUIHICA}

\subsubsection{COMPLEKO SORTIVO \\ - resultado das analises do complexo} sortivo desses sedimentos eståo relacionados na Tabela 3 . Esses sedimentos apresentam um teor de calcio entre 0,5 a 1,5 e.mg/100 g; magnésio com concentraçes de 0,4 a 4,4 e.mg/100 g; s6dio apresenta variaç̃o de 0,5 a 1,3 e.mg/100 g: o potassio com teores variando de 0,3 a 0,8 e.mg/100 g; - alumio, apresenta-se com concentraçơes de 2,3 a 3,6 e.mg/100 g.

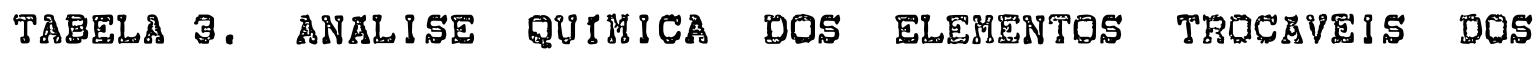
SEDIMENTOS DOS LAGOS PERTENCENTES AO ECOSSISTENA DO RIO NEGRO

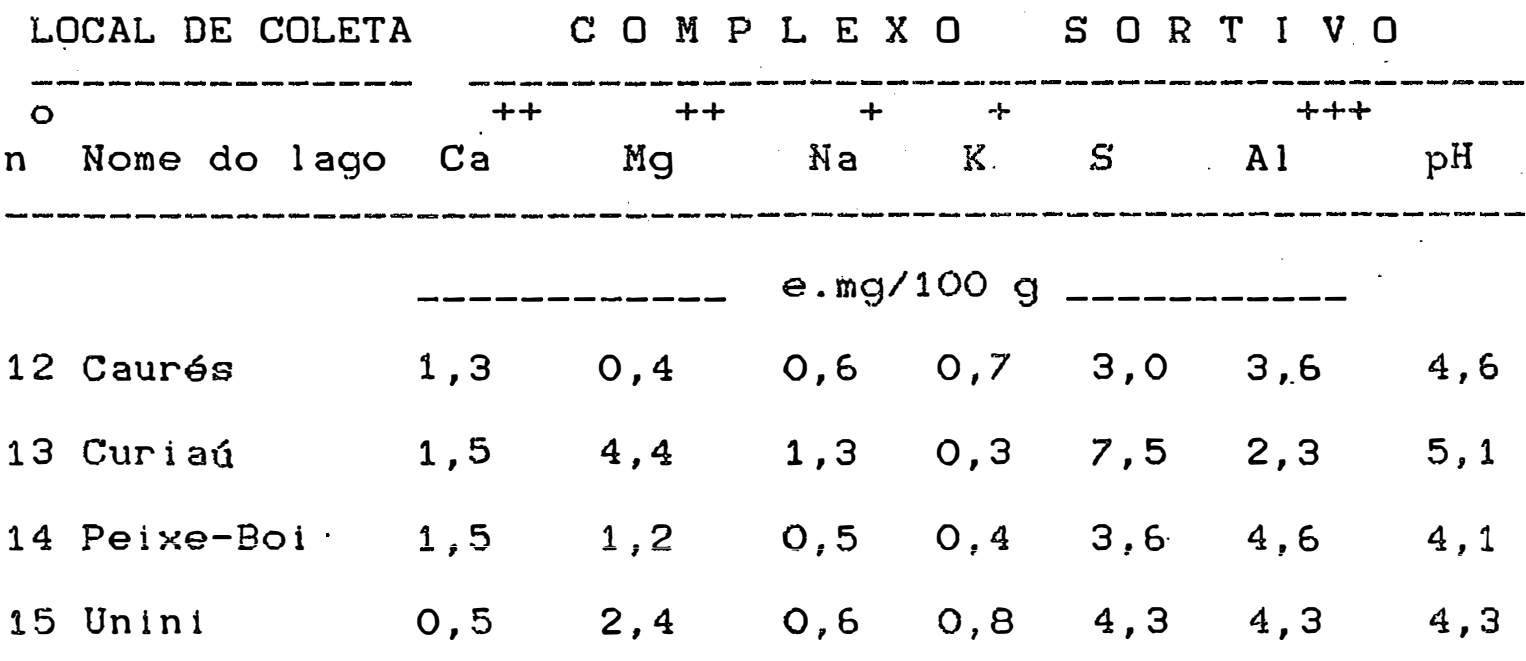




\subsubsection{ANALISE QUYMICA TOTAL}

A Tabela 4 apresenta os resultados analiticos dos sedimentos dos lagos que situam-se na bacia do rio Negro e que năo sofrem influência do rio Branco. Esses resultados indicam um teor de aluminio variável entre de 2,46 a $7,22 \mathrm{~g} / 100 \mathrm{~g}$. Notando-se uma quase inexistôncia do fósforo $(0$ a $0,06 \mathrm{~g} / 100 \mathrm{~g})$ e do manganês $(0$ a $0,03 \mathrm{~g} / 100 \mathrm{~g})$ nos sedimentos desses lagos. Praticamente, a variaç̃o no conteúdo de sódio é pequena, da ordem de 0,26 a 0,45 g/100g. Para o poţ́ssio, essa varią̛̆ está na ordem de 0,26 a $0,87 \mathrm{~g} / 100 \mathrm{~g}$ enquanto que para o ferro, esses sedimentos apresentam teores entre 0,34 a $1,04 \mathrm{~g} / 100 \mathrm{~g}$.

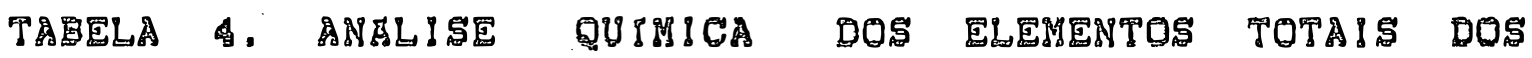
SEDIMENTOS DOS LAGOS DO RIO NEGRO

LOCAL DE COLETA

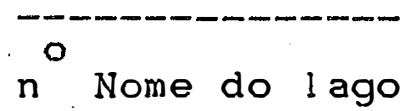

E L E N

\begin{tabular}{|c|c|c|}
\hline$A 1$ & $P$ & $\mathrm{Na}$ \\
\hline
\end{tabular}

$S \quad T O T A I S$

3) Mn

$\mathrm{Fe}$

$\begin{array}{lllllll}12 \text { Caures } & 2,46 & 0 & 0,35 & 0,87 & 0 & 0,47 \\ 13 \text { Curiaú } & 4,66 & 0 & 0,45 & 0,26 & 0,03 & 0,34 \\ 14 \text { Peise-Boi } & 7,22 & 0,06 & 0,26 & 0,60 & 0 & 1,04 \\ 15 \text { Unini } & 6,10 & 0 & 0,45 & 0,83 & 0 & 0,64\end{array}$




\subsubsection{FRAGEO ORGHNGA}

Os dados analiticos da fração orgânica, para os sedimentos dos lagos do rio Negro săo mostrados na Tabela 5. Eesee reeultadoe indicam uma pequena varlaça noe teores de nitrogênio $(0,12$ a $0,16 \mathrm{~g} / 100 \mathrm{~g})$ e 0 carbono, apresenta teores entre 1,60 a $2,83 \mathrm{~g} / 100 \mathrm{~g}$. Os resultados de $\mathrm{C}$ e $\mathrm{N}$, induzem a esses sedimentos, um $\mathrm{razaro} \mathrm{C} / \mathrm{N}$, da ordem de 11 a 24; o conteúdo da matéria orgânica, presentes nesses sedimentos variam entre 2,76 a $4,88 \%$, enquanto que o teor de clorofila (pigmentos total) saro constantes ( 4,1 $u g / g)$.

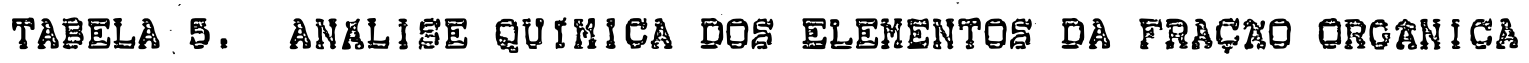
(C, $N, C / N$, MATERIA ORGENICA, N/P E PIGMENTO TOTAL) NOS SEDIMENTOS DOS LAGOS DO RIO NEGRO.

LOCAL DE COLETA

no Nome do 1 ago
F R A C A

$O R G A N I C A$

C N C $/ \mathrm{N}$ M.O. N/P. Pig.Total

\section{-- g/100g _- \% \%}

12 Caures

1,60

0,14

11

2,76

0,12

24

4,88

0,16

18

4,84

2,67

0,13

214,80

15 Unini

2,78

ug/g

4,1 


\subsection{SEDIMENTO DOS LAGOS DO RIO BRANCO}

Săo considerados lagos de várzeas, do ecossistema do rio Branco," devido a movimentą̧̊o de subida e descida do nivel do rio (Figura 10):

\section{Q.2.1. ANALIEE FISICA E FISICO - QUIMICA}

\subsubsection{ANELISE GRANULOPETRICA}

A granulometria dos sedimentos dos lagos localizados na bacia do rio Branco săo do tipo Areía fina argilosa, com um conteúdo de $6,0 \%$ de argila coloidal $<<$ $0,001 \mathrm{~mm}) ; 13,0 \%$ de argila; $10,0 \%$ de silte; $76,0 \%$ de areia fina e $1,0 \%$ de areia média.

4.2.1.2. $\mathrm{pH}$

A concentração hidrogeniônica dos sedimentos desses lagos (Tabela 6), mostra teores de $\mathrm{pH}$ entre 5,1 a 6,0. Esses resultados indicam que os sedimentos dos lagos do rio Branco constituem um meio de leve acidificą̧̃o. 


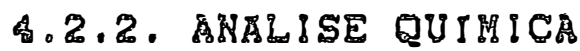

\subsubsection{COMPLEYO SORTIVO}

Os resultados dos elementos trocáveis, eståo mostrados na Tabela 6. Notam-se variaç̋es, principalmente nos teores de calcio (1,9 a 2,1 e.mg/100 g). Quanto aos teores de magnésio $(0,2$ a 0,3 e.mg/100 g); sódio $(0,5$ a 0,7 e.mg/100 g) e potássio $(0,4$ a 0,8 e.mg/100 g), nåo sofrem multa variaçăo. Apresentam soma de base entre 3,3 a 3,6 e.mg/100 g e o Alumínio variando entre 0,9 a 2,3 e.mg/100 g.

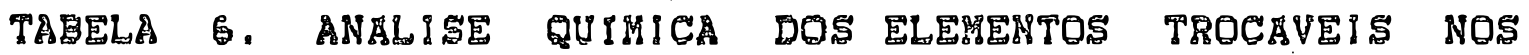
SEDIMERTOS DOS LAGOS DO RIO BRANCO.

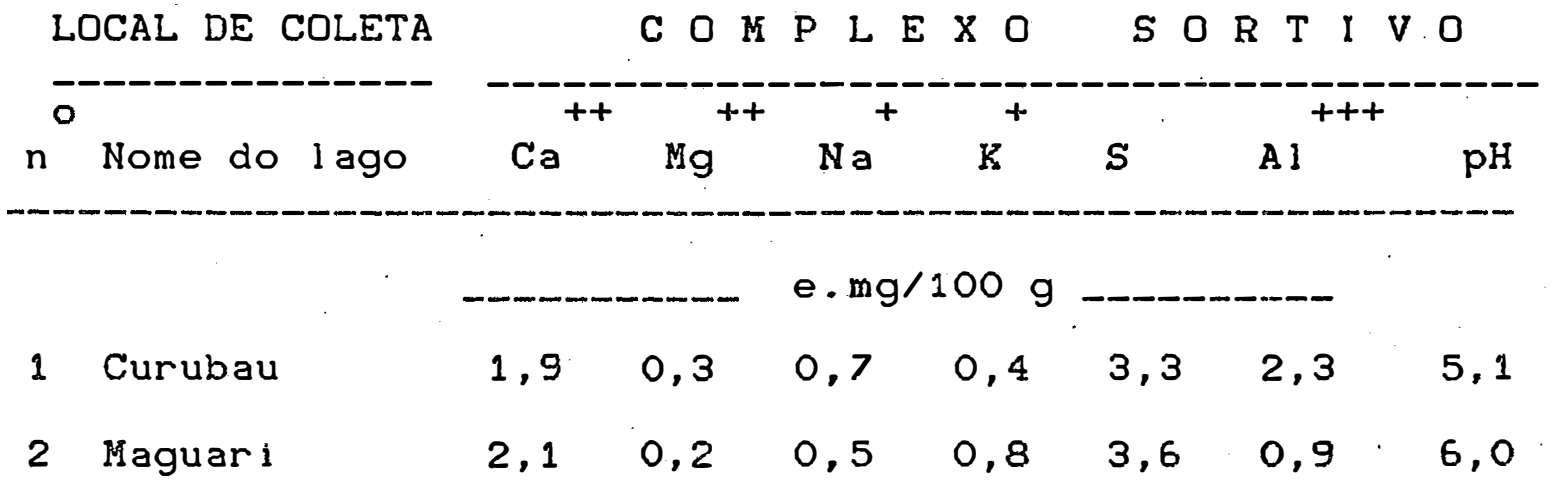




\subsubsection{ANALISE QYYYYCA TOTAL}

Os sedimentos dos lagos que pertencem a bacia do rio Branco (Tabela 7) apresentam um teor de sódio cuja concentração é pouco variável $(0,29$ a 0,31 $\mathrm{g} / 100 \mathrm{~g})$ e um teor de potássio $(0,20$ a $1,00 \mathrm{~g} / 100 \mathrm{~g})$, indicando maior variaçăo. Os teores de alumínio total presentes nesses sedimentos estão em concentraçðes que variam entre 3,56 a $7,06 \mathrm{~g} / 100 \mathrm{~g}$. Nota-se ainda, a presença do ferro, com teores entre 0,37 a 1,66 g/100 g, quanto ao fósforo e ao manganês, a anslise química evidência a total ausência do primeiro e um baixo teor do segundo elemento, cuja concentraço 6 da ordem de 0,04 a $0,08 \mathrm{~g} / 100 \mathrm{~g}$.

TAEELA 7. ANELIE QUYMSCA DOF ELERETTE TOTAIS NOS SEDIMENTOS DOS LAGOS DO RIO BRANCO.

LOCAL DE COLETA

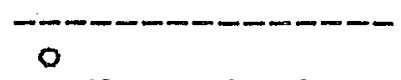

$\mathrm{n}$. Nome do lago
E L E M E N T O S T 0 T T A I S

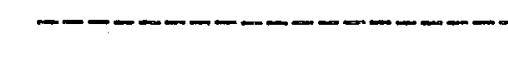

1 Curubau

2 Maguari

Al $P$ Na $K$ Mn Fe

\section{g/100 g}

$\begin{array}{llllll}3,56 & 0 & 0,31 & 0,20 & 0,08 & 0,37 \\ 7,06 & 0 & 0,29 & 1,00 & 0,04 & 1,66\end{array}$




\section{A․2.2.3. FRAGAO ORGANICA}

Os resultados analiticos dos sedimentos dos lagos que pertencem aे bacia do rio Branco (Tabala 8), apresentam teores de nitrogênio da ordem de 0,14 a 0,21 g/100 g, que. juntamente com os resultados obtidos para o carbono $(1,66$ a $2,91 \mathrm{~g} / 100 \mathrm{~g})$, produzem uma razåo $\mathrm{C} / \mathrm{N}$ entre 12 a 14 enquanto que a matéria orgânica apresenta uma percentagem da ordem de 2,86 a 5,01. Quanto a clorofila (pigmentos totais) presentes nesses sedimentos, variam entre 6,8 a $21,8 \mathrm{ug} / \mathrm{g}$.

TABELA \%. ANALISE QUTMICA DOS ELMMETOS DA FRACKO

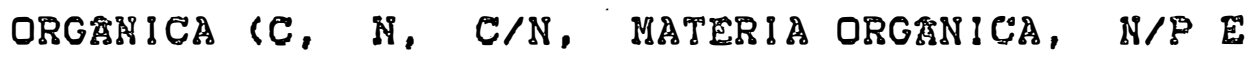
PIGNENTO TOTAL) NOS SEDIMENTOS DOS LAGOS DO RIO BRANCO.

\section{LOCAL DE COLETA \\ FRACA O ORGA I C A}

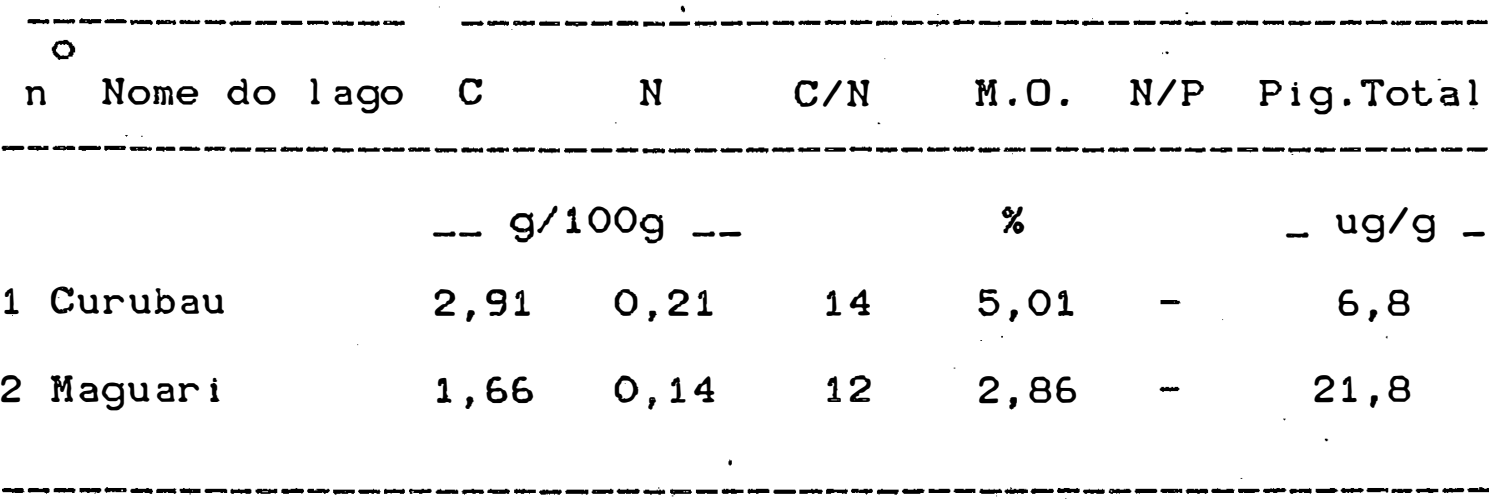


4.3. SEDIMENTO DOS LAGOS DO RIO NEGRO INFLUEMCIADO PELO RIO BRANCO.

Saro lagos de vorzeas pertencentes à bacia do rio Negro que sofrem influência do rio Branco, como também devido a movimentą̧ăo da subida e descida do nivel de água do rio Negro (Figuras 11):

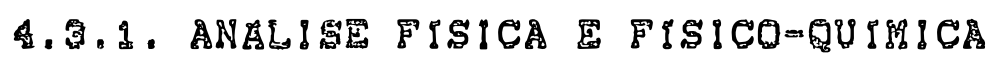

\subsubsection{AN\&LISE GRANYLOMETRICA}

A granulometria dos sedimentos desses lagos, mostram que os lagos que se situam próximo da foz do rio Branco possuem sedimentos constiturdos de Areia fina argilosa, contendo $19 \%$ de argila coloidal $(<0,001 \mathrm{~mm})$; $25,0 \%$ de argila; $22 \%$ désilte; $53 \%$ de areia fina.

Os sedimentos dos lagos que estao localizados mais a montante da foz do rio Branco, apresentam um textura do tipo Argila silte arenosa, com $31,7 \%$ de argila coloidal $(<0,001 \mathrm{~mm}) ; 45 \%$ de argila; 31 \% de silte; $22,0 \%$ de areia fina e $2,0 \%$ de areia média.

\subsubsection{2. $\mathrm{pH}$}

Os sedimentos dos lagos pertencentes ao 
rio Negro e que nåo sofrem influência do rio Branco, apresentam um meio moderadamente acidificado e, em alguns casos, esses sedimentos estão perto da neutralidade. Os teores de $\mathrm{pH}$, para esses sedimentos, variam entre 5,1 a 6,8 (Tabela 9).

4. 동.? A

\subsubsection{COMPLEYO SORTIVO}

Os elementos trocaveis do complexo sortivo dos sedimentos dos lagos que constituem esse ecossistema (Tabela 9). Mostram teores de calcio entre $(0,5$ a 4,8 e.mg/100 g): magnésio $(1,8$ a $6,5 \mathrm{e} \cdot \mathrm{mg} / 100 \mathrm{~g})$; śdio $(0,7$ a $1,4$ e.mg/ $100 \mathrm{~g})$; potássio $(0,5$ a 1,5 e.mg/100 g) e alumínio $(0,4$ a 4,1 e.mg/100 g). Essas determinações do complexo sortivo fornecem a esses sedimentos, uma soma de base com variaçơes entre 5,9 a 10,1 e.mg/100 g. 
TABELA 9. MMLISE QUYMICA DOS ELEMENTOS TROCEVEIS NOS SEDIRENTOS DOS LAGOS DO RIO NEGRO QUE SOFREH I NELUENCI DO DIO BRARCO.

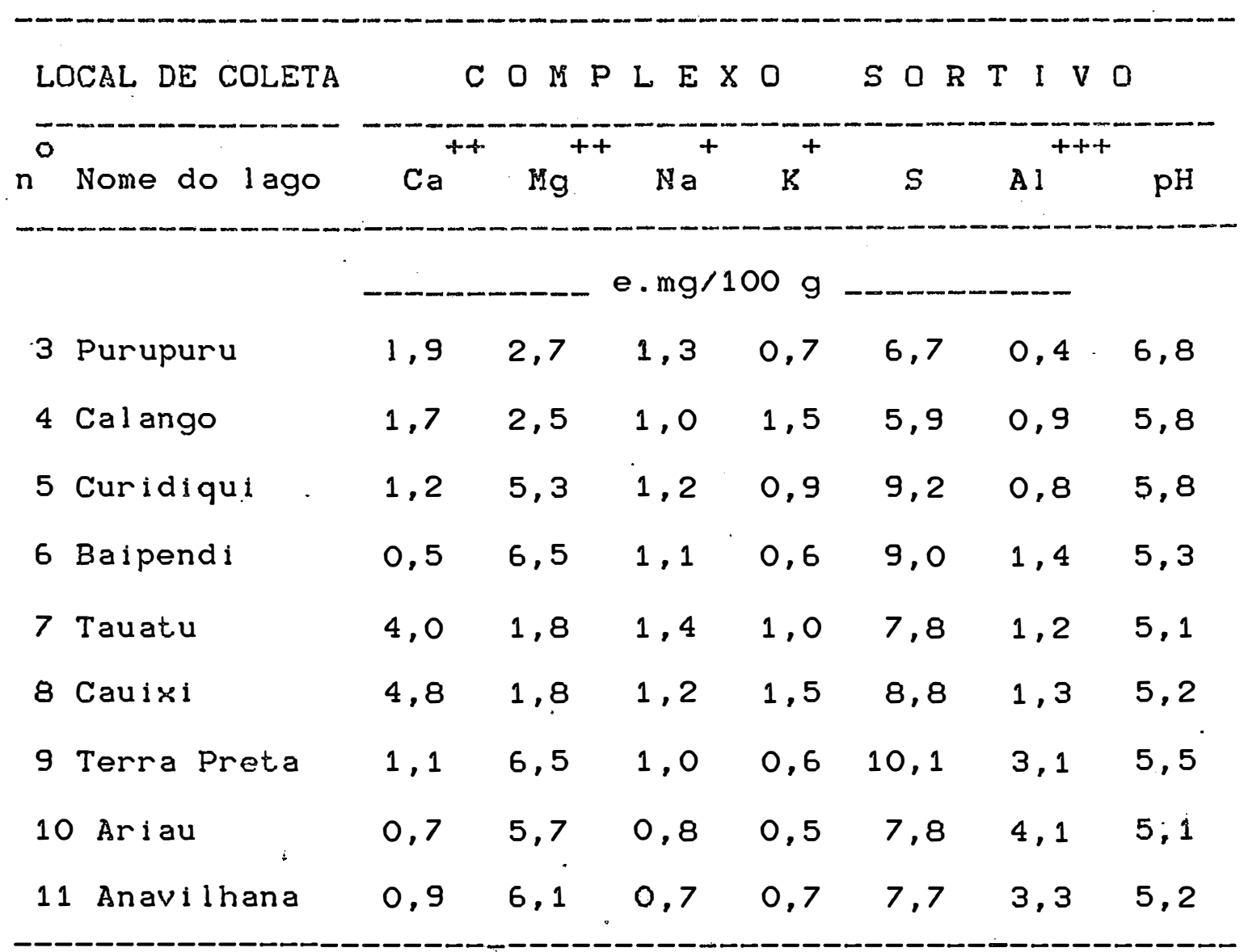

4.3.2.2. ANALISE QUYMICA TOTAL

Os lagos pertencentes a este ecossistema da bacia do rio Negro e que săo fortemente influenciados 
pelo rio Branco (Tabela 10), causando modificafốes físicoquímicas. Esses sedimentos apresentam teores de alumínio entre 3,40 a $9,32 \mathrm{~g} / 100 \mathrm{~g}$. Os resultados analsticos do fósforo indicam uma evidência desse. elemento en um maior número de lagos estudados, porém sua concentrafăo $\theta$ baixa $(0$ a $0,03 \mathrm{~g} / 100 \mathrm{~g})$.

Quanto ao manganês, a mesma evidência 6 observada nesses sedimentos, porém em concentraçóes baixas (0 a $0,06 \mathrm{~g} / 100 \mathrm{~g})$. Ş̊ mostrados também, que o sódio $(0,34$ a $0,55 \mathrm{~g} / 100 \mathrm{~g})$ e o potassio $(0,97$ a $2,95 \mathrm{~g} / 100 \mathrm{~g})$, năo sofrem variaçoses entre um lago e outro, entretanto para o ferro, os resultados apresentam-se mais varisveis $(0,58$ a $2,92 \mathrm{~g} / 100 \mathrm{~g})$. 
TABELA 10. ANALISE QUIYICA DOS ELEMENTOS TOTAIS NOS SEDIMENTOS DOS LAGOS DO RIO NEGRO INFLUENCIADOS PELO RIO BRANCO.

LOCAL DE COLETA E L E M E N T O S T O T T A I S

\begin{tabular}{|c|c|c|c|c|c|c|}
\hline no Nome do I ago & Al & $P$ & $\mathrm{Na}$ & $\mathrm{K}$ & $M n$ & $\mathrm{Fe}$ \\
\hline & & & $g / 1 c$ & $g$ & & \\
\hline Purupuru & 9,32 & 0 & 0,33 & 2,32 & 0,06 & 2,92 \\
\hline Cal ango & 4,45 & 0,01 & 0,40 & 1,25 & 0 & 0,90 \\
\hline Curidiqui & 7,17 & 0 & 0,40 & 1,08 & 0,03 & 0,97 \\
\hline Baipendi & 3,40 & 0 & 0,40 & 1,22 & 0,04 & 0,58 \\
\hline Tauatu & 4,60 & 0,01 & 0,55 & 1,36 & 0 & 1,18 \\
\hline Cauissi & 6,39 & 0,03 & 0,40 & 2,95 & 0 & 1,49 \\
\hline Terra Preta & 4,55 & 0,01 & 0,40 & 2,05 & 0 & 2,17 \\
\hline Ariau & 4,55 & 0,01 & 0,34 & 0,97 & 0 & 0,97 \\
\hline Anavulhana & 6,49 & 0,03 & 0,36 & 1,47 & 0 & 1,87 \\
\hline
\end{tabular}

\subsubsection{FRAG ORG}

Os resultados analiticos dos elementos que compoâm a frą̧̃o orgânica dos sedimentos de fundo dos lagos do rio Negro, que sofrem influencia do rio Branco, 
estäo relacionados na Tabela 11. Esses sedimentos apresentam teores de nitrogênio entre 0,11 a $0,16 \mathrm{~g} / 100 \mathrm{~g}$ e carbono de 1,44 a $2,93 \mathrm{~g} / 100 \mathrm{~g}$. A razåo $\mathrm{C} / \mathrm{N}$ varia entre 12 a 26, enquanto que a matéria orgânica nå apresenta muita varią̧̃o $(2,41$ a $5,05 \%)$.

TABELA 11. ANELIEE DYMICA DA FRAGTO ORGANICA DOS (C, N, C/N, HATERIA ORGANICA, N/P E PIGMENTO TOTAL) SEDYMENTOS DOS LAGOS DO RIO NEGRO QUE SOFRER INFLUENCIA DO RIO BRANCO.

LOCAL DE COLETA

$F$ R A C A O

O R G A N I C A

\begin{tabular}{|c|c|c|c|c|c|c|c|}
\hline n & Nome do lago & C & $\mathrm{N}$ & $\mathrm{C} / \mathrm{N}$ & M.O. & $\mathrm{N} / \mathrm{P}$ & Pig. Total \\
\hline & & $-\ldots g /$ & $\log -$ & & $\%$ & & _-ug/g__ \\
\hline 3 & Purupuru & 1,44 & 0,12 & 12 & 2,41 & - & 9,6 \\
\hline 4 & Cal ango & 2,47 & 0,16 & 15 & 4,26 & 16,00 & 8,2 \\
\hline 5 & Curidiqui & 2,83 & 0,14 & 20 & 4,88 & - & 8,2 \\
\hline 6 & Baipendi & 2,83 & 0,11 & 26 & 4,88 & - & 8,2 \\
\hline 7 & Tauatu & 2,83 & 0,14 & 20 & 4,88 & 14,00 & 8,2 \\
\hline 8 & Cauixi & 2,93 & 0,13 & 23 & 5,05 & 4,33 & 27,3 \\
\hline 9 & Terra Preta & 2,41 & 0,12 & 20 & 4,15 & 12,00 & 16,4 \\
\hline 10 & Ariau & 2,85 & 0,15 & 19 & 4,91 & 15,00 & 30,0 \\
\hline 11 & Anavi Ihana & 2,30 & 0,12 & 19 & 3,97 & 4,00 & 12,3 \\
\hline
\end{tabular}


4.4. SEOMENTOS DOS LAGOS DO RIO SOLIMOES/AMAZONAS

Săo lagos típicos de varzeas do ecossistema Solimôes/Amzonas, sofrendo influência desse rio, que traz material em suspensäo, durante a época cheia, cujo material $b$ um dos principais fornecedores de nutrientes. Esses lagos possuem extensos tapetes de capim flutuantes (Gramineas do genero Paspalum) e outras macroidrofitas (victorla, Azolda, Elchornia, Sauvinia, Pigtia) que sâo características de agua branca. Na Figuras 12 e 13, observam-se as localizaç̧es desses lagos.

4.A.1. ANALISE FISICA E FISICO-QUบYMICA.

\section{A.1.1. ANELISE GRANULOMETRICA}

a rio Solimäes/Amazonas contribui

fortemente para a formaço dos sedimentos dos lagos de várzeas que constituem esse ecossistema. A granulometria desses sedimentos é do tipo Argila arenosa siltosa. Pelas características físicas, observa-se teores de argila coloidal $(<0,001 \mathrm{~mm})$ da ordem de $16,0 \%$; argila $41,0 \%$; silte $21,0 \%$; areia fina $35,0 \%$ e areia media $3,0 \%$. 


$$
\text { Q.A.2.2. PH }
$$

Os sedimentos dos lagos do rio Solimoes/ Amazonas, por estarem em uma regiăo geologica mais recente, apresentam um meio levemente acidificado, em alguns casos, próximo da neutralidade, com variaç̧os de pH entre 6,0 a 6,6 (Tabela 12).

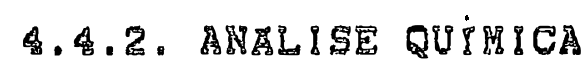

$$
\text { 5.4.2.1. COMPLEXO SORTIVO }
$$

Na Tabela 12 são observados os resultados das anslises quimicas dos elementos trocaveis nos sedimentos desses lagos, verificando -se variaçes nas concentraços do calcio ( 5,2 a 15,6 e.mg/100 g); magnésio $(1,2$ a 7,7 e.mg/100 g); sodio (1,0 a 1.4 e.mg/100 g), potassio $(0,6$ a 0,9 e.mg/100 g) e alumínio $(0$ a 0,9 e.mg/100 g). Esses valores proporcionam aos sedimentos de fundo dos lagos que constituem o ecossistema do rio Solimðes/Amazonas, uma soma de base, que apresentam variaços entre 9,1 a 22,7 e.mg/100 $\mathrm{g}$. 
TABELA 12. ANALISE QUYYSCA DOS ELEMEYTOS TROCAVEIS NOS SEOIMESTOS DOS LAGOS DO RIO SOLYHOES/AMAZONAS.

LOCAL DE COLETA

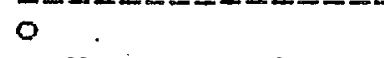

n Nome do lago
C O M P L E X O

S O R T I V O

$\mathrm{Ca}^{+\mathrm{Hg}^{++}} \mathrm{Na} \quad \mathrm{K} \quad \mathrm{S} \quad \mathrm{Al} \quad \mathrm{pH}$

e.mg/100 g

16 Paciência

$10,8 \quad 5,9 \quad 1,4 \quad 0,6 \quad 18,7 \quad 0,1 \quad 6,6$

17 Jaraqui

6,8

4,4

1,0

$0,8 \quad 12,8$

0

6,3

18 Manaquiri

10,0

4,0

1,2

$0,7 \quad 16,0$

$0,8 \cdot 6,1$

19 Muratu

11,6

2,3

1,1

$0,7 \quad 15,7$

0

6,2

20 Jutai

15,6

3,6

1,1

$0,7 \quad 21,0$

0,9

6,0

21 Formiga

$15,6 \quad 5,3$

1,2

$0,6 \quad 22,7$

0,7

6,4

22 Castanho

9,6

2,8

1,0

$0,6 \quad 14,0$

0,9

6,1

23 Reis

9,3

1,2

1,2

$0,7 \quad 12,4$

0

6,5

24 Tarumanduba

5,2

2,0

1,3

0,6

9,1

0,9

6,1

25 Macaco

$7,2 \quad 2,7$

1,4

0,8

12,1

0,3

6,5

26 Arroz

11,6

4,9

$0,7 \quad 18,5$

0,9

6,4

27 Jagaretinga

6,8

3,9

1,4

$0,8 \quad 12,9$

0

6,4

28 Passarinho

6,0

7,7

1,4

$0,916,0$

0,3

6,5

29 Capitari

$\begin{array}{lllll}6,4 & 1,3 & 1,2 & 0,8 & 9,7\end{array}$

0,3

6,1 
9.4.2.2. ANELISE QUYMICA TOTAL

Os resultados analiticos dos elementos totais dos sedimentos dos lagos que pertencem ao rio Solimơes/Amazonas estão contidos na Tabela 13. Esses sedimentos apresentam teores de aluminio entre 2,54 a $9,00 \mathrm{~g} / 100 \mathrm{~g}$. Observa-se que o f6sforo $(0,01$ a $0,03 \mathrm{~g} / 100$

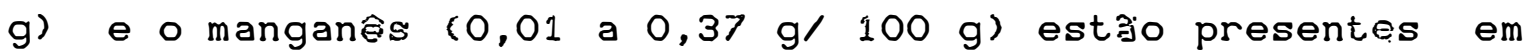
todos os sedimentos desses lagos, porém em concentraçes relativamente baixas, principalmente o fosforo.

Quanto ao s6dio $(0,48$ a $1,73 \mathrm{~g} / 100 \mathrm{~g})$ e 0 potássio $(0,80$ a $13,73 \mathrm{~g} / 100 \mathrm{~g})$, verifica-se que não existe uma variaça muito forte para o primeiro, enquanto que para - segundo (potássio), essa variaç̃o é muito mais aprecisvel. O ferro presente nesses sedimentos mostra teores entre 2,27 a $8,46 \mathrm{~g} / 100 \mathrm{~g}$, em que 6 constatável também, uma variaça bem nítida entre esses sedimentos. 


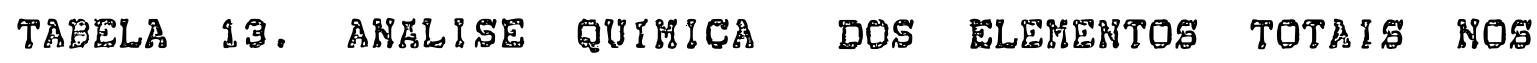
SEDIMENTOS DOS LAGOS DO RIO SOLIHOES/AMBZONAS.

LOCAL DE COLETA

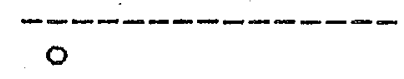

n Nome do lage

\section{E L E M E N T O S T T O T A I S}

$\mathrm{g} / 100 \mathrm{~g}$

16 Paciência

$4,250,02$

1,73

13,73

$0,13 \quad 8,46$

17 Jaraqui

6,57

0,02

1,35

9,92

0,01

7,33

18 Manaquiri

9,00

0,02

1,58

12,38

$0,017,97$

19 Muratu

2,54

0,01

1,53

10,21

$0,09 \quad 2,56$

20 Juta i

4,56

0,01

0,98

9,92

$0,20 \quad 2,34$

21 Formiga

5,18

0,02

0,49

2,96

$0,05 \quad 2,46$

22 Castanho

5,13

0,01

1,42

10,83

$0,04 \quad 2,76$

23 Reis

5,08

0,01

0,63

6,18

$0,37 \quad 2,27$

24 Tarumanduba

5,50

$.0,03$

0,74

7,71

$0,014,23$

25 Macaco

$5,34 \quad 0,02$

0,71

0,80

$0,05 \quad 7.96$

26 Arroz

8,61

0,02

0,62

5,62

$0,03 \quad 7,31$

27 Jacaretinga

7,02

0,03

0,76

5,28

$0,07 \quad 2,98$

28 Passarinho

4,30

0,01

0,73

4,28

$0,13,2,50$

29 Capitari

0,74

5,49

$0,08 \quad 2,50$ 
Q. A.2.3. FRAGAO ORGAMICA

Os resultados analíticos da fraçăo orgânica, para os sedimentos dos lagos do rio Solimôes/ Amazonas, podem ser observados na Tabela 14 .

Esses resultados indicam teores de nitrogênio entre 0,3 a $1,00 \mathrm{~g} / 100 \mathrm{~g}$ e carbono com variaçóes de 0,7 a $2,46 \mathrm{~g} / 100 \mathrm{~g}$. Com isso, esses sedimentos apresentam uma variaça na razão $C / N$ entre 14 a 27 e uma percentagem de matéria orgânica entre 1,21 a 3,05. Quanto aos teores de pigmento total (clorofila), esses sedimentos mostram teores que variam de 1,4 a $15,0 \mathrm{ug} / \mathrm{g}$. 
TAEELA 1A. ANELLISE QUYMICS DOS ELEMENTOS DA FRAGYO ORGSNICA

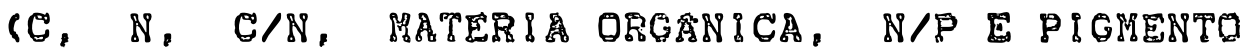
TOTAL), NOS SEDIMENTOS DOS LAGOS DO RIO SOL \& METE / MMEORAS.

LOCAL DE COLETA

$$
F R A G \text { F O OR G } A N \text { I C A }
$$

$\mathrm{n}^{\circ}$ Nome do lago $\mathrm{C} N \mathrm{~N} \quad \mathrm{C} / \mathrm{N}$ M.O. N/P Pig.Total

$-9 / 1009$

$\%$

- ug/g -

16 Paciôncia

$0,87 \quad 0,06$

151,50

6,00

1,4

17 Jaraqui

$0,85 \quad 0,04$

$21 \quad 1,47$

2,00

5,5

18 Manaquiri

$0,80 \quad 0,03$

$27 \quad 1,38$

1,50

4,1

19 Muratu

$0,76^{\circ} 0,03$

$25 \quad 1,34$

3,00

9,6

20 Jutai

$1,770,09$

$20 \quad 3,05$

9,00

9,6

21 Formiga

$2,46 \quad 0,09$

$27 \quad 4,24$

4,50

15,0

22 Castanho

$0,83 \quad 0,06 \quad 14 \quad 1,43$

6,00

4,1

23 Reis

$1,410,10$

142,43

10,00

12,3

24 Tarumanduba

$1,250,06$

212,16

2,00

15,0

25 Macaco

$1,280,07$

$18 \quad 2,21$

3,60

15,0

26 Arroz

$1,610,06$

$27 \quad 2,78$

4,00

2,7

27 Jagaretinga

$\begin{array}{llll}1,10 & 0,04 & 28 & 1,89\end{array}$

2,00

2,7

28 Passarinho

$1,35 \quad 0,04 \quad 34 \quad 2,33$

4,00

8,2

29 Capitari

$0,70 \quad 0,05$

141,21

5,00

6,8 
E. DISCUSSAัO DOS BESULTADOS

3.1. SEDIMENTO DOS LAGOS DO RIO NEGRO

5.1.1. COMPLEKO SORTIVO

Os maiores valores de calcio foram verificados nos lagos do Curiaú (rio Curiaú) e do PeixeBoi (rio Cuieiras) (1,5 e.mg/100 g). Para o magnésio, as malores concentraçôes ocorreram, também, no lago do Curiaú $(4,4$ e.mg/ $100 \mathrm{~g}$ ) e Unini (rio Unini) cuja concentraçăo é 2,4 e.mg/100 g. Embora esses teores de magnésio sejam considerados elevados dentro dos critérios de fertilidade do solo, mas, para a regiăo Amazônica, mostram a baixa capacidade de tamponaça desses sedimentos, devido aos baixos teores de calcio e altas concentraçós de alumínio (Tabela 3).

- lago do Curiaú, localizado no rio Curiaú, apresenta um pH 5,1 (Tabela 3), que associado com a alta concentraça de magnesio e a presença de

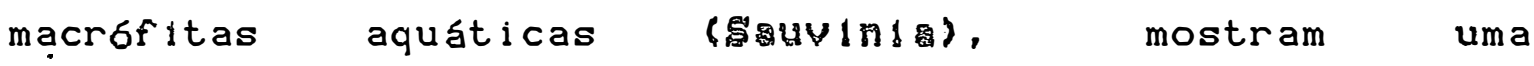


pecullaridade (anomalla) para esse sedimentos dos lagos de

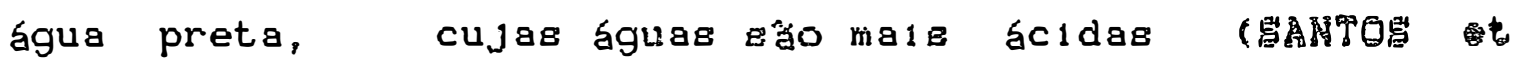
21: 1984 ).

Esses fatos observados nos sedimentos do lago do Curiaú, săo de difícil explicaçăo, pols podem refletir uma possivel influência "externa", ou seja entrada de sedimentos e aguas, provenientes de desmatamento e queinadas, que possivelmente ocorrem nas regides das cabeceiras dos rlo Jauper1, Alalaú, Camanaú e Curiaú

Na Tabela 3 , contem or resultados analíticos do complexo sortivo para os sedimentos dos lagos do rio Negro indicando a presença do calcio e magnesio. Esses lagos, constituidos de squa mostram concentraços de sals minerals săo consederadas baixas (\$IOLI, 1950 1965

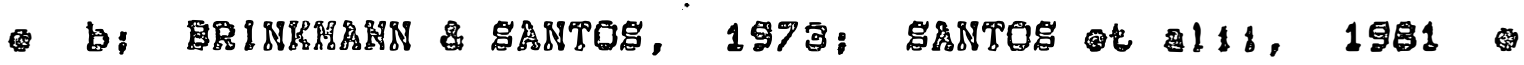

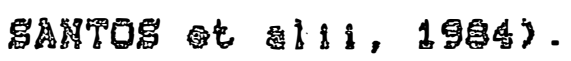

A presença desses dols elementos, principalmente nos sedimentos de fundo de lagos do rio Negro, evidenciam que sào, possivelmente, orlundos das precipitaçés e da decomposiço da materia orgânica, que por sua vez, podem ser carreados para o lago e precipitados na forma de pectiatos. 


\subsubsection{ELERENTOS TOTAIS}

Na Tabela 4, estæ̋o distribuídas as concentraçes dos elementos totais que for am determinados nos sedimentos dos lagos do ecossistema do rio Negro. 0 aluminio, presente nos sedimentos desses lagos, tem sua maior concentraça no lago do Peise-Boi, no rio Cujeiras $(7,22 \mathrm{~g} / 100 \mathrm{~g})$ enquanto que a menor, ocorreu no lago do Caurés, no rio Caurés $(2,46 \mathrm{~g} / 100 \mathrm{~g})$.

E possível, que esses lagos, cujos sedimentos apresentam um meio de acidez elevada ( $\mathrm{pH}$ 4,1 a 4,6 Tabela 3), corrobore com a liberaço do alumínio na forma trocavel, uma vez que os sedimentos desses lagos săo constitúdos de maţ́ria orgânica em decomposiç̃o, silte e areia fina, assim, seria possível a solubilizaço da silica e do alumínio. O alumínio 6 perdido pelo sistema aquatico devido as altas concentraçoes observadas nas aguas do rio Negro (5A\&Tos et alii, 1984). Quanto à sílica, uma parte também é perdida pelo sistema aquatico e a outra, possivelmente seja utilizada por animais esponginarios conhecidos como "eaulxi".

Esses animais esponginarios monaxônidas da familia dos espongilídeos, de agua doce, cujo contato produz forte comichão, por causa dos espiculos que provocam 
irritaq̧a da pele. Crescem nas varzeas alagadicas ou igapós e se acumulam nas raizes das arvores. Să também conhecidos como "esponja-d'agua-doce, cabixi, caui, ou ainda cauxi" (FERREIRA, 1975).

Na Gpoca da cheia, esses pequenos animais "espoja", agregam-se nas raizes e galhos das grvores, que, com o inf́cio da Epoca da seca, sofrem processo de cristalizaço, que ao secar-se, tornam-se, a primeira vista, parecido a uma "casa de cupim", sendo contituído inteiramente de sílica. SABTOS to ali (1994), informam que as aguas pretas do rio Negro apresentam altos teores de silica. Esses fatos devem ser perscrutados futuramente, af im de se mostrar a verdadeira funço desse cauixi.

Sendo os solos da bacia do rio Negro, classificados como Latossolo Amarelos, onde são encontrados desde os de textura muito pesada até os Hidromórficos (IPTAAGC, 1971). Na bacia do rio Solimões/Amazonas, os solos mais representativos, na grea investigada, săo os de varzeas, ou seja, aquele cuja formaça deve-se à deposiça dos sedimentos carreados por esse rio, e, dăo formaça às florestas de varzeas. Esses solos estão mais próximos da neutralidade se comparados com os solos do rio Negro, em cujas margens aparecem as florestas de igapo, onde a água sofre processos de estagnaço, favorecendo a 
decomposiça da mat.éria orgânica depositada no fundo desses lagos.

Tal fato, possivelmente dificulte a precipitaça e a fixaço do fósforo e do manganês nesses sedimentos, uma vez que poderá ser facilmente assimilados pela vegetaça dos lagos. Na bacia do rio Negro, somente o lago do Peixe-Boi, no rio Cuieiras, 6 que apresentou a concentraçăo de fosforo da ordem de $0,06 \mathrm{~g} / 100 \mathrm{~g}$ e 0 lago do Curiaú, no rio Curiaú, apresentou uma pequena quantidade de manganês, na ordem de $0,03 \mathrm{~g} / 100 \mathrm{~g}$. Com isso, constata-se a inexistêcia tanto do fosforo como do manganês, no ecossistema do rio Negro.

Entretanto, essas condiçðes parecem favorecer aos conteúdos de nitrogênio e carbono nos sedimentos desses lagos, que têm sua entrada provenientes das precipitaç̃es pluviométricas na superffcie dos lagos; pela lavagem da floresta e seu carreamento via lixiviaço e decomposição da matêria orgânica.

Esses sedimentos apresentam uma concentração de nitrogênio bastante apreciável, sendo que - maior teor foi verificado no lago do Peixe-Boi, no rio Cuieiras $(0,16 \mathrm{~g} / 100 \mathrm{~g})$ e a menor concentraç̧o, ocorreu no lago do Curiaú, no rio Curiaú $(0,12 \mathrm{~g} / 100 \mathrm{~g})$, enquánto que para o carbono, destacam-se os lagos do Curiaú, no rio 
Curlaú $(2,83 \mathrm{~g} / 100 \mathrm{~g})$; do Felme-B01, no rlo Cule1rae ( 2,81 $g / 100 g)$ e o lago Unini, no rio unini $(2,78 \mathrm{~g} / 100 \mathrm{~g})$ e a menor concentraça, fol verificada no lago do Caurés, no rio Caures $(1,60 \mathrm{~g} / 100 \mathrm{~g})$

A raza̧o $C / N$ (Tabela 5) 6 malor para os lagos do Curiak (rio Curiaú) de 24 e no Unini, (rio Unin1) 6 de 21 e menores, nos lagos do Pelse-Bo1, (r10 Culeiras) de 18 e Caurés, (rio Caurés) essa razăo é de 11. - conteúdo de matéria orgânica nos sedimentos desses lagos săo equivalentes aos do rio Negro que ests sobré a Influência do r to Branco. Destacando-se os lagos do Curuaú $(4,88 \%)$; Pe1xe-Bo1 $(4,84 \%)$ e Unin1 $(4,80 \%)$, observandose que o menor conteúdo de matéria orgânica, verifica-se no lago Caures $(2,76 \%)$.

Ficou evidenciado a quase inexistoncia do fósforo, magnésio e cálcio (Tabela 3 e 4 ) nos sedimentos dos lagos de sgua preta, no caso os do ecossistema do rio Negro. Esses elementos săo mals circulantes na bacia do rio Negro, devido as caracteristicas quimicas de suas aguas "pretas", do que nos amblentes de squa "branca", como 60 caso do rio Amazonas (Tabelas 12 e 13). Na Tabela 15, mostram-se os conteúdos de P: K: Mg: $\mathrm{Ca}$ e $\mathrm{Na}$, nas Sguas do rio Negro e nas folhagens bem como o fator de concentraçăo para esse ecossistema. 


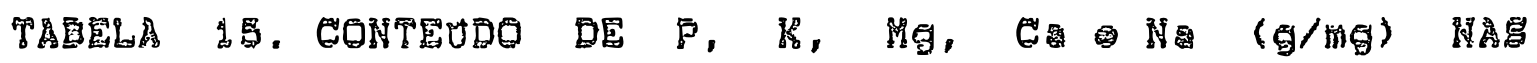

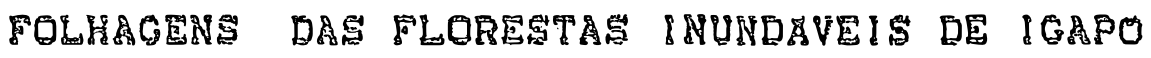

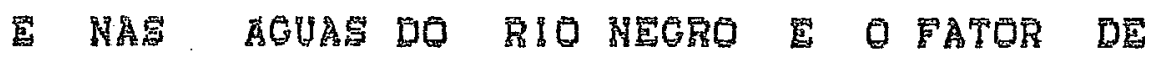

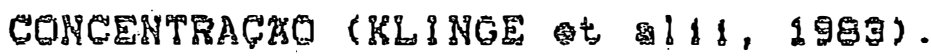

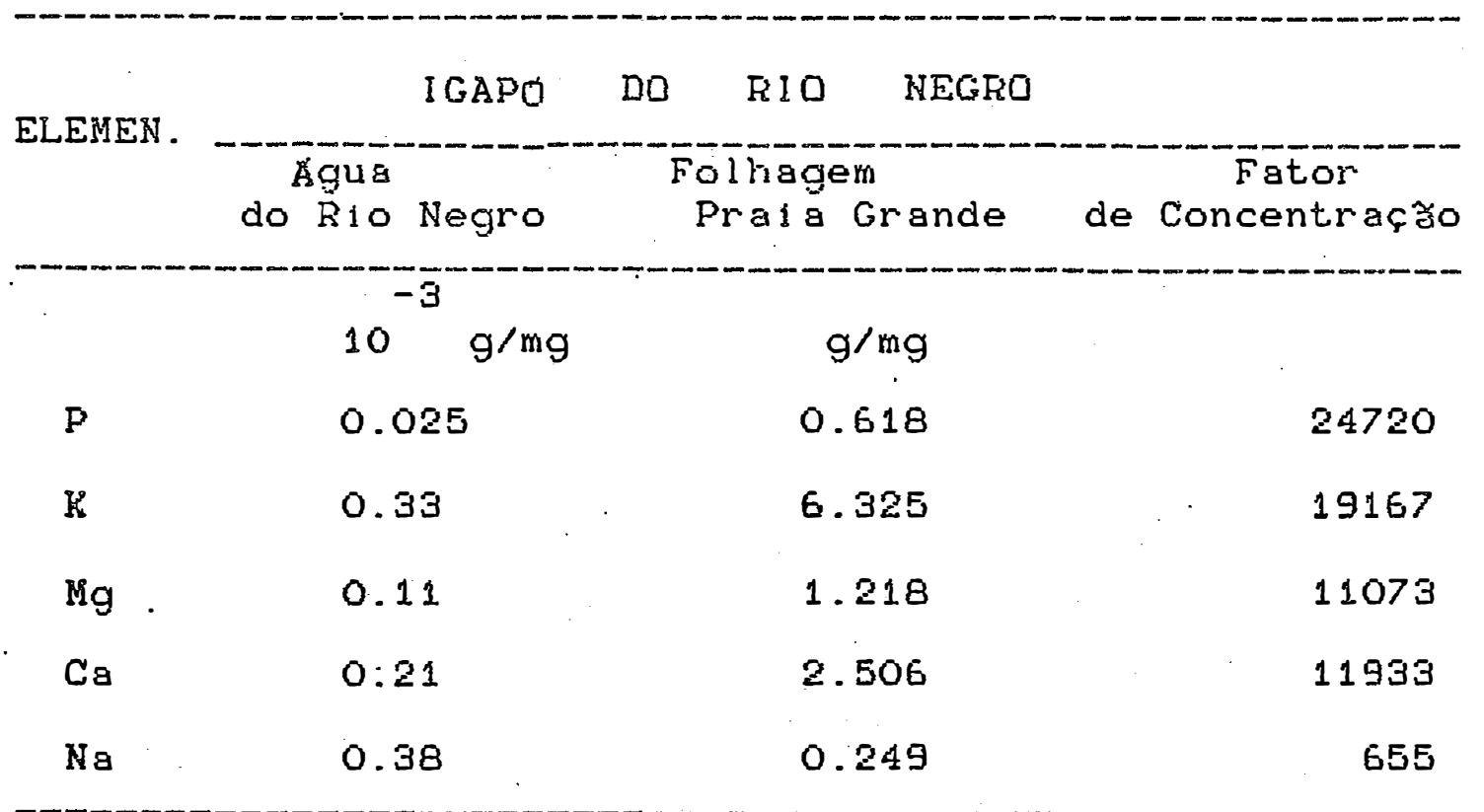

Comprovadamente, o fator de concentraço do P, Mg e Ca no ecossistema do rio Negro, 6 multo maior que o observado para a bacia do rio Sollmbies/Amazonas (Tabela 17). Isto evidencia que esses elementos, devido a

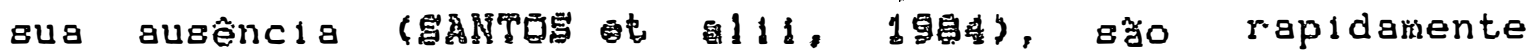
absorvidos pela vegetaço e que sua presenca nos sedimentos do fundo dos lagos, deve-se a uma possível reaça com a materia orgânica, formando compostos organometal 1 cos. 
- sodio apreaenta-ze em quantidades menores que as do potsssio. Somente no lago do Curiaú e no lago do Unini (rio Ununi), mostram uma concentracăo mais elevada de sbdio $(0,45 \mathrm{~g} / 100 \mathrm{~g})$. Para os dema1s lagos, as concentraçơes nos sedimentos, săo praticamente idênticas.

Para o potassio, dos valores observados, as malores concentraçóes ocorreram no lago do Caur 6s, no rio Caurés de $0,87 \mathrm{~g} / 100 \mathrm{~g}$ e a menor, observa-se no lago do Cur1au, no rio Curlaú de $0,26 \mathrm{~g} / 100 \mathrm{~g}$ (Tabela 4).

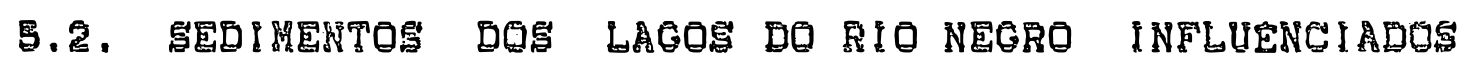
PELO RIO GRANCO

\subsubsection{COMPLEYO SOETIVO}

Os valures de cálcio e magnésio mostram uma concentraça um pouce malor daquel a que fol observada na bacia do rio Negro (Tabela 3), indicando, que esses

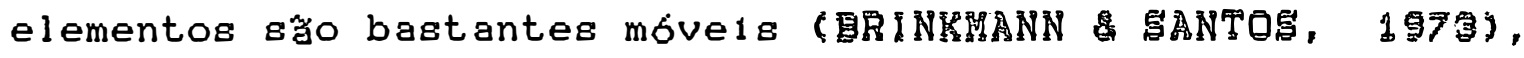
mas podem, também, ocorrer uma possível precipltaçấo na forma de pectatos, Induzida pelo pH dos sedimentos, uma vez que esse pH ests pr $6 \times 1$ mo da neutralidade, como observados nos lagos do Purupuru e Anavilhanas (Tabela 9). 
Qe malores teores de calcio foram encontrados noe sedimentos dos lagos do Caulxi (4,8 e.mg/100 g) e Tauatu $(4,0$ e.mg/100 g) e os menores, ocorreram nos lagos do Arlau $(0,7$ e.mg/100 g) e Balpend1 $(0,5$ e.mg/100 g). Is para o magnés10, destacam-se os lagos do Balpend1 e Terra Preta $(6,5$ e.mg/100 g): Anavilhana (6,1 e.mg/100 g): Arlau $(5,7$ e.mg/100 g) e Curidiqu1 (5,3 e.mg/100 g), enquanto que as menores concentraçöes, verificaram-se nos lagos do Tauatu e Caulxi com 1,8 e.mg/100 g (Tabela 9).

Sendo esses dols cstions praticamente ausentes nas squas dos afluentes do rio Negro (s

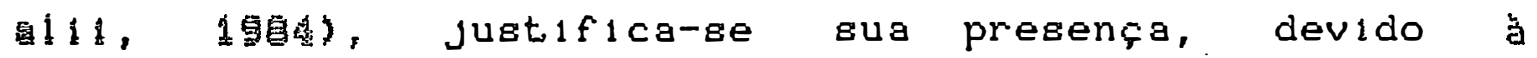
precipltaçăo juntamente cở a matéria orgânica, formando pectatos, uma vez que os lagos que apresentam as malores concentraçớę de matéria orgânica (Tabela 11), sàंo aqueles em que o calcio e o magnesio, estào presentes em quantidades mals elevadas, como o caso dos lagos do Cau1X1 (5,05\% de M.O.): Tauatu e Balpend1 $(4,88 \%$ de M.O.) e Ar1au $(4,91 \%$ de M.0.).

Tals lagos, pertencentes à bacia rio Negro e que sato fortemente influenciados pelo rio Branco, apresentam modificaç̧es fisico-quimicas e quimicas, tanto

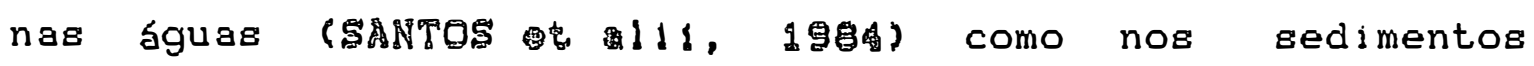


(Tabela 10), mostram um $\mathrm{pH}$ cuja acidez 6 menos acentuada e em alguns casos, próximo da neutralidade, como 6 o caso do lago do Purupuru que apresenta um pH $=6,8$ (Tabela 9).

Analiee de solo realizado em alguns locala da bacia do rio Negro, demonstraram uma pequena concentraçăo de cálcio e magnélo (menor que 0,5 e.mg/100 g), evidenciando a sua quase lnexistência nos solos dessa bac1a, como fol o caso dos solos do rio Demint e do rio Araca e do local demominado Seringueiro, no rio Negro. Desses solos, os da localidades Seringueiro no rio Negro e do rio Araca, apresentaram teores de aluminlo trocsvel, na ordem de 1,5 e 0,7 e.mg/100 g, respectivamente.

Esses resultados evidenclan que a falta de cálcio e do riagnesio como tambem a presença do alumínio, nos solos da bacla do rio Negro, nâjo sâ̆o fatores $11 \mathrm{~m} 1 \mathrm{tantes}$ ou inibidores para o crescimento e sustentaço da floresta Amazón1ca, uma vez que o calcio e o magnésio, sendo considerados elementos em constante clrculaça nesta regl צ̧o, săo facllmente absorvidos pela vegetaçăo, enquanto que o alumínio, possivelmente, năo se encontre em nívels tóxicos para a floresta Amazônica ou alnda, essa floresta esteja adaptada a tals condiçoses.

Anslise de sedimentos na confluência do 
rio Negro com o rio Branco como também a montante deate, apresentam baixa concentraçôs de cálcio e presença conelderavel de magnélo (Tabela 16).

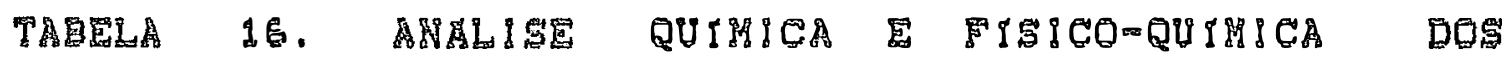

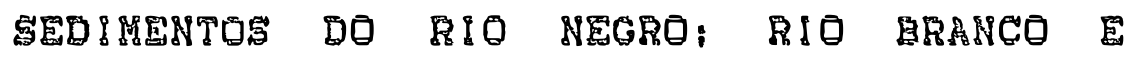

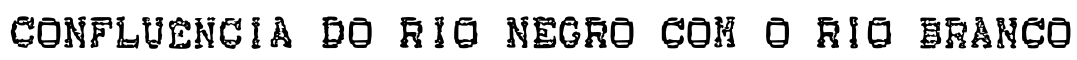

S E D D I H

FISICO-QUYMICA

$\mathrm{pH}$

4,7

5,3

5,5

ELEMENTOS TROCÄVEIS
Ca e.mg/100g
0,4
1,8
0,6
$\mathrm{Hg}$ e.mg/100g
1,62
4,46
5,26
Al e.mg/100g
2,0
0,2
0,4

ELEMENTOS TOTAIS
A] $9 / 100 \mathrm{~g}$
1,15
0,68
1,43
p $\quad$ g/100g
0,01
0,03
0,01
Na
$9 / 100 g$
0,56
0,93
0,24
R $\quad \mathrm{g} / 100 \mathrm{~g}$
0,83
1,33
2,34
$\operatorname{Mn} \quad g^{\prime 100 g}$
0,02
0.09
0,03
Fe $\quad g / 100 g$
0,58
$1,6 E$
1,73 
Continuaça da Tabela 16 .

FRAÇAO ORGENICA

$\begin{array}{lcccc}\text { N } & 9 / 100 g & 0,07 & 0,07 & 0,07 \\ \text { C } & 9 / 100 g & 0,98 & 1,00 & 2,10 \\ \text { M.O. } & \% & 1,69 & 1,72 & 3,62 \\ \text { C/N } & & 14 & 14 & 30\end{array}$

\subsubsection{ELEMENTOS TOTAIS}

Pode ser observado com auxil to da Tabela 10 a presenca do alumínio total, com teores oscilando entre 3,40 a $9,32 \mathrm{~g} / 100 \mathrm{~g}$, bem como a presença do s6dio total e do potassio total na ordem de 0,34 a $0,55 \mathrm{~g} / 100 \mathrm{~g}$ e 0,97 a $2,95 \mathrm{~g} / 100 \mathrm{~g}$ respectivamente. Nota-se tamb $6 \mathrm{~m}$, a presença do nitrogênio $(0,11$ a $0,15 \mathrm{~g} / 100 \mathrm{~g})$ e do ferro total $(0,58$ a $2,92 \mathrm{~g} / 100 \mathrm{~g})$. Quanto ao fósforo total e manganes total, estes estäo presentes, em um malor número de lagos, principalmente o fosforo, com teores entre o a 0,03 g/100 g e o manganês entre 0 a 0,06 g/100 g. Observa-se também, uma percentagem de matéria orgânica ma1s acentuada, como também uma razào $\mathrm{C} / \mathrm{N}$ em nivels apreciavels (Tabela 11). 
Esses elementos, sendo constituintes dos minerais de argila, e, por conseguinte, fazendo parte de sua rôde cristalina, era de se esperar uma major ou menor quantidade deseses elementos. Observa-se tambem, que a presencra doe elementos $P: M n: N \in C$, que dependendo das condiçoes Hidróquímicas das gquas que dăo formaç̧o a esses lagos, e sua presença $e$ de fundamental importância para a regiło Amazônica, principalmente o fóforo, devido a sua carência nos solos desea regizo, enquanto que o ferro, estars presente nos processos de oxi-reduço que ocorre nos 1 agos.

Da teores de ferro, para o ecoseistema do rio Negro (Tabela 4), mostram valores menores aos veriflcados para os sedimentos dos lagos do rio sol mấes/ Amazonas (Tabela 13), evidenciando, que as substâncias húm1cas, nesse ecosilstema, apresentam balxa capacidade de formarem complexos com o ferro, como observado por JUR\& \&

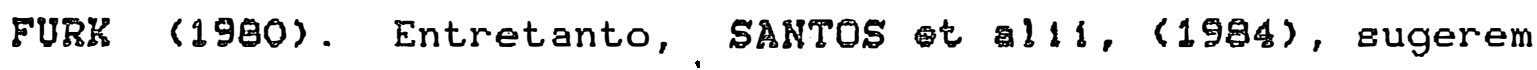
que a formaço de substancias metal-orgânicas na forma de complexos, somente ocorra em sguas com melhores condiçes físico-químicas, com pH neutro e com maiores concentraçôes de sals dissolvidos ou complexados, e năo para as bguas do rio Negro, que apresentam-se pobres em nutrientes minerais. 
Porem, a fassa do rio Negro que sofre Influência do rio Branco (Tabelae 9 e 10), a hidroquínica apresenta melhores condiç̧es que as do rio Negro (Tabelas 3 e 4), e o pH proximo da neutralidade e com melhores conteúdo de nutrientes minerais. Essas conciçốes parecem favorecer a formaçäo de um complexo de ferro com a matêr 1 a orgânica, como 6 constatsvel para os sedimentos dos lagos do Furupuru: Caulxi e Ansvilhanas (Tabela 11), devido - elevado teor de ferro nesses sedimentos.

Na bac1a do r1o Negro (Tabela 4), nota-se a auzência do fosforo nos sedimentos desses lagos. Entretanto, o aparecimento do fosforo nos sedimentos dos lagos do rio Negro que sofrem influências do rio Branco (Tabela 10), seria possível, devido ao sedimento caulinf́tico do rio Branco, terem uma melhor afinidade pelo fosforo (LEEMHER \& SANTOS, 1980), ou seja, esses sedimentos ao entrarem na bacia do rio Negro, cujos

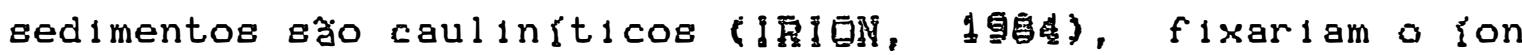
H PO em substitulç̧o a oxidrila, semelhante às 24
substitulçoses do silicioe os átomos de oxigên1o, onde agrupar 1 am quatro oxigên10 ao redor do f 6 fororo.

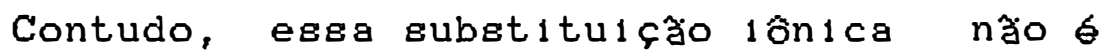
multo favorál, devido as condiçôes de pH mostrarem uma 
leve acidificacià, possivelmente, prejudicando as substituiçoses. Entretanto, poders sofrer uma aça favorbuel, devido ao conteúdo da materia orgânica contida

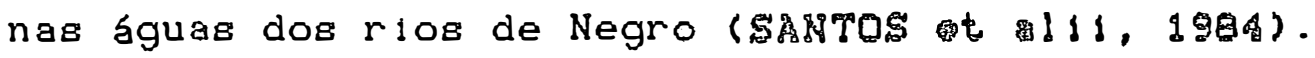

Esse conteúdo de fisforo mostra a sua quase inesistâcia nos solos e sedimentos, evidenciando a facilidade de assimilaçào pela vegetaçăo. Sua presença nesses sedimentos, devem-se a essa possivel substituiçă丶, como tambsm pela entrada atraves das precipitaçoes pluviometricas, e, no caso expecifico dos lagos desse ecossistema, pela presença de capim flutuante (\$ que sofre o processo de decomposiç̃o, uma vez que os iagos da bacia do rio Negro nåo apresentam esse tipo de veget açăo.

\subsubsection{INFLUENEIAS DO RIO BRANCO SOBRE O RIO NEGRO}

Os lagos localizados nessa falxa do rio Negro, sào aqueles que sofrem influênclas hidrogeoquímicas das aguas e sedimentos do rio Branco, cujos sedimentos cauliniticos em suspensào sào floculados pela sgua preta e acida do rio Negro, dando origem ao arquipelago das Anav1 lhanas (LEENHEER \& SANTOS, 1980). 


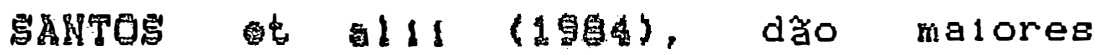
destaques para os rios Branco e Jauper 1; primeiro pela sua poseivel formaçăo do arquipélago das Anavilhanas, sendo que atualmente, esses rios estäo fertillaando areae inundavele da margen esquerda do balxo rio Negro, devido aos fatores erosivos, provocados pelo desmatamento intensivo que vôm ocorrendo em suas bacias.

Esses sedimentos apresentam caracteristicas químicas diferentes (Tabelas 9; 10 e 11), daqueles do ecossistema do rio Negro propriamente dito (Tabelas 3: 4 e 5), ou seja, aqueles cujag águas săo pretas e năo săo influenciadas pelo rio Branco, como também as constitulçôes físicas sa diferentes (Figuras 14, 15 e 16). Os mesmos apresentam-se menos ácidos, sendo que os lagos que estro com os malores valores de pH, săo os lagos do Purupuru $(p H=6,8)$, Calango e Curidiqu1 $(\mathrm{pH}=5,8) \in$ os menores, foram observados nos lagos do Tauatu e Arlau $(\mathrm{pH}=5,1)$. 


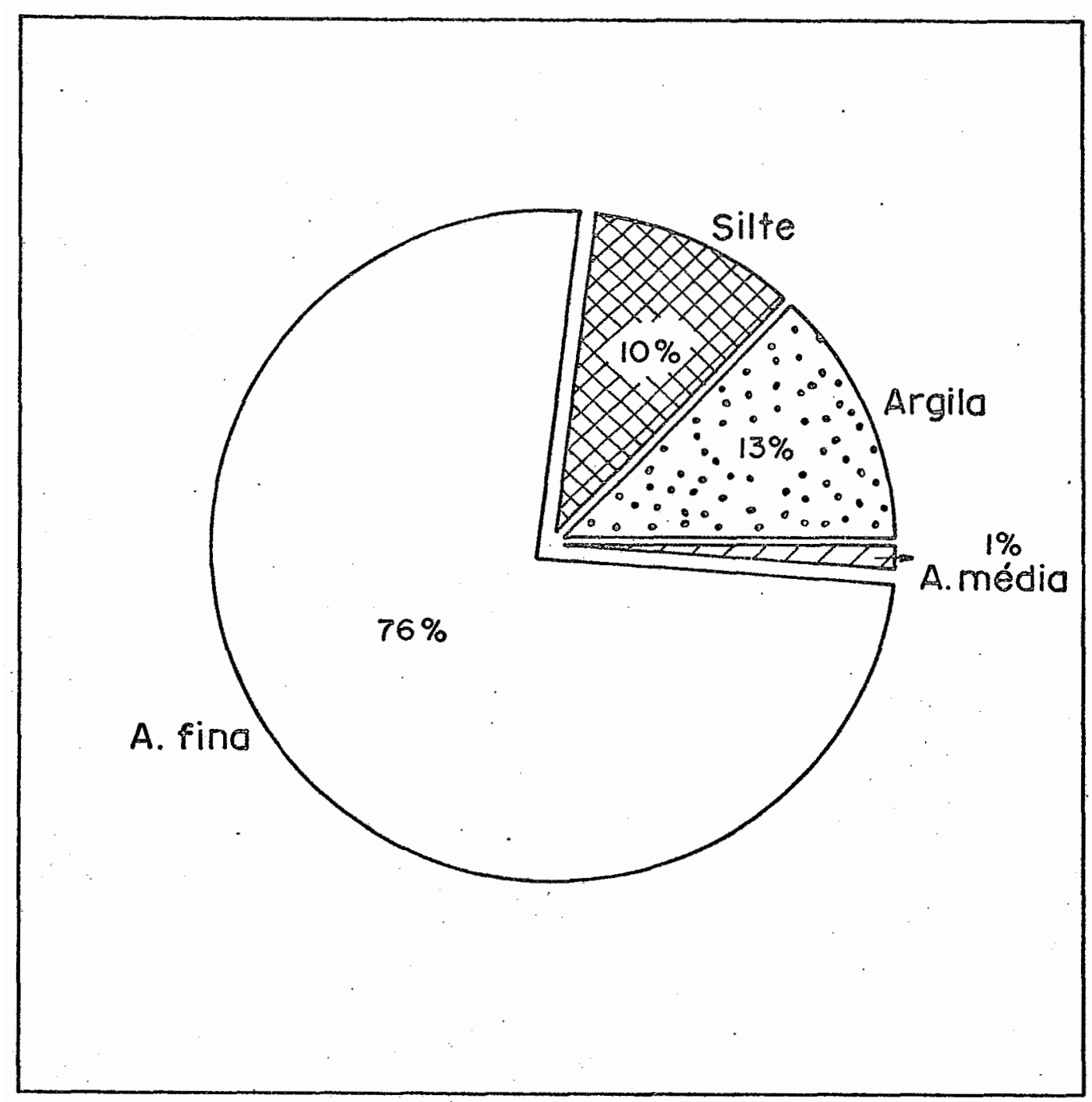

FIGURA 14. Teores de Argila, silte, Aseia Fina Areia

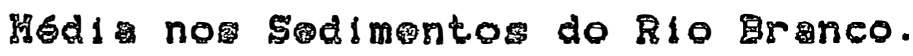




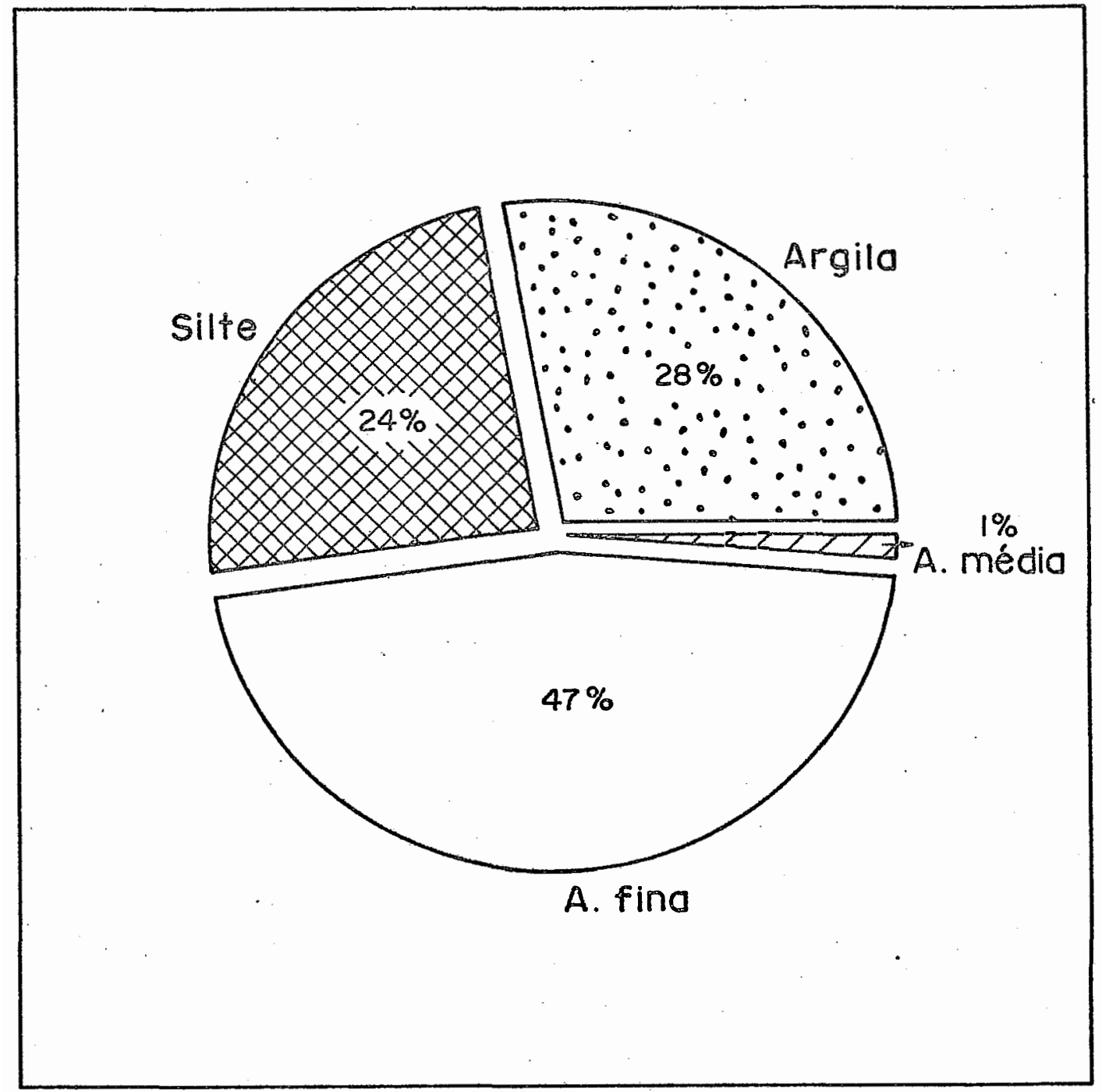

FIGURA 15. Tores do Argila, Silto, Areia fina Arela

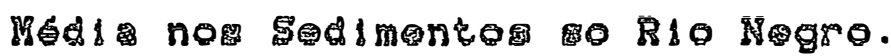




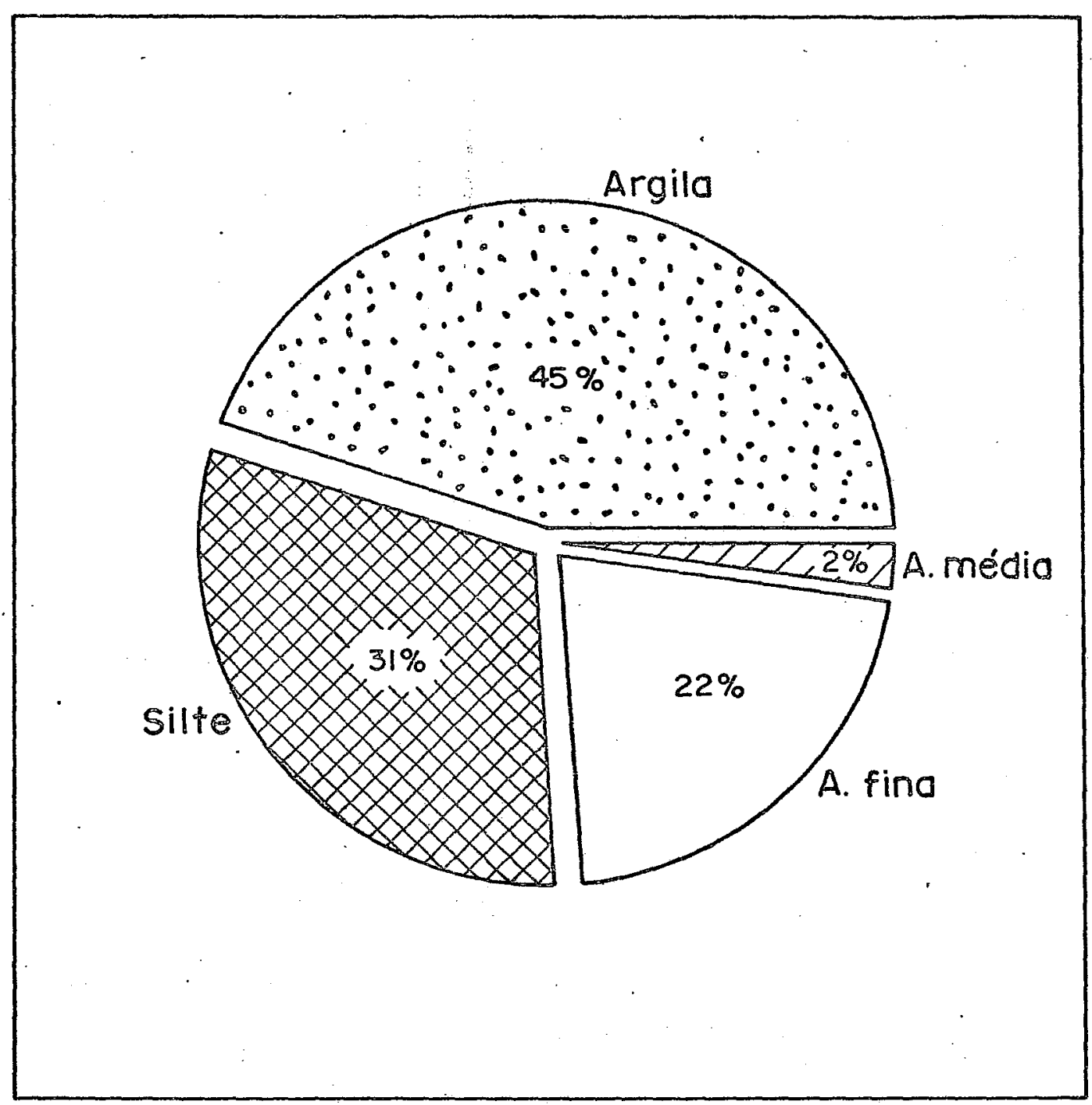

FIGURA 16. Teorea de Argila, Silto, Areia Fina Areia

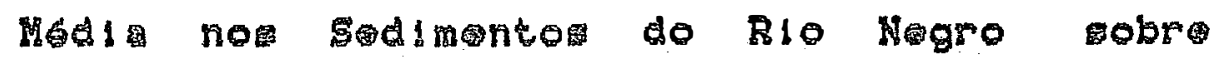
In lu 
Estudo realizado nessa faixa do rio Negro por LEEHYER \& SABPTOS (1980), mostram que os sedimentos finos, provenientes do rio Branco, floculavam a uma distância de $100 \mathrm{~km}$ da foz e que nessa ópoca nåo existia nas áreas inundáveis (várzeas) e lagos do rio Negro, quaisquer indício de formąăo de macrófitas aquáticas, fato destacado por JURY (1970).

SARTOS et lid (1984), mostraram que entre 1979 a 1980, no período em que o rio subia de nível, formaçós de pequena quantidade macrófitas em um canal que dé acesso do Parang da Floresta ao rio Jauaperi, como țambem em um local denominado de Tauatu, ja pertencente ao arquipelago das Anavilhanas.

Esses autores, constataram tambem, em 1981, que em lugares onde nåo existem corredeiras e nos lagos das ilhas, partindo do Parana da Floresta até próximo ao Estreito (Baia do Buiuçu), extensos tapetes flutuantes de capim-arroz (Oryza paronnds), e, em menores quantidades, a canarana (Eechinochloa polystachya) e saluínia (Salninia gurleulation). Mostraram ainda, que nas areas inundaveis desse trecho de rio, a existência de cultivos de milho, arroz mandioca, macacheira, mamão entre outras.

Relatam ainda, que do ano de 1974 a 1980 
houve un aumento, ate certo ponto, considerado substancial de sais minerais nessas aguas; bem como o aparecimento de macrórita aquaticas, sugerindo que essa fertilizaça deve-se em parte, pelas aguas e sedimentos dos do rio Branco como tambám de um desmatamento Indiscriminado, seguido de queimadas em escala crescente, na regi å das bacias do rio Branco e Jauaperi.

Este fato, também foi constatado no mês de agosto de 1982, quando da realizaço das coletas dos sedimentos nos lagos que se situam nessa faixa do 'rio Negro. Notou-se quantidades significantes de macrofitas aquaticas, como também uma quantidade de sedimento em suspensăo nas águas do rio Branco, principalmente durante chuva recente, tornando as aguas do rio Negro um pouco turbidas.

Considerando-se. os ecossistema do rio Branco, rio Negro e rio Negro sobre influencia do rio Branco como um todo, para que possamos avaliar as modificaçóes causadas pelo rio Branco ao rio Negro. Relacionou-se, de uma maneira percentual, os teores de Argila coloidal, Argila e silte obtidos para esses sedimentos (Figuras 17,18 e 19). Constata-se, que existe uma alteraça nos constituintes físicos no sedimento do rio Negro, logo após a junço deste, como o rio Branco, 
cujas modificaçชes, săo perceptı́ris nos sedimentos dos lagos do rio Negro sobre influência do rio Branco.

Nessa relaço, observa-se que a argila coloidal $(<0,001 \mathrm{~mm})$, para os sedimentos do rio Negro sobre influância do rio Branco, apresentam-se em 72 \% alteradas (FIGURA 17). Ja os teores de argila, indicam que a parte influenciada do rio Negro, apresenta-se $58 \%$ alterada (FIGURA 18). Para o silte, os resultados mostram que essa faixa do rio Negro, apresenta-se com $37 \%$ alterada (FIGURA 19). 


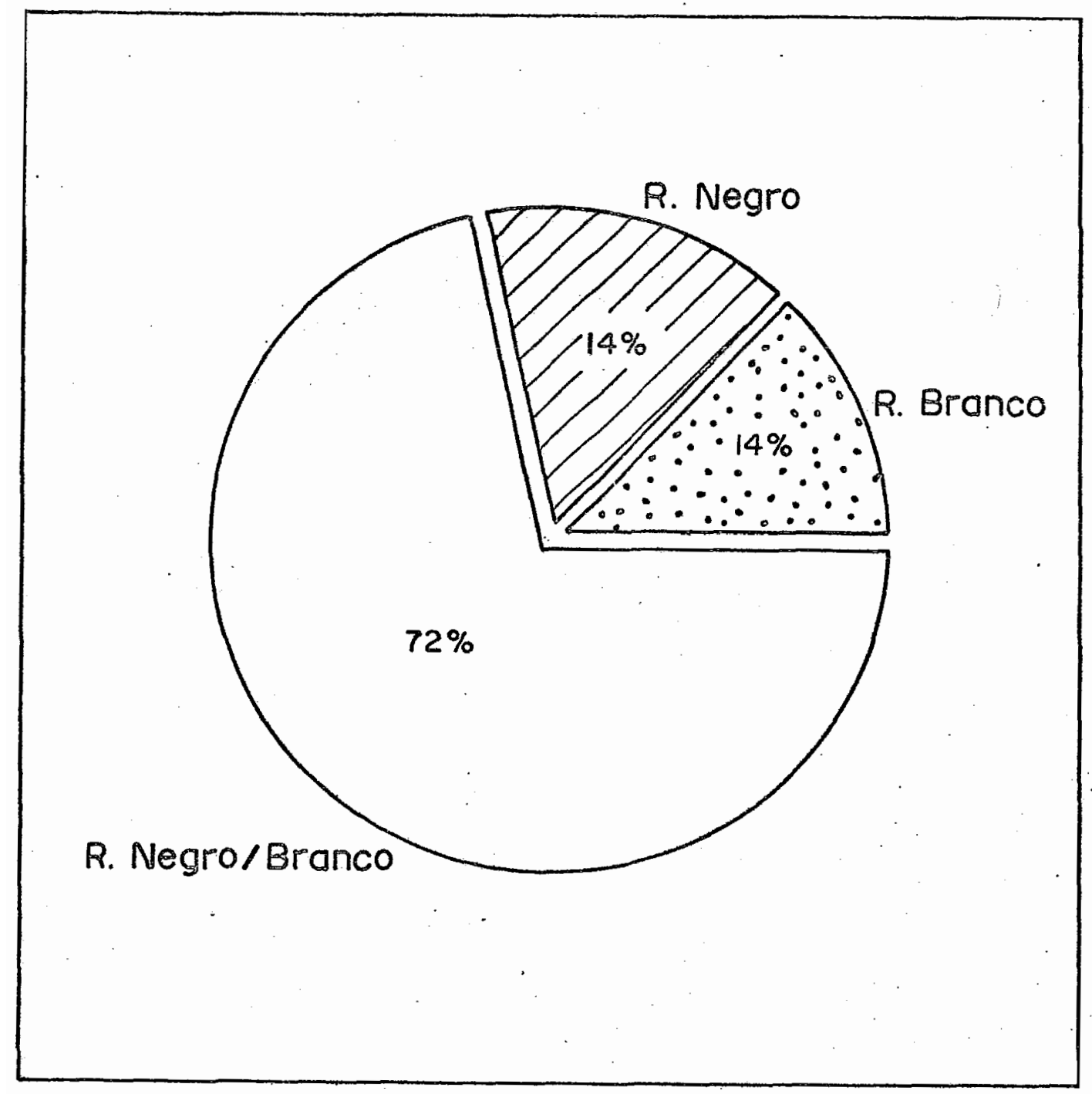

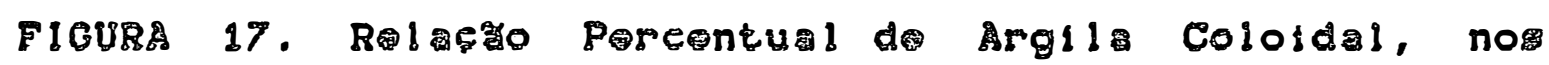
Sedimento do Rio Negro, Rio Branco Rio

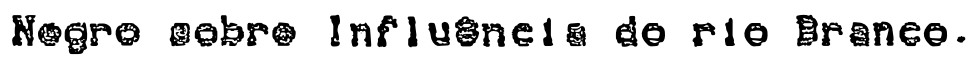




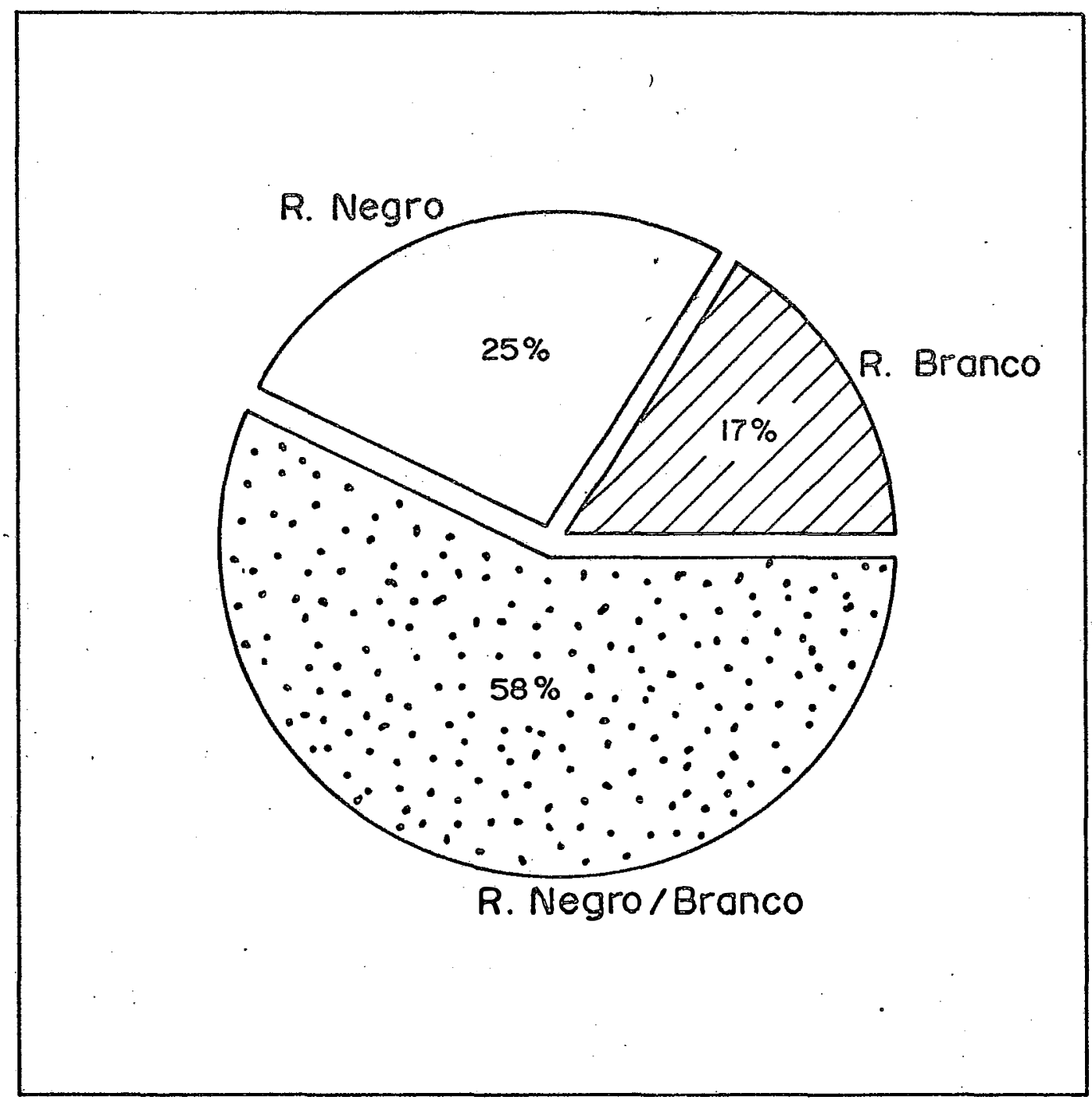

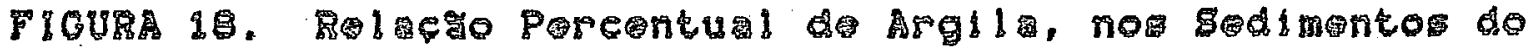
Rio Negro, Rio Branco Rio Negro sobro

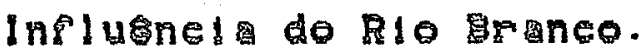




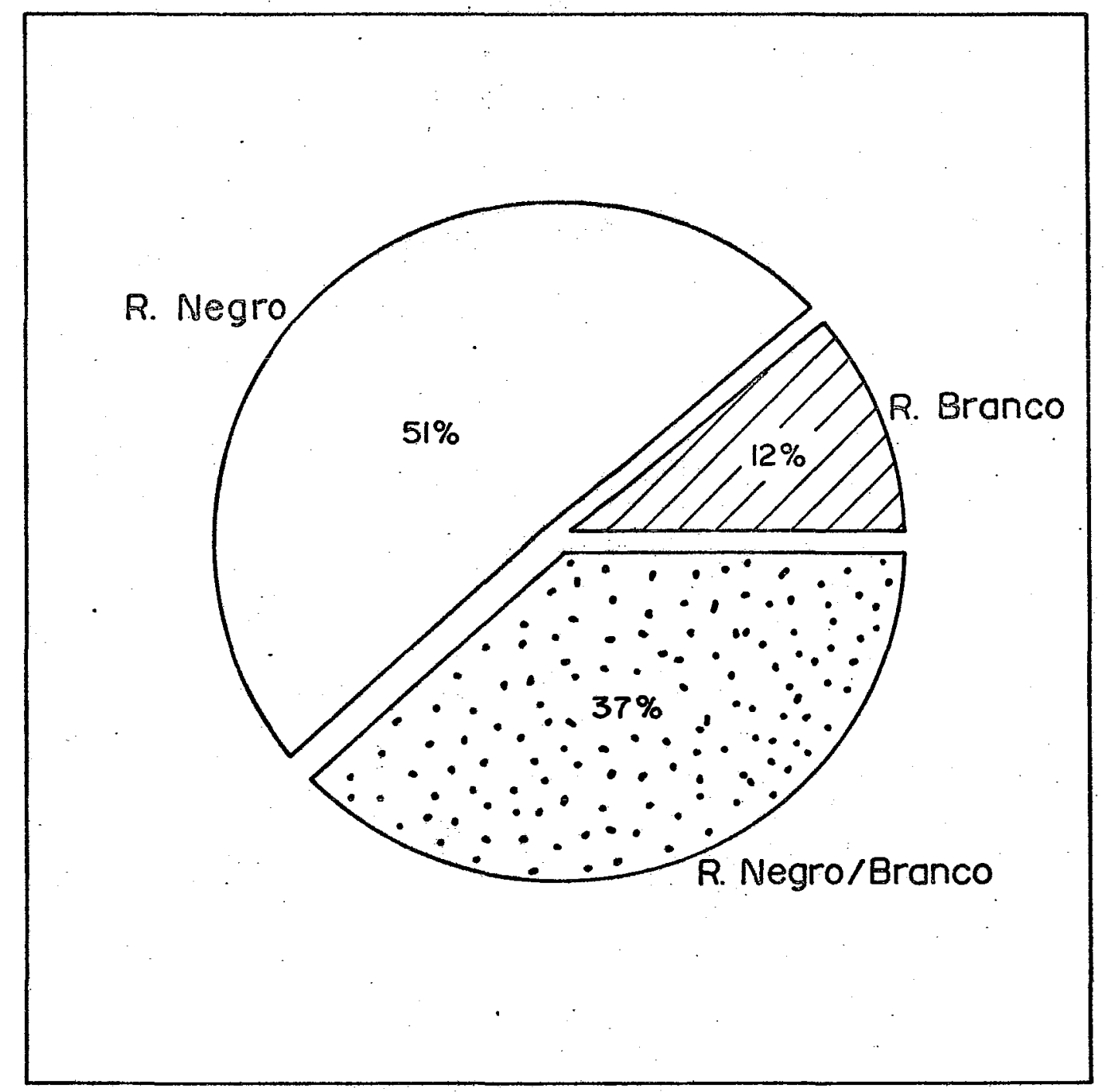

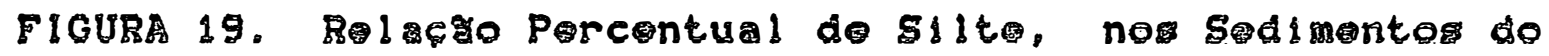
Rio Negro, Rio Branco e Rio Negro sobro Influêned do rio Branco. 
Isto, reflete, nitidamente, nos sedimentos dos lagos que se localizam na faixa do rio Negro sobre influência do rio Branco, o que, comprova a fertilizaça que está ocorrendo tanto nas aguas como nos sedimentos desse lagos, devido aos teores dos elementos qusmicos que foram detectados nesses sedimentos (Tabelas 9 e 10), se comparados com os resultados obtidos para os sedimentos dos lagos da margem direita do rio Negro, sem influência do rio Branco (Tabelas 3 e 4 ).

Os resultados obtidos para esses sedimentos (Tabela 16), corroboram tambem para essa evidência, pois mostram que os sedimentos dos lagos do rio Negro, cuja faixa da margem esquerda, sofrem também influência do rio Branco, eståo nitidamente alteradas.

Outra constatação, de que está ocorrendo modificaçoes fisicomquimicas como também físicas e químicas, 6 a composi६̧̧o mineral6gica desses sedimentos (Figura 20).

Essa Figura contém os difratogramas de raios-X dos sedimentos do rio Negro (A), mostrando uma composicăo meneral6gica, de caulinita, quartzo e evidâcias de mineral $2: 1$, possivelmente a goetita. 


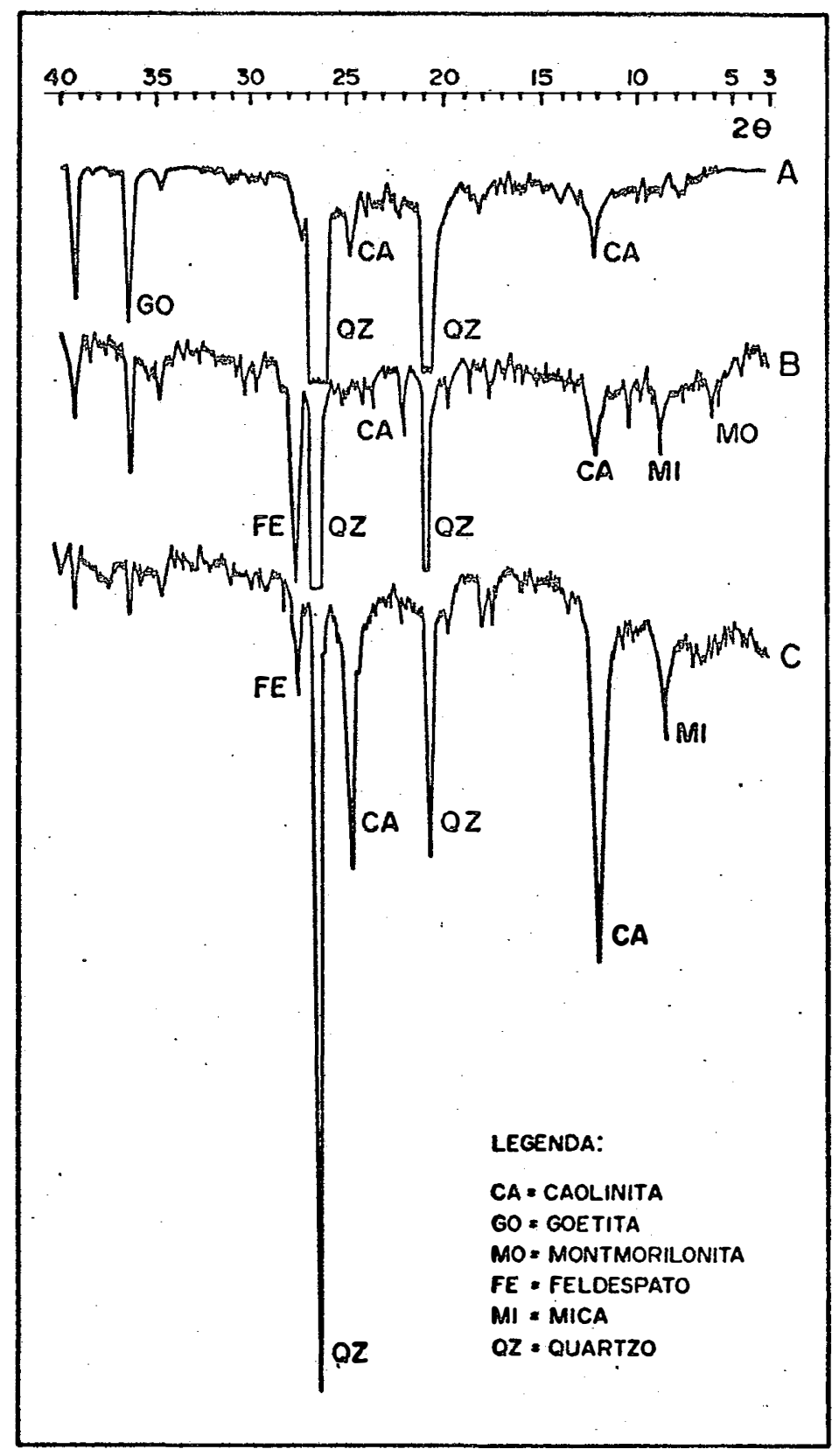

FIGUR 20. Difratograma de ralog-K. (A) Sedimentos do Rio Negro: (B) Sodimento do Rio Branco (C) Sadimenta: do Rio Negro Bobro Insluencla do Rlo Braneo. 
No espectro (B) do sedimento do rio Branco, $\theta$ racilmente identificavel, uma mineralogia constituida de montemorilonita, mica, caulinita, quartzo, feldspato e evidencias de outros minerais 2:1, possivelmente a goetita.

Por outro lado, o espectro de refração do sio-X para o sedimento do rio Negro sobre influência do rio Branco (C), mostra que esses sedimentos estão em parte alterados, em comparąåo ao do rio Negro (A), indicando a existência al $6 \mathrm{~m}$ da caulinita e do quartzo, da mica e feldspato e outros minerais 2:1, entre esses, possivelmente, esteja presente, a goetita.

\subsection{SEDIMESTOS DOS LAGOE DO RIO SOLIMOES}

\subsubsection{CORPLERO SORTIVO}

As aguas desse ecossistema, provenientes de regiăo geologicamente mais recente, contribuem com sedimentos andinos, ricos em minerais alcalinos que ao depositarem esses sedimentos, tormam os solos de varzeas que circundam esses lagos, mais férteis.

Ds valores de pH para os sedimentos desses lagos (Tabela 12), mostram uma leve acidificaço, 
aproximando-se da neutralidade, como o caso do lago da Paciência $(\mathrm{pH}=6,6)$.

Esses lagos formados por sguas ricas em sólidos em suspensăo, em cuja composifão química da água eståo presentes elementos em quantidades apreciáveis para a regiăo Amazônica (GIBBS, 1967), săo lagos que na 6poca da cheia, esţo constantemente ligados com o rio Solimőes/ Amazonas, cujas sguas alagam a planície de inundaçăo e por conseguinte, ocorre a deposiçăo dos s6lidos em suspensaro tanto no leito dos lagos, como nas varzeas al agáveis.

- calcio e o magnesio presentes nesses sedimentos, sð̊ provenientes das particulas em suspenşว nas sguas, bem como do material vegetal que se depositam no fundo do lago e que faræ̧o parte da remineralizaçăo e entradas provenientes da lixiviaçă erosiva dos solos que circundam o lago.

Os maiores teores de calcio foram observados para os sedimentos dos lagos do Jutai e Formiga $(15,6$ e.mg/100 g), 'seguido dos lagos do Muratu e Arroz $(11,6$ e:mg/100 g). Para o magnésio, a maior concentraça observada, ocorreu no lago do Passar inho $(7,7$ e.mg/100 g), seguidos dos lagos da Paciência $(5,9$ e.mg/i00 g): Formiga $(5,3$ e.mg/100 g) e $\operatorname{Arroz}(4,9$ e.mg/100 g). 
IRION Ot III (1983), determinaram quantidades apreciáveis de cálcio e magnésio total no sedimento do rio Solimßes/Amazonas, na ordem de 8.900 ppm de Ca e $11.700 \mathrm{ppm}$ de $\mathrm{Mg}$. Isso, vem corroborar com a teoria de que esses elementos nđo săo encontrados dispontveis, mais sim, em circulaçăo, podendo ser

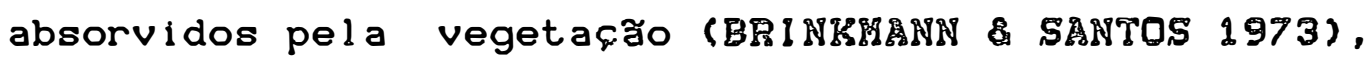

- alumínio está presente em quantidades menores do que foi observado para os outros sedimentos dos lagos em estudo. Entretanto, as maiores concentrações verificaram-se nos lagos do Jutas, Castanho e Arroz 10,9 e.mg/100 g) seguido dos lagos do Manaquiri $(0,8$ e.mg/100 g) e Formiga com 0,7 e.mg/100 g (Tabela 12). seguido do lago do Castanho de 2,9 e.mg/100 g e do Jutai de 2,0 e.mg/100 g (Tabela 12).

\subsubsection{ELERERTOS TOTAIS}

E notável a presença de sódio e potássio total (Tabela 13), onde as maiores concentraçes de s6dio, verifica-se nos lagos da Paciência $(1,73 \mathrm{~g} / 100 \mathrm{~g})$ e Manaquiri $(1,58 \mathrm{~g} / 100 \mathrm{~g})$ seguido do lago do Muratu $(1,53$ g/100 g). Para o potassio total, os lagos do Macaco $(0,80$ g/100 g); Formiga $(2,96 \mathrm{~g} / 100 \mathrm{~g})$ e Passarinho $(4,98 \mathrm{~g} / 100$ g), foram os que apresentaram as menores concentraços. 
Enquanto que, os demais lagos, contêm teores acima de 5,00 g/100 g de T.F.S.A., sendo que o lago da Paciencia foi o que apresentou a maior concentracăo de 13,73 g/100 g (Tabela 13).

0 alumínio total está em quantidades relativamente elevadas, como 6 o caso do lago do Manaquiri e Arroz, cuja concentraçăo 6 da ordem de 9,00 g/100 e $8,61 \mathrm{~g} / 100 \mathrm{~g}$ respectivamente ( $\mathrm{T}$ abela 13 ).

A presença desse elemento nos sedimentos dos lagos, também şa provenierites dos minerais de argilas desses s6lidos em suspensăo que săo carreados $e$ depositados nesses lagos, como os ja existentes nesses ecossistemas. Observa-se uma concentrąåo bastante apreciável no teor de alumínio total, sendo que as maiores concentrações foram encontradas nos lago do Manaquiri $(9,00$ g/100 g), seguidos dos lagos do Arroz (8,61 g/100 g): Jacaretinga $(7,02 \mathrm{~g} / 100 \mathrm{~g})$ e do Jaraqui $(6,57 \mathrm{~g} / 100 \mathrm{~g})$ e a menor, verificou-se no lago do Muratu $(2,54 \mathrm{~g} / 100 \mathrm{~g})$.

Esses elementos, sendo constituintes dos minerais de argilas e por conseguinte, fazendo parte da rêde cristalina desses minerais, era de esperar que tal ocorresse, devido esses sedimentos serem carreados da regiăo andina. Observa-se tamb6m, que esses sedimentos 
apresentam ainda, os elementos $\mathrm{P} ; \mathrm{Fe} ; \mathrm{Ne} \mathrm{C}$, que estaro em maior ou menor quantidade, dependendo das condifores hidrogeoquímicas do lago e săo de importâncla fundamental, principalmente o fosforo, devido a sua carância nessa regiăo, enquanto que o ferro, participara dos processos de oxi-reduça que ocorrem nos lagos.

E possível que nesses sedimentos mesmo com alto teor de argila (Figura 21), nåo ocorram as substituigres do Al por outros elementos, como 6 o caso do $S i$ e o Mg ou seja, essas substituifros iônicas (isom6rficas) năo ocorrem, ou esses sedimentos (argilas) ainda nå tiveram tempo necessario para que essas substituições a fossem processadas: uma vez, que as deposiçơes do material em suspensao ocorrem a cada seis meses. Isto ocorre durante a Gpoca das enchentes, quando as águas do rio Solimơes/Amazonas inundam as terras de várzeas e consequentemente ocorrem um aumento do volume de sgua no lago. Segundo IRION et li i (1983), os sedimentos do rio Solimôs/Amazonas, såo constituídos de montemorilonita, llita e caulinita. 


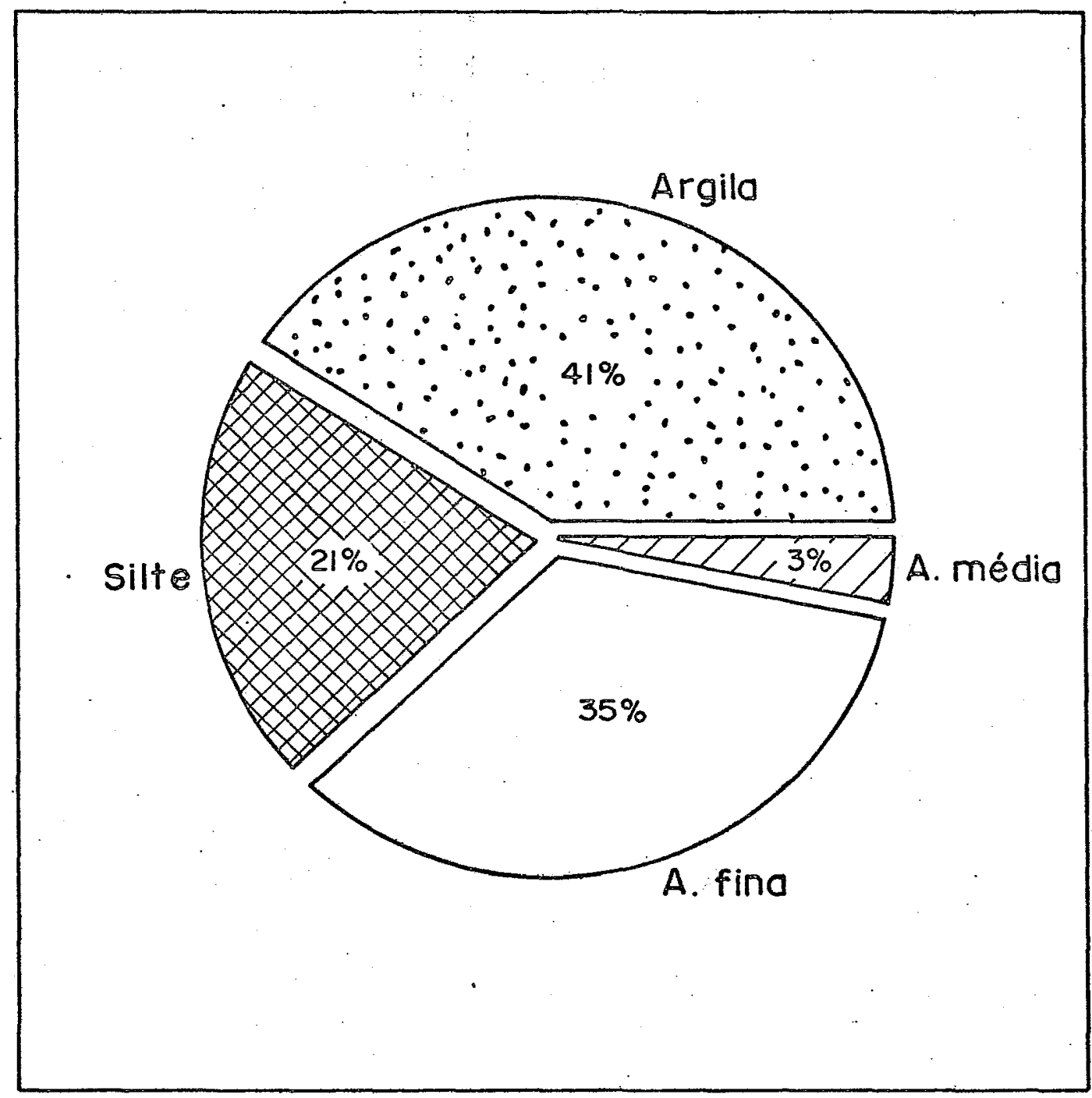

FIGURA 21. Toorea de Argila, Silte, Aroila Fine Arelo

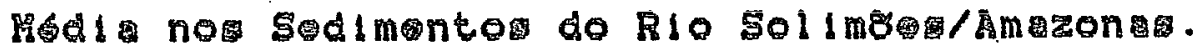


Anslise de raio- $X$ realizada nesses sedimentos (Figura 22), mostram-se idênticas à constituiç̆o observada por IBIO\& ot ald (1993). Entretanto, evidenciase uma diferenca na composiça mineralógica desses sedimentos, dentre os lagos que estão situados na ilha do Careiro (B) e os sedimentos dos lagos da regi đo do Janauaca (A).

- sodio e o potgssio, constatavel nos sedimentos desses lagos, tamber, constituem o mineral de argila depositado por sedimentaço no fundo dos lagos, provenientes dos contra fortes andinos e das terras caidas, provocadas pela erosão desse rio, nas terras altas. Outra porçă provém dos solos circunvizinhos do lago, devido zे lixiviaço que ocorre nos campos de varzeas, intensamente utilizados, na atividade agropecuaria.

As maiores concentraçơes de sbdio foram observadas no lago da Paciência $(1,73 \mathrm{~g} / 100 \mathrm{~g})$, seguido dos lagos do Pianaquiri $(1,58 \mathrm{~g} / 100 \mathrm{~g})$; $\operatorname{Muratu}(1,53 \mathrm{~g} / 100 \mathrm{~g})$; Castanho $(1,42 \mathrm{~g} / 100 \mathrm{~g})$ e Jaraqui $(1,35 \mathrm{~g} / 100 \mathrm{~g})$ e a menor foi verificada no lago do Formiga $(0,49 \mathrm{~g} / 100 \mathrm{~g})$. 


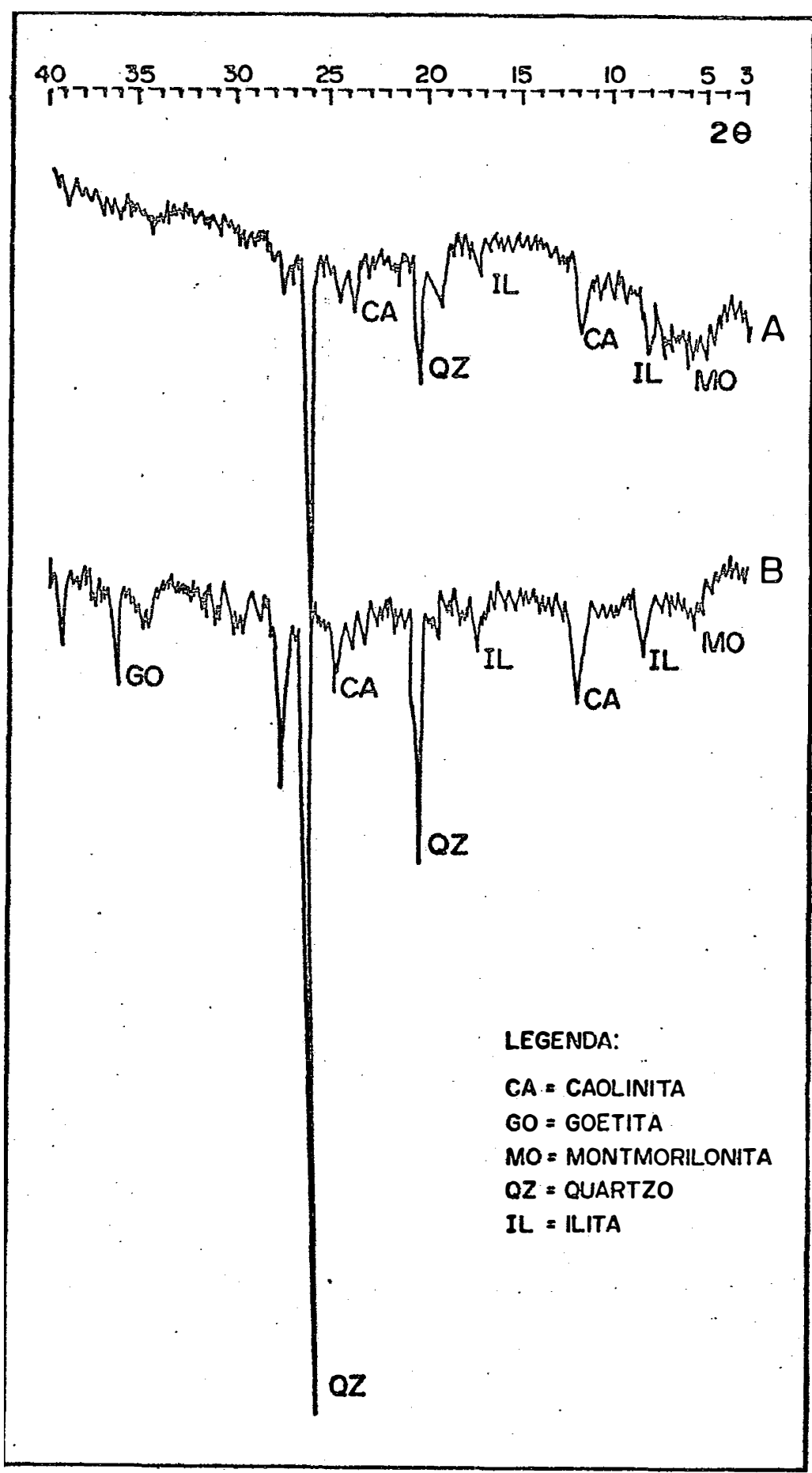

FIGURA 22. Difratograma do Rajos-K. Sedimento dos Lagos do

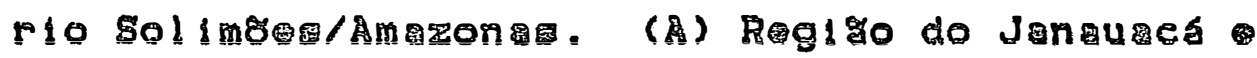
(B) Røg! \%o do Caroiro. 
Para o potassio total, os lagos que apresentaram os maiores teores, foram os lagos da Paciencia $(13,73 \mathrm{~g} / 100 \mathrm{~g})$; Manaquiri $(12,38 \mathrm{~g} / 100 \mathrm{~g})$ : Castanho $(10,83$ $\mathrm{g} / 100 \mathrm{~g})$ e do Muratu $(10,21 \mathrm{~g} / 100 \mathrm{~g})$ e a menor concentraçăo, encontrou-se no lago do Macaco $(0,80$ g/100 g)

Essas elevadas concentraçŏes de potássio, que ocorrem nos'lagos da Paciência, Muratu, Manaquiri, Castanho, Jaraqui e Jutai devem-se ao conteúdo de sólidos em suspensão nas aguas do rio Solimðes/Amazonas.

IRION et alii (1983), estudando esses sedimentos, obtiveram valores de $2.800 \mathrm{ppm}$ de Na $e$ $18.600 \mathrm{ppm}$ de $\mathrm{K}$. E que os teores de s6dio e potásio nos sedimentos dos lagos desse ecossistema, são em sua maior parte, provenientes dos sedimentos em suspensão existentes nesse rio.

Convém salientar, que grande parte das terras que circundam esses lagos, sao utilizados nas atividades agropecuarias, principalmente na época da seca. Com isso, seria possivel também, uma maior contribuicão de sódio e potásio, para os sedimentos dos lagos dessa regi æo em decorrência dessas atividades. 
- fósforo total encontrado nos lagos do ecossistema do rio Solimores/Amazonas ( $T$ abela 13), tâm súa fonte principal, devido ao transporte de compostos orgânicos e inorgônicos pela agua de precipitaça e pela inundaçes provocadas por esse rio; decomposicão dós vegetais, principalmente capim flutuante, animais e mi croorganismos.

Os maiores valores encontrados nesses sedimentos, for am observados nos lagos do Tarumanduba $(0,03 \mathrm{~g} / 100 \mathrm{~g})$; enquanto os lagos do Jacaretinga; Macaco: Manaquiri e Jaraqui, apresentaram $0,02 \mathrm{~g} / 100 \mathrm{~g}$ e 0 lago que apresentou a menor concentraçăo, foi o lago da Paciência com $0,01 \mathrm{~g} / 100 \mathrm{~g}$.

Entretanto, $\sigma$ possível, uma reciclagem quanto ao teor de fósforo nos sedimentos desses lagos, principalmente pelas atividades biológicas, uma vez que esses lagos na época da seca, ocorre a resuspensăo dos sedimentos, tanto provocada pela acão eblica; como pelos peixes, o que pode possivelmente, permitir a estocagem de fófroro nos sedimentos (LOPES t 111,1983 ).

$$
\text { Para os rios de agua branca }
$$

(Solimđes/Amazonas), existe uma paralelismo entre o rio e os lagos que săo influenciados por esse rio, como mostrado por SCHभIDT (1972b), para o f6sforo e o ferro. 
SAมTOg (1980), constata uma concentraço muito baixa de fosforo nas aguas dos lagos desse ecossistema, tanto na Gpoca cheia como na Gpoca seca, indicando que sua presença viabiliza a produça de fito e zooplâncton.

Entretanto, a capacidade dos s6lidos em suspensão das sguas brancas, de liberar ou absorver certas quantidades de fosforo (GESSHER, 1960), depende das condiços ecol6gicas. A viabilidade desse elemento para a produça primgria $\theta$ de importancia fundamental, quanto a sua concentraçăo nesses sedimentos.

Esse fosforo pode ser adsorvido por $\mathrm{Fe}(\mathrm{OH})_{3}$, onde os rons fosfatos ficariam mais facilmente troçveis, do que quando o fosforo se apresentar na forma de $\mathrm{FePO}_{4} \cdot$ Segundo BANTOS (1980), não existe at6 0 presente, algas capazes de obterem fosforo de outra maneira que não seja, adsorvido ao $\mathrm{Fe}(\mathrm{OH})$. Sugere ainda, que o fosforo presente nas sguas dos lagos, \& motivado pela vazante e turbulância da sgua do fundo do lago, causando uma intensa resuspensão do sedimento. Sendo que o fósforo e - ferro encontram-se em um círculo fechado de combinaçós nos sedimentos dos lagos de varzeas desse ecossistema, provenientes de depositos de sólidos suspensos, que săo carreados pelo rio Solimores/Amazonas. 
o ferro e o manganês total também se acham presentes nos sedimentos dos lagos de várzeas pertencentes ao ecossistema do rio Solimðes/Amazonas. Devido as suas peculiaridades químicas, existe uma relaço entre esses elementos, principalmente nas águas dos lagos de varzeas (LOPES of 11\%. 1983). Sendo o ferro um elemento que esta presente nas sguas do rio Solimơes/Amazonas em concentraçses variando de 1,10 a $4,10 \mathrm{mg} / \mathrm{l}$ (SCHIDT, 1972b), logo era de se esperar, que os sedimentos desses lagos com forte influência desse rio, tivessem concentraçes relativamente elevadas.

As maiores concentraçoses de ferro total foram verificadas nos lagos da Paciencia $(8,50 \mathrm{~g} / 100 \mathrm{~g})$; do Manaquiri $(7,97 \mathrm{~g} / 100 \mathrm{~g})$; do Macaco $(7,96 \mathrm{~g} / 100 \mathrm{~g})$; do Jaraqui $(7,33 \mathrm{~g} / 100 \mathrm{~g})$ e do Arroz $(7,31 \mathrm{~g} / 100 \mathrm{~g})$ e a menor foi observada no lago do Reis $(2,30 \mathrm{~g} / 100 \mathrm{~g})$.

Ja o manganôs, suas maiores concentraçơs foram observadas nos lagos do Reis $(0,40 \mathrm{~g} / 100 \mathrm{~g})$; do Jutai $(0,20 \mathrm{~g} / 100 \mathrm{~g})$; da Paciência $(0,13 \mathrm{~g} / 100 \mathrm{~g})$, enquanto que as menores foram encontradas nos lagos de Manaquiri; do Jaraqui e Tarumanduba $(0,01 \mathrm{~g} / 100 \mathrm{~g})$.

IRION alii (1983), observaram concentraços elevadas de ferro e manganes, nos sedimentos 
dos rios. Sol imơes/Amazonas, na ordem de 54.400 ppm de Fe e 804 ppm de Mn. Como o ecossistema desse rio 6 uma fonte predoninantemente de elementos nutritivos para os lagos de varzeas, onde evidencia-se um forte processo de oxiredução, ou com possíveis assimilaç㐅̆ pela vegetaçạo tanto aquatica como terrestre, que circunda esses lagos.

Na Tabela 17, mostram-se os teores de P; K: Mg: Ca e $\mathrm{Na}(\mathrm{g} / \mathrm{kg})$ nas folhas das florestas inundGveis de varzeas e nas gguas do rio Solimöes/Amazonas.

Pode ser observado que essas vegetaç्ôs, apresentam maiores conteúdos de calcio e potassio seguidos de magnésio e fósforo, porem, indicando um fator de concentraç̃o maior para os dois ulltimos elementos. Indicando que a presenqa desses elementos no ecossistema, principalmente o fosforo, magnesio e calcio estão sempre baixos, devido a sua râpida absorç̃o pela vegetaç̃o dos lagos. 
TABEL 17. CORTEDDO DE P; KR Mg, C FLORESTAS DE INUHDAGRO E NAS BGUAS DO BIO SOL1MGES E O FATOR DE CONCEATRAGRO (KLINGE OH बdii, 2983).

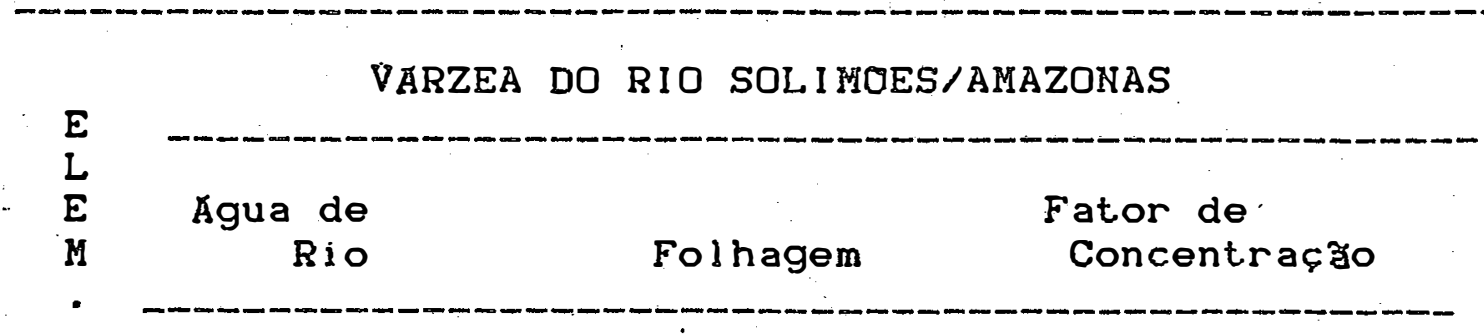

Solimơes Marchantaria Iranduba Marchantaria Iranduba

$\begin{array}{lccccc} & 10^{-3} \mathrm{~g} / \mathrm{kg} & \mathrm{g} / \mathrm{kg} & \mathrm{g} / \mathrm{kg} & & \\ \mathrm{P} & 0.105 & 1.755 & 0.871 & 16714 & 8295 \\ \mathrm{~K} & 0.9 & 13.183 & 8.609 & 14684 & 9566 \\ \mathrm{Mg} & 1.1 & 3.982 & 4.029 & 3620 & 3663 \\ \mathrm{Ca} & 7.2 & 19.141 & 16.314 & 2653 & 2266 \\ \mathrm{Na} & 2.3 & 0.195 & 0.085 & 85 & 37\end{array}$

o nitrogênio total encontrado nos sedimentos dos lagos perscrutados do rio Solimöes/Amazonas (Tabela 14), tem sua entrada nesses lagos, atraves da precipitą̧วo sobre a superficie de fixąão; material 
orgânico aloctone, incluindo agua de infiltrą̧a; material orgânico autóctone, proveniente de decomposiço de vegetais e animais. Entretanto, a principal fonte de nitrogênio nesses lagos săo os provenientes da decomposição da vegetaçวo aquătica (JUมK, 1980 SANTOS, 1980).

As concentraçôes de nitrogônio, mais elevadas foram observadas nos lagos do Reis $(0,10 \mathrm{~g} / 100 \mathrm{~g})$; do Jutai e do Formiga $(0,09 \mathrm{~g} / 100 \mathrm{~g})$ e as menores, verificaram-se nos lagos do Manaquiri e Muratu $(0,03 \mathrm{~g} / 100$ g). Em tais concentraçôes, incluem-se o Nitrogênio Orgânico, proveniente da decomposiço de produtos tais como: proteinas, aminofcidos, ureia e acido metilamínico como também, estão inseridos os nitratos e nitritos.

Contudo, esses lagos podem perder quantidades de nitrogênio através de ligaçôes direta dom o rio: pela diffusaro dos compostos volateis na superfície do lago e pala denitrificaça (LOPE్ at a 11, 1983).

Os lagos estudados, apresentam também uma concentraçăo de carbono, da ordem de $2,46 \mathrm{~g} / 100 \mathrm{~g}$, para o lago do Formiga, que foi considerada maior e a menor, ocorreu no lago do Capitari $(0,70 \mathrm{~g} / 100 \mathrm{~g})$, dando 
uma razăo $C / \mathbb{N}$ de 27 e 14 respectivamente, consequentemente, - teor da materia orgânica para o lago do Formiga foi de $4,24 \%$ e para o lago do Capitari de $1,21 \%$ (Tabela 14).

5. ESTUDADOS

\section{A.1. COHPIEXO SORTIVO}

o complexo sortivo dos sedimentos dos lagos perscrutados da bacia Amazónica (rio Amazonas e Negro), 6 bastante distintos $e$ divergentes quanto d composiço físico-química e química (Tabelas $3,4,12$ e 13), mostrando uma acidez acentuada para os sedimentos dos lagos do rio Negro (Tabela 3) isto, se nao levarmos em consideraço as concentraços dos sedimentos que pertencem a esse ecossistema e que sofrem influência do Branco (Tabela 10); que por sua vez, mostram uma concentraçăo hidrogeniônica ( $\mathrm{pH})$ se aproximando da neutralidade, o mesmo acontecendo com os sedimentos dos lagos que pertencem ao rio Sol imores/Amazonas (Tabela 12).

A parte investigada do rio Negro, principalmente, aqual năo sofre influência do rio Branco (Tabela 3), mostra a pobreza do material de origem em 
çtions, dando provas de que as condiços de pedogêneṣe favorecem a remoçăo de cations, onde se destaca o grau de intemperismo do solo. VRH RAIJ (1983), destaca que, quanto mais intemperizado for o solo, maior a tendência que o mesmo tem para perder sua bases trocaveis.

Perscrutando-se os sedimentos dos lagos do rio Sol imơes/Âmazonas, observa-se, uma condi çăo adversa ao do rio Negro, onde as concentraçōes hidrogeniônicas, mostram a quase neutralidade dos sedimentos, confirmando assim, sua maior quantidade de bases troçveis existente no complexo sortivo. MARTINELLI (1986), sugere que tanto esses sedimentos, como os adjacentes aos lagos, bem como os sedimentos do rio Solimores/Amazonas, podem suportar uma agricultura à níveis ideais dos sais basicos.

Nas Greas investigadas (Tabelas $3 ; 6 ; 9$ e 12), mostram que os cations troçveis ( $\mathrm{Ca}$; $\mathrm{Mg}$; $\mathrm{Na} \mathrm{e} \mathrm{K}$ ), aparecem em maiores quantidades, nos sedimentos dos lagos do rio Solimơes/Amazonas (Tabela 12) e nos sedimentos dos lagos do ecossistema do rio Negro que sofrem influôncia do rio Branco (Tabela 9).

A concentraça desses elementos troçveis nos sedimentos dos lagos, tem uma tendência de apresentar uma concentração de çlcio menor nos lagos do rio Negro: 
seguindo em ordem crescente nos lagos do rio Branco; dos lagos do rio Negro influenciados pelo rio. Branco e dos lagos do rio Solimores/Amazonas.

Para o magnesio, existe uma pequena inversão, onde os sedimentos dos lagos do rio Negro apresentam uma concentração maior que às que foram verificadas nos sedimentos dos lagos do rio Branco. Por outro lado, os sedimentos dos lagos do rio Negro influenciados pelo rio Branco, apresentam uma concentraçăo maior que às observadas para o rio Negro, e, os maiores teores, foram encontrados nos sedimentos dos lagos do rio Sol imres/Amazonas .

No caso do sodio, existe uma tendência a igualdade entre os sedimentos dos lagos do rio Negro com os do rio Branco, e estes, apresentam uma concentracão maior que às do rio Negro influenciado pelo rio Branco, notanto-se tambøm, uma igualdade para com os sedimentos dos lagos que pertencem ao rio Solimðes/Amazonas. Para o potássio, os ecossistemas estudados mostram que næo há uma variaçă nitida, uma vez que apresentam concentraçðes similares.

Como as varzeas e mesmo os sedimentos dos fundos dos lagos do ecossistema do rio Solimðes/Amazonas 
săo formados por deposi६̧̧o de sedimentos transportados por esse rio, a composif̧o química e mineralógica deriva dos horizontes de intemperismo que ocorrem na bacia do rio Sol imőes/Amazonas (

Tais evidências, podem, possivelmente, ser aplicadas ao rio Negro, que pela composifão química de

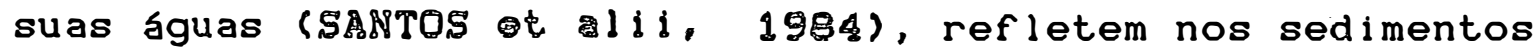
do fundo dos lagos, a pobreza em cations trocáveis. Porém, para os sedimentos dos lagos do rio Negro influenciado pelo rio Branco, dg-se de um modo diferente, onde o rio Negro ao receber as gguas e sedimentos que săo carreados pelo rio Branco, sofre uma alteraçăo na composiçăo química de suas aguas (SARTOS 2111,1984 ), como nos sedimentos dos lagos, que săo enriquecidos com bases trocáeis provenientes das descargas do rio Branco.

Essas sequâncias e as diferentes concentraç̋es observadas nos ecossistemas estudados săo coerentes, uma vez que STALLARTD \& EDHOND (1983), sugerem que as grandes bacias dos rios que formam a bacia Amazônica, encerram substratos geológicos bastantes distintos e que dessa forma a quantidade e qualidade do material transportado por esses tributários, que săo depositados nas v̧rzeas, serăo também distintos. 
Tambem as concentraçðes de cattions busicos trocaveis da frąaro argila do material em suspensão no rio Solimós/Amazonas, realizada por IRION (1976), mostram essa tendência (Tabela 18) e justificam as concentraçðes encontradas para os sedimentos dos lagos do rio Solimões/ Amazonas.

TABELA 1\%. CATIONS BESICOS TROCAVEIS DA FRACTO ARGILA DO MATERIAL EM SUSPERSEO DO RIO SOLIMOES/ AHAZONAS (IRION, 1976).

LOCAL

\section{E L E M E N T O S T R O C A V E I S}

\begin{tabular}{lcccc} 
& $\mathrm{Ca}$ & $\mathrm{Mg}$ & $\mathrm{K}$ & $\mathrm{Na}$ \\
Andes & & $\mathrm{meq} / 100 \mathrm{~g}$ & \\
Sub-Andes & 0.0 & 14.0 & 18.5 & 30.0 \\
Alto Solimós & 64.0 & 8.6 & 10.0 & 13.0 \\
Mgdio Solimðes & 60.0 & 8.6 & 10.0 & 13.0 \\
Baixo Amazonas & 45.0 & 8.6 & 9.0 & 13.0 \\
\hline
\end{tabular}


As concentrações dos elementos trocáveis do complexo sortivo dos sedimentos dos lagos dos ecossistemas Amazônicos est ăo relacionados com as concentraçres desses mesmos cations tanto na forma total como solúvel, que se apresenta tanto nos sedimentos em suspensăo, como nos que fazem parte da composiço química das Śguas do rio que dăo formą̧ro a esses lagos.

A razăo entre o calcio e a soma de base, mostram valores mais elevados para o rio Solimoes/ Amazonas, seguindo em ordem decrescente, o rio Branco; rio Negro influericiado pelo rio Branco e o rio Negro. Por outro lado, a razäo entre o magnésio e a soma de base, tem seu maior valor para os sedimentos dos lagos do rio Negro influenciado pelo rio Branco, seguindo em ordem decrescente, o rio Negro: rio Solimøes e rio Branco (Tabela 19).

Tais condiçชes relacionadas com a razăo $\mathrm{Ca} / \mathrm{Mg}$ seguem, praticamente, a mesma tendância e com valores significantes, uma vez que mostram a contribuiç̃o do rio Branco sobre o rio Negro.

\section{THOMPSON \& TROEH (1978); MALAVOLTA (1976)}

- VAN RAIJ (9993), atribuem que o potassio ocorre no solo principalmente em duas formas; como fon monovalente na 
soluça do solo. e ou adsorvido a minerais de argila, fazendo parte da estrutura de minerais como mica e feldspato. Da quantidade total de $K$ que se encontra no solo, 99 \% fazem parte da estrutura de alguns minerais e $1 \%$ se encontra na forma trocavel. Esta forma, atraves de equilíbrio dinâmico, passa para a soluça do solo e 6 rapidamente absorvido pelas plantas. Entretanto, se comparado ao çlcio e ao magnésio, o potassio 6 fracamente adsorvido pela argila, passando assim, facilmente à soluça do solo, onde haverá a absor६ão pelas plantas, ou podem ser lixiviado.

Das bases troçveis, geralmente o potassio 6 o terceiro, e esta abaixo do calcio e do magnásio. Segundo THORPSOH TROEH (1978), O potassio geralmente encontra-se entre 1 a $3 \%$ do total das bases.

Com base em tais explicaçôes, justifica-se que, muito embora năo haja uma varią̧̊ excessiva entre os sedimentos dos lagos perscrutados, observa-se porém, que o rio Branco, contém as maiores concentraços de potassio como tambøm, as maiores razós $\mathrm{K} / \mathrm{Na}$.

Tratando-se de lagos cujas caracteristicas geológicas săo diferentes, essas variaç̋es são consideradas normais, para os lagos amazónicos, principalmente pelo fato de estarem envolvidos dois sistemas ecologicos 
bastantes distintos, sendo um do rio Solimores/Amazonas e o outro, do rio Negro.

Para os lagos persicrutados do rio Solimóes existe uma vegetaçăo aquatica em grande escala, que domina praticamnte todo o lago, devido à fertilidade das aguas e dos sedimentos (SANTOS, 1980 JUN\&, 1980). Quanto aos lagos do rio Negro, observa-se uma pobreza nesses tipo de

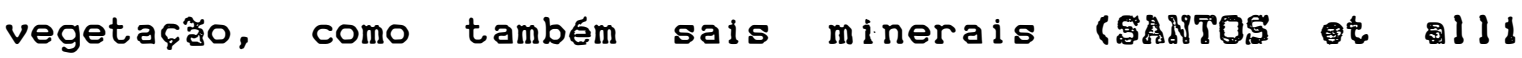
$(1984)$.

Com isso, nos sedimentos dos lagos do rio Sol imóes/Amazonas, o potassio \& rapidamente absorvido pela plantas, enquanto que nos sedimentos dos lagos do rio Negro fica fracamente adsorvido nas argilas desses sedimentos, principalmente para os lagos que sofrem influência do rio Branco.

Essas razóes dos elementos trocsveis, que existem no complexo sortivo dos sedimentos dos lagos (Tabela 19), tem significância, por mostrarem que esses sedimentos, divergem entre si e principalmente entre regiŏes, ou mesmo dentro de uma mesma regiăo, como $\epsilon$ o caso dos lagos do rio Negro, em que os sedimentos dos lagos såo diferentes quimicamente, devido à faixa da margem esquerda do rio Negro, sofrer influência do rio Branco, dando melhores condiçes hidrogeoqurmicas. 


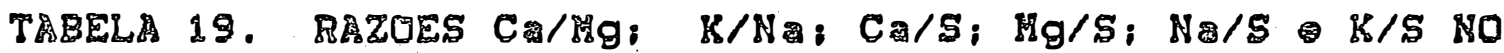
COMPLEXO SORTIVOS DOS SEDIMENTOS DOS LAGOS ESTUDADOS.

LOCAL.

C O M P L E X O SOR T I V O

$\mathrm{Ca} / \mathrm{Mg} \mathrm{K} / \mathrm{Na} \mathrm{Ca} / \mathrm{S} \mathrm{Mg} / \mathrm{S} \quad \mathrm{Na} / \mathrm{S} \mathrm{K} / \mathrm{S}$

RIO BRANCO

$\begin{array}{llrlllll}1 & \text { Curubau } & 3,00 & 0,75 & 0,39 & 0,13 & 0,30 & 0,17 \\ 2 & \text { Maguar1 } & 10,50 & 1,60 & 0,60 & 0,06 & 0,16 & 0,25\end{array}$ RIO NEGRO INFLUENCIADO PELO RIO BRANCO

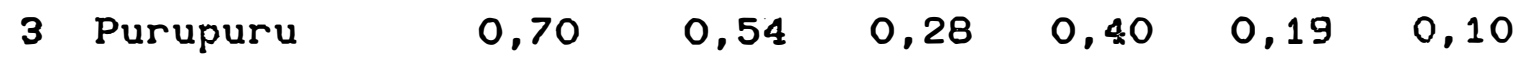

4 Cal ango $\quad \begin{array}{lllllll}0,68 & 1,50 & 0,29 & 0,42 & 0,17 & 0,25\end{array}$

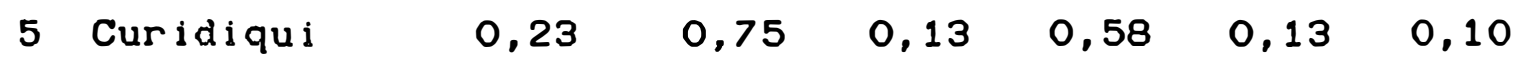

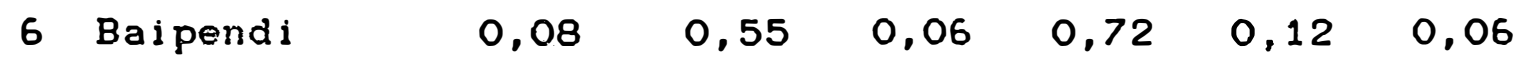

$\begin{array}{lllllll}7 \text { Tauatu } & 2,22 & 0,71 & 0,51 & 0,23 & 0,18 & 0,13\end{array}$

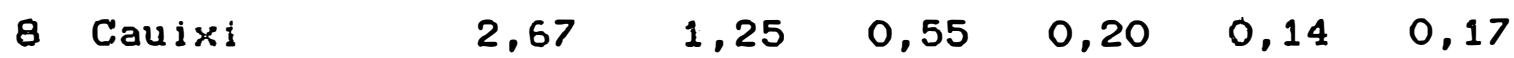

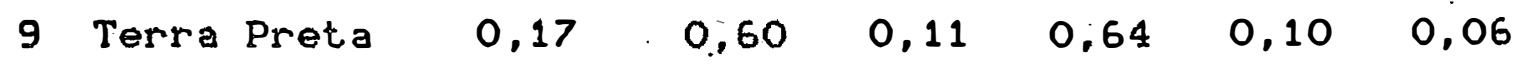

$\begin{array}{lllllll}10 \text { Ariau } & 0,12 & 0,63 & 0,09 & 0,73 & 0,10 & 0,06\end{array}$

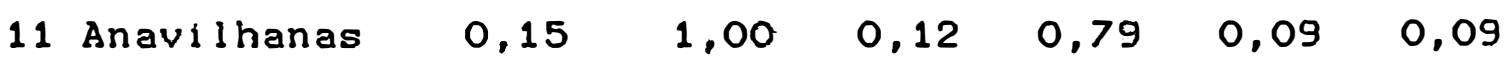
RIO NEGRO

$\begin{array}{lllllll}12 \text { Caurés } & 3,25 & 1,17 & 0,54 & 0,17 & 0,25 & 0,29 \\ 13 \text { Curiaú } & 0,34 & 0,23 & 0,19 & 0,56 & 0,16 & 0,04 \\ 14 \text { Peixe Boi } & 1,25 & 0,80 & 0,43 & 0,34 & 0,14 & 0,11 \\ 15 \text { Unini } & 0,21 & 1,33 & 0,13 & 0,62 & 0,15 & 0,21\end{array}$


Continuaça da Tabela 19.

RIO SOLI MOES/AHAZONAS

$\begin{array}{lcccccc}16 \text { Paciôncia } & 1,83 & 0,43 & 0,58 & 0,32 & 0,07 & 0,03 \\ 17 \text { Jaraqui } & 1,55 & 0,80 & 0,53 & 0,34 & 0,08 & 0,06 \\ 18 \text { Manaquiri } & 2,50 & 0,58 & 0,63 & 0,25 & 0,08 & 0,04 \\ 19 \text { Muratu } & 5,04 & 0,64 & 0,74 & 0,15 & 0,07 & 0,04 \\ 20 \text { Jutai } & 4,33 & 0,64 & 0,74 & 0,17 & 0,05 & 0,03 \\ 21 \text { Formiga } & 2,92 & 0,50 & 0,69 & 0,23 & 0,05 & 0,03 \\ 22 \text { Castanho } & 3,43 & 0,60 & 0,69 & 0,20 & 0,07 & 0,04 \\ 23 \text { Reis } & 7,75 & 0,58 & 0,75 & 0,10 & 0,10 & 0,06 \\ 24 \text { Tarumanduba } & 2,60 & 0,46 & 0,57 & 0,22 & 0,14 & 0,07 \\ 25 \text { Macaco } & 2,67 & 0,57 & 0,60 & 0,22 & 0,12 & 0,07 \\ 26 \text { Arroz } & 2,37 & 0,54 & 0,63 & 0,26 & 0,07 & 0,04 \\ 27 \text { Jacaretinga } & 1,74 & 0,57 & 0,53 & 0,30 & 0,11 & 0,06 \\ 28 \text { Passarinho } & 0,78 & 0,64 & 0,38 & 0,48 & 0,09 & 0,06 \\ 29 \text { Capitari } & 4,92 & 0,67 & 0,66 & 0,13 & 0,12 & 0,08 \\ \text { - } & & & & & \end{array}$

5.4.2. ELEMENTOS TOTAIS

5.2.2.1. NITROGENIO

VAN RAIS (1983), sugere que a forma predominante de nitrogênio no solo 6 a forma orgânica, com cerca de $98 \%$ do total e que os $2 \%$ restantes, estro na 
forma inorgânica $\left(\mathrm{NH}_{4}^{+}\right.$e $\mathrm{NO}_{3}^{-}$), sendo que as plantas absorvem exclusivamente as duas formas inorgânicas e que os processos de mineralizaço e imobilizaço săo responsáveis pela conversấo do $\mathbb{N}$-Orgânico para $\mathbb{N}-M i n e r a l$ e vice-versa.

Sendo o ciclo do nitrogênio bastante complexo em comparaço com os cătions básicos, uma vez que esse elemento apresenta-se na forma gasosa e faz com que cicle atraves do solo, da biota e da atmosfera. Com isto, o nitrogênio, em alguns ecossistemas, torna-se limitante, fazendo com que seu processamento pela biota seja um tanto mais ativo em relaçăo aos cătions básicos trocáveis. Isto identifica que a relaça do nitrogênio com o substrato

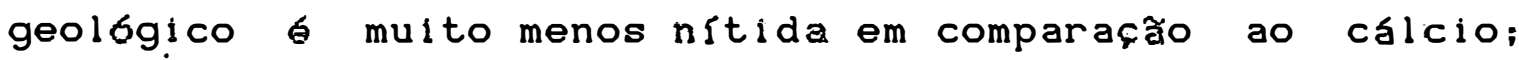
magnésio; potassio e sódio (MARTIRELLI, 1986).

Os resultados de nitrogênio obtidos para os sedimentos dos lagos do rio Solimőes/Amazonas (Tabela 14), mostram-se compatíveis com os obtidos por MARTINELLI (1586), para os sedimentos do rio Solimôes/Amazonas. Por outro lado, VIEIRA (1975), ao estudar os LatossolosAmarelos de terra- firme, verificou que a concentraça de nitrogênio, variava entre 0,2 a $0,9 \%$, isto para um solo de textura media enquanto que um solo de textura argilosa essa concentraçăo era da ordem de 0,05 a $0,07 \%$, e se tratando de um solo de textura muito argilosa essa variaço de nitrogênio apresentava valores entre 0,06 a $0,31 \%$. 
Se utilizarmos os criterios estabelecidos por GARGANTINI ot alii (1970), podemos considerar os sedimentos dos lagos do rio Solimaes/Amazonas, com baixos teores de nitrogânio, uma vez que segundo esse autor, um solo variando entre 0,075 a $0,125 \%$, são considerados com teores médios e os solos acima de 0,125 \%, sâo considerados ricos em nitrogênio.

Para os sedimentos dos lagos do rio Negro (Tabelas 5 e 11), os resultados obtidos para o nitrogenio, mostram que esses sedimentos săo mais ricos que os encontrados nos lagos do rio Sol imôes/Amazonas. Observa-se também que os lagos pertencentes ao ecossistema do. rio Negro (Tabela 5), contém teores de nitrogônio maiores que os verificados nos sedimentos dos lagos do rio Negro que sofrem influência do rio Branco (Tabela 11).

FORSEERG (1984), af irma que o nitrogênio 6 um elemento essencial e limitante em qualquer ecossistema, principalmente quando esse elemento $\sigma$ processado por uma biota bastante ativa como a Amazônia. Ja MARTINELLI (1986), ao perscrutar, os sedimentos do rio Amazonas, afirma que a Jigação do nitrogênio com o substrato geol6gico 6 bem menos evidente se comparado aos cations trocaveis. 
Em consequância da grande imobilidade e sua ciclagem complexa, torna-se dificil uma comparaça do nitrogénio, nos ecossistemas estudados, principalmente, quando se tem situaçôs, onde o sistema ecologico local, encontra-se bastante "alterado", devido as atividades agropecusrias, como ocorrem nos lagos do ecossistema do rio Sol i môes/Amazonas .

Nos sedimentos dos lagos de varzeas do rio Solimoes/Amazonas, evidencia-se a existência de uma ciclagem de nitrogônio através de gramíneas e macrofitas aquaticas, onde o solo pode sofrer uma adicăo de nitrogênio devido a fixaçăo atmosférica realizada pelas leguminosas que habitam as varzeas, como tamberm os lagos que fazem parte do ecossistema desse rio (LOPES ot alif. 1983; SANTOS, 1980; JUNK, 1980; RIBEIRO, 1983 S SHITH-MORRILL, 1987).

As concentraçß̊es de nitrogênio săo mais elevadas para os sedimentos dos lagos do ecossistema do rio Branco, e na ordem decrescente, aparecem as verificadas nos sedimentos dos lagos do ecossitema do rio Negro, seguindo da rio Negro influenciado pelo rio Branco e as do rio Sol i mores/Amazonas.

Nos sedimentos dos lagos do rio Negro que 
sofrem influância do rio Branco (Tabela 11): verifica-se um comportamento similar ao do rio Solimbes/Amazonas, onde a fertilizaço dessas aguas pelas do rio Branco mostram o aparecimento de macrófita aquatica em alguns desses lagos e mesmo nas margens do rio Negro (SANTOS te alii, 1984), fazendo com que ocorra uma possível fixaça desse nitroganio, uma vez que essas macrofitas, podem absorver o nitrogênio que se encontra nas aguas desses lagos. Um possível aumento nas concentraços dos sedimentos do fundo do lago săo atribuídas à fixaçăo biologica (N-atmosferico) tanto pelas gram ́neas como pelas macrofitas que na ́bocá da seca, se decompơem. Entretanto, estudo nesse sentido, revelaria, uma fraç̧o muito importante, do ciclo do Nitrogênio nos ambientes aquaticos da Amazônia Central .

Esses teores de nitrogônio săo justificaveis, pelo fato desses sedimentos apresentarem composiça granulometrica, onde os sedimentos dos lagos do rio. Negro sofrem influência do rio Branco. Contém as maiores percentagens de argila, principalmente de argila coloidal fraço menor que $0,001 \mathrm{~mm}$, onde o nitrogênio possivelmente, ficaria agregado. VIEIRA (1975), estabelece, que um solo com alto teor de argila, tende a apresentar maiores percentagens de nitrogênio. 
5.4.2.2. FOSFORO

a fosforo, encontrado no solo, se caracteriza pela presença em trôs formas distintas: dissolvido na soluç̧o do solo: na forma labil e uma outra ñ̃o 1 Gbil (MALAPOLTA, 1975 VAS RAIJ,1983). Observaram também, que a concentraço de fosforo na solucão do solo 6 baixa, devido à solubilidade de seus compostos serem tambóm, baixa. VAN BAIJ (1983), afirma que essas concentraçes de fosforo, raramente atinge 0,1 ppm. Entretanto maLPOLTA (1976), atribui que os teores de fosforo em soluçăo, podem atingir aţ $20 \mathrm{ppm}$ e que essa forma de fosforo $\theta$ derivada do scido ortofosforico $\left(\mathrm{H}_{3} \mathrm{PO}\right)$.

Nos sedimentos dos lagos perscrutados, as concentraç̋es mais elevadas de fosforo-total, foram verificadas nos sedimentos dos lagos do rio Negro que sofrem influência do rio Branco, onde em alguns lagos, esse elemento inexiste (Lago do Purupuru; Curidiqui e Baipendi), entretanto, foi no lago do Cauixi e Anavilhanas $(0,03$ g/100 g), que se constatou a maior concentraço. Nos sedimentos dos lagos do rio Solimßes/Amazonas observou-se que todos os lagos apresentaram concentraç̋es de fosforo-total, muito embora, alguns desses lagos, tambøm, mostram teores muito bai $x$. 
A razåo $N$-total/P-total, para os solos minerais segundo HeGRILL \& CHRISTIE (1983) $\sigma$ de aproximadamente 6. RERTINELLI (1986), estudando os sedimentos do canal do rio Sol imores/Amazonas, observou que essa razăo 6 da ordem de 2,06. Para as sguas dos lagos de vorzeas da Amazônia, FOBSBEBG ot alı (g.d.), sugere a mesma tendência emcontratada por MARTINELLI (1986).

Nos sedimentos dos lagos estudados, observa-se, que muitos dos sedimentos, seguem essa tendôncia sugerida por MARTINELLI (1986) - FORSBERG at II (o.d.), principalmente para sedimentos dos lágos perscrutados do rio Solimơes/Amazonas. Entretanto, nesse ecossistema, existem lagos que ultrapassam em valores, a razão sugerida por HeGRILL \& CHRISTIE (1983), como 60 caso dos lagos dos Reis e Jutai cuja razåo N/P è 10,00 e 9,00 (Tabela 14). Essa razåo $\mathbb{N}$-total/P-total (Tabelas 5, 11 e 14), também é bem superior para os sedimentos dos lagos do rio Negro que sofrem influência do rio Branco, como observado para os lagos do Calango $(16,00)$; $\operatorname{Ariau}(15,00)$; Tauatu $(14,00)$ e Terra Preta $(12,00)$.

Essa razăo N/P, pode ser justificada, devido aos sedimentos do rio Negro que estæ̌o sobre influência do rio Branco mostrarem um maior conteúdo de argila como também uma fraça importamte de argila 
coloidal, fraça menor que $0,001 \mathrm{~mm}$. Com isso, esses sedimentos apresentam uma maior superficie de contacto, facilitando a adsorcão do nitrogênio e do fosforo.

Contudo, FORSBERG ot alil (B.d), sugerem que a razăo N/P 6 maior nos lagos, se comparados aos teores do rio Solimões/Amazonas, devido a sedimentaçă. Essas razŏes mais elevadas săo de difíceis explicaç̃es, uma vez, que para os sedimentos do rio Negro que sofrem influência do rio Branco, podem identificar que os lagos desse ecossistema, ş̧o enriquecidos pela deposiço que se verifica nesses lagos. Para os lagos do rio Solimões/ Amazonas, estes, estro intimamente relacionados com a hidrogeoquímica desse rio. Por $6 \mathrm{~m}$, deve-se observar, que em muitos desses lagos, ocorrem atividades agropecária, e, este fator, deve ser objeto de estudo futuro, para que se possa chegar a uma melhor avali aça.

\subsubsection{FRACEO ORGAHICA}

Para o presente estudo, a fraço orgânica, esta constituída de nitrogênio, carbono e pigmento total. Com isso, pretende-se fazer uma comparaço desses constituintes, nos ecossistemas estudados. 


\subsubsection{MATERIA ORGANICA}

Nos ecossistemas do rio Negro (Tabelas 5 e 11), apresentam teores de carbono e nitrogônio, em concentraçoes mais elevadas que as do sedimentos dos lagos do rio Sol imores/Amazonas (Tabela 14), evidenciando um maior conteúdo de matéria orgânica, uma vez que os sedimentos do rio Śolimôes/Amazonas, devido ao seu tamanho, precipitam mais rapidamente que os colbides presentes nas aguas do rio Negro, aumentando os processos de adsorcăo, e consequentemente, havers um aumento do conteúdo de $\mathrm{C}$ e $\mathrm{N}$, nesse ecossistema.

A entrada de carbono nos ecossistemas fluviais, depende do sistema da drenagem e deposicão direta dos ecossistemas terrestriais adjacentes e da fixaça de carbono autóctone. Nesse processo de entrada, a matéria orgânica particular grossa b lixiviada e degradada a partículas mais finas e a carbono orgânico dissolvido, possivelmente, durante o seu trânsito rio abaixo (DARHELL, 1975). E possível que no ecossistema do rio Negro, devido ao seu maior conteúdo de carbono, ocorra uma contínua degradą̧̧o desse carbono, onde grande parte do carbono dissolvido que permanece, săo compostos refratários, constiturdos de acidos fúlvicos e húmicos. 
RICHEY ot alli (1980), fizeram uma

extrapol ą̧̧o com base em estudos do rio Amazonas, onde estimaram de $4 \mathrm{~g}$ de C.m na forma de carbono organico dissolvido; sendo que 5 \% for am encontrados na forma orgânica particulada e $2 \%$ nos s6lidos suspensos. At 6 momento, pouco se perscrutiu sobre lagos de sgua preta na regið̧o Amazônica, por isso, dados consernentes ao rio Negro, næ̊o såo disponiveis, entretanto, BECK et alı1 (1974), mostraram que a carga de carbono de um rio sub

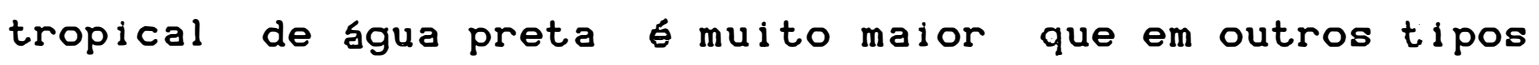
de sgua, devido a sua afinidade com o substrato que dăo formaçăo a esses tipos de sgua.

Estudos relacionando as perdas de carbono provenientes da floresta Amazônica, devem ser correlacionados com o tamanho de sua bacia hidrográfica, tanto no ecossistema do rio Solimaes/Amazonas, como do rio Negro, uma vez que podem mostrar algumas implicaçes. Primeiro, poder sefletir a natureza refrataria dos compostos orgânicos, especialmente o carbono orgânico particulado. Segundo, o carbono organico alóctone que possivelmente 6 oxidado nesses dois tipos de rios, poderao eer balanceado pela produgajo autóctone de carbono orgânico. Finalmente, o carbono orgânico particulado poderá ser degradado equivalentemente à compostos orgânicos refratários dissolvidos (DARNELL, 1975). 
Segundo SCKLESINGER \& MELACK (1981), ñฺึo existe indicaço de uma correlaça positiva entre a proporģo de carbono orgânico dissolvido e o carbono

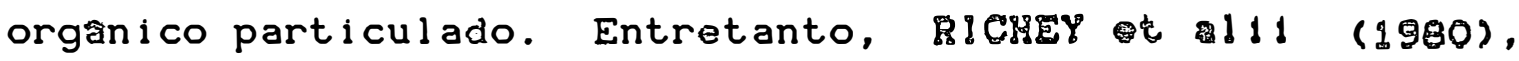
sugere, que o tranporte de carbono orgânico particulado em regiờes Tropicais, como a Amazônia, deverá ser um fator muito importante.

Os valores mais elevados de carbono que se - verificam nos sedimentos dos lagos do rio Negro em comparą̧o com os do rio Solimões/Amazonas, podem ser explicados, como sugerem BECK et alii (1978), ou ainda, devido a uma maior quantidade de detrito de plantas, os quais. parecem persistir por muito mais tempo nessse sistema aquatico, onde podemos incluir os materias estruturais de celulose e ligninas, como tambem detritos de animais como: dente; ossos; escamas; cristalino dos olhos e outros, que săo as partes mais duráveis, que por sua vez, podem esta inserido no material mole do fundo do lago (DASBNELL, 1975).

Pelos resultados obtidos (Tabelas 5: 11; 14 e 20), G facilmente constatavel, uma nitida diferenca, quanto ao teor de carbono nos ecossistemas da Amazônia, sendo que o rio Negro tem um conteúdo maior que o do rio Branco, este, maior que o do rio Solimaes/Amazonas. Se for 
observado a subdivisaro do ecossistema do rio Negro, teremos: um teor de carbono no ecossistema do rio Negro sobre influencia pelo rio Branco, maior que o observado no rio Negro e este, maior que o verificado no rio Branco, ficando a menor concentraçăo de carbono no ecossistema do rio Sol imð̄es/Amazonas.

Com isso, a distribulç̧o do conteudo de carbono nos ecossistemas Amazônicos, apresentam-se variaveis, entretanto, um cuidadoso estudo da exportaça de carbono orgânico total proveniente das florestas tropicais, no caso específico, a Amazônia, poder ́́ fornecer indicaçoses quanto aos efeitos do desmatamento na bacia Amazônica .

\subsubsection{PJGMENTO TOTAL}

Uma possivel explicaçăo para :o aparecimento de Pigmento Total (Clorofila), ericontrada nos sedimentos do fundo dos lagos, seria, sua possivel produçăo em sua maior parte nas aguas superficiais e em escala menor, provenientes dos restos das celulas das plantas. Por outro lado, a decomposicão de parte dessa clorofila seria provavelmente o resultado de um breve comensalismo, como sugere ROZRIRSRI (1938). 
Entretanto, com a baixa temperatura e baixo contérido de oxigônio que geralmente ocorre nas água que estão mais profundas, ou seja, no fundo do lago, como observado por SARTOS (1980), essa taxa de decomposiço pode ser maior. Na verdade, $\theta$ possível, que ocorra um equilíbrlo parcial entre a chegada do material de clorofila no fundo do lago e a decomposį̧๐o. Estudos nesses sentidos, devem ser direcionados, para sua possível comprovaça.

Nos lagos de agua preta, ou seja aqueles pertencentes ao ecossistema do rio Negro (Tabela 5), mostram que todos os lagos apresentam 0 mesmo teor'de clorofila $(4,1 \mathrm{ug} / \mathrm{g})$.

Já nos sedimentos dos lagos de agua preta, pertencentes ao ecossistema do rio Negro que sofrem influências do rio Branco (Tabela 11), as concentraçães de clorofila, variam de 8,20 a 30,0 ug/g.

A presença de clorofila nos sedimentos dos lagos localizados no ecossistema do rio Solimbes/ Amazonas, fornece uma correlaça positiva com o carbono, indicando que $o$ aumento deste, causara um aumento na concentraça da clorofila. Entretanto, essa clorofila, decresce com 0 aumento da concentraça de magnésio nos sedimentos desses lagos, devido esse elemento fazer parte 
do núcleo central da clorofila, e, sua degradaçăo, aumentara o teor de magnésio nesses sedimentos.

E possível, que as altas taxas de pigmento total (clorofila), encontradas nos sedimentos dos lagos do ecossistema do rio Sol lmȫes/Amazonas ( $T$ abela 14); nos sedimentos dos lagos do rio Negro que sofrem influência do rio Branco (Tabela 11) e nos sedimentos dos lagos do rio Branco (Tabela 8), a luz, seja um fator muito importante na ocorrência dessa clorofila, como também, na sua distribu i fão. Segundo RIBE\RO (1978), a clorofila existente nas aguas dos lagos de varzeas do ecossistema do rio Sol imơes/Amazonas apresentam teores mais elevados que nas aguas do ecossistema do rio Negro. Esta afirmativa, corrobora, com os teores encontrados para os sedimentos dos lagos do rio Solimơes/Amazonas, como para os do rio Negro (Tabelas 5 e 14).

Nos sedimentos dos lagos perscrutado do rio Negro (Tabela 5), sendo lagos de agua preta, a penetraçăo da luz é prejudicada enquanto que nos lagos de agua branca e clara, a penetraço da luz pode chegar a alguns metros (RIBEIRO, 1983 SHITH-MORRILL, 1987). Entretanto, em alguns lagos de sgua branca, ou seja, os do ecossistemas do rio Solimð̋es/Amazonas (Tabela 14), şo obervados lagos, cujos sedimentos apresentam teores baixos 
de clorofila, isto possivelmente, devido a alta taxa de material em suspenşo, que dificulta a penetraça da luz.

Investigaçes consernentes a taxa de fotossintese em lagos da Amazônia, tanto os de ggua preta, branca e clara săo necessarios para que possamos conhecer a taxa m̧xima desse processo, entretanto, a luz solar, tem um papel extremamente decisivo. Outro desconhecimento nos lagos desses ecossistemas, 6 a exata profundidade onde esses processos podem correr, uma vez, que dependendo principalmente da transmissăo da luz, que 6 varíavel nos diversos tipos de aguas que ocorrem na Amazônia (SCHMIDT, 1973; RIBEIRO, $1980 \ominus 1983$ SHITH-PORRILL, 1987).

Entretanto, pelos dados de pigmento total (clorofila) obtidos nos sedimentos dos lagos formados por esses tipos de agua, indicam a possibilidade de ocorrer fotossinteses em regizes de baixa densidade de luz, como 6 - caso dos lagos do rio Negro e em alguns lagos de śgua branca (RIBEIRO, 1980 1983). Por 6 , os teores mais elevados que se observam nos sedimentos de sgua branca (TABELA, 14), devem-se principalmente, a uma consequência de melhores condiços da penetraça da luz na agua desses lagos. Quanto aos teores verificados no ecossistema do rio Negro que sofrem influência do rio Branco (Tabela,. 11), confirmam essa condiçăo, como tamberm, comprovam, a 
fertilização das aguas do rio Negro pelas aguas do rio Branco.

Para que ocorra a presença de clorofila nos sedimentos do fundo dos lagos, esses lagos deverão apresentar algumas condiçóes 11 mnológicas, como o limite entre o trofogennico e o trof6lico das aguas e produçăo material orgânico e inorgânico que são carreados (KOZMINSKI, 1938). Entretanto, a falta desses trabalhos expeḉficos em aguas de lagos na regiăo Amazônica, næ̧o foi possível uma melhor discussăo no presente trabalho. Por nåo poder deixar de ser realizado em estudos futuros.

A presença de clorofila fisiologicamente inativa, que possivelmente esteja presente nos lagos da Amazónia com temperaturas acima de $26^{\circ} \mathrm{C}$ e profundidade entre 10 a 13 metros (SANTOS, 1980), como ocorrem nesta regiăo, tem mais significância na simples determinaçăo da clorofila. Essas determinaçōes năo podem dar medidas exatas nem. de massa de fitoplancton ou de intensidade de fotossintese, quando ocorrer a uma certa profundidade do lago (KOZMINSKI, 1938).

Segundo RIBEIRO (1978), os lagos do ecossistema do rio Solimơes/Amazonas săo mais produtivos que os lagos do ecossistema do rio Negro. E, que a produçăo 
de nanofitoplancton (frą̧̃o menor de $50 \mathrm{u}$ ) apresentam uma maior producão que o microfitoplancton (fraço maior que $50 \mathrm{u})$, nas águas dos lagos do ecossistema do rio Solimßres/ Amazonas, enquanto que nas águas do rio Negro, a produçao do microfitoplanction 6. maior que a produço do nanofitoplancton, sendo que essa produço tende diminuir com a profundidade. 


\section{CONCLUSTE}

Os resultados analiticos dos sedimentos dos lagos de varzeas que constituem os ecossistemas do rio Negro; rio Branco; rio Negro influenciado pelo rio Branco e rio Solimoes/Amazonas, permitem estabelecer as seguintes conclusర̃es :

1 - Os sedimentios da margem esquerda do rio Negro şo fortemente influenciados pelos sedimentos e aguas do rio Branco, sobretudo, na faixa que vai da foz do rio Branco ate ao arquipelago das Anavilhanas. Esisa faixa apresenta maiores valores de soma de base; de $\mathrm{pH}$; de pigmento total e argila, em relaço aos sedimentos do rio Negro, antes da confluência do rio Branco;

$$
2 \text { - o teor de calcio trocavel } 6 \text { menor nos }
$$
sedimentos do rio Negro $(0,5$ a $1,5 \mathrm{e} \cdot \mathrm{mg} / 100 \mathrm{~g})$, seguindo em ordem crescente para os sedimentos dos lagos do rio Branco $(1,9$ a 2,1 e.mg/100g), rio Negro influenciado pelo rio Branco $(0,5$ a 4,8 e.mg/100g) e rio Solimbes/Amazonas $(5,2$ a $15,6 \mathrm{e} \cdot \mathrm{mg} / 100 \mathrm{~g})$. 
3 - As concentrą̧̋es de magnésio troçuel nos sedimentos dos lagos rio Negro $(0,4$ a 4,4 e.mg/100g), foram maiores que às observadas no rio Branco $(0,2$ a 0,3 e.mg/100g). Os sedimentos dos lagos do rio Negro influenciado pelo rio Branco (1,8 a 6,5 e.mg/100g), mostram-se superiores às do rio Negro e às dos sedimentos dos lagos do rio Solimões/Amazonas, (1,2 a 7,7 e.mg/100g);

$$
4 \text { - } 0 \text { s6dio total apresentou }
$$

concentrações maiores nos sedimentos dos lagos do rio Sol imđ̃es/Âmażonas $(0,49$ a $1,73 \mathrm{~g} / 100 \mathrm{~g})$. Seguindo em ordem decrescente, nos sedimentos dos lagos do rio Negro influenciado pelo rio Branco $(0,33$ a $0,55 \mathrm{~g} / 100 \mathrm{~g})$, nos lagos do rio Negro $(0,26$ a $0,45 \mathrm{~g} / 100 \mathrm{~g})$ e nos lagos do rio Branco $(0,29$ a $0,31 \mathrm{~g} / 100 \mathrm{~g})$;

5 - As concentraçoes de potassio total ş̧o maiores nos sedimentos dos lagos do rio. Solimơes/ Amazonas $(0,80$ a $13,75 \mathrm{~g} / 100 \mathrm{~g})$. Seguindo em ordem decrescente, nos sedimentos dos lagos do rio Negro influenciado pelo rio Branco $(0,97$ a $2,95 \mathrm{~g} / 100 \mathrm{~g})$, nos lagos do rio Negro $(0,26$ a $0,87 \mathrm{~g} / 100 \mathrm{~g})$ e do rio Branco $(0,2$ a $1,00 \mathrm{~g} / 100 \mathrm{~g})$;

6 - 0 fosforo encontra-se sempre em baixas concentraçðes $(0,003 \mathrm{~g} / 100 \mathrm{~g})$. A presença do 
fósforo em um maior número de lagos da bacia do rio Negro sobre influância do rio Branco. Isto deve-se provavelmente pela entrada dos sedimentos cauliniticos provenientes desse rio;

$$
7 \text { - Pela análise mineralogica, constata- }
$$
se que os sedimentos do rio Negro sofrem modificaçðes com a entrada dos sedimentos do $\mathrm{rio}$ Branco, resultando no aparecimento da mica e evidências de minerais 2:1. Por outro lado, os sedimentos dos lagos do rio Solimąes/ Amazonas, nฐ̃o sofrem grandes alteraç̃es em sua composiç̃o mineralógica.

$$
8 \text { - Comparando-se os resultados analíticos }
$$
obứdos para os sedimentos dos lagos dos dois ecossistemas do rio Negro, comprova-se a fertilizaçăo da faixa do rio Negro pela margem esquerda, atribuidos aos sedimentos e águas do rio Branco.

9 - As concentrações de nitrogênio săo maiores para os sedimentos do rio Branco $(0,14$ a 0,21 $\mathrm{g} / 100 \mathrm{~g})$ e em ordem decrescente, eståo as observadas para o rio Negro $(0,12$ a $0,16 \mathrm{~g} / 100 \mathrm{~g})$, do rio Negro influenciado pelo rio Branco $(0,12$ a $0,16 \mathrm{~g} / 100 \mathrm{~g})$ e rio Solomzes/ Amazonas $(0,03$ a $0,10 \mathrm{~g} / 10 \mathrm{~g})$;

$$
10 \text { - Evidencia-se uma nitida diferença }
$$


quanto ao conteúdo de carbono nos sedimentos dos lagos amazônicos. Relaciomando-se os quatros ecossistemas estudados, as maiores concentraçбes de carbono, esţo nos sedimentos dos lagos do rio Negro influenciado pelo rio Branco $(1,44$ a $2,93 \mathrm{~g} / 100 \mathrm{~g})$, seguindo em ordem decrescente, os sedimentos dos lagos do rio Branco (1,66 a 2,91 g/100g), do rio Negro $(1,60$ a $2,83 \mathrm{~g} / 100 \mathrm{~g})$ e do rio Solimăes/ Amazonas $(0,70$ a $2,46 \mathrm{~g} / 100 \mathrm{~g})$;

11 - Os sedimentos dos lagos do rio Negro influenciado pelo rio Branco, apresentam teores de clorofila $(8,2$ a $30,0 \mathrm{ug} / \mathrm{g})$, maiores que às do rio Negro $(4,1 \mathrm{ug} / \mathrm{g})$. As concentraçes de clorofila nos sedimentos dos lagos do rio Sol imశes/Amazonas ( 1,4 a $15,0 \mathrm{ug} / \mathrm{g})$, são variáveis, porǿm em teores menores que às do rio Negro influenciado pelo rio Branco:

12 - A falta de estudos que indca os limites entre o trofogênico e o trofólito nas aguas e a produço de maţria orgânica e inorgânica nos lagos da regiăo Amazônica, não nos permite no momento, uma melhor explicaço para o aparecimento da clorofila nos sedimentos do fundo dos lagos das regiốes analisadas, porém, ño podera deixar de ser realizada em estudos futuros. 


\section{BIBLIOGRAFIA}

BECK, K.L.; REUTER, J.H.; PERDUE, E.M. Organic and Inorganic geochimistry of some coastal plain rivers of the southe astern United States. Gochimica ot Cosmochimica Acta, 38:341-364, 1974 .

BRASIL. Ministerio das Minas e Energia. Levantamento de recursos naturais. Brasilia, MME/DNPM, 1978, 623p. (Projeto radambrasil, 18).

BRASIL. Ministerio das Minas e Energia. Geograsia do Bragl l. Brasilia, MME/DNPN, 1984, $501 p$.

BRASIL. Minist6rio dos Transportes. Departamento Nacional de Estradas de Rodagem. Matodos e instruços de ensaios II. Anslise granulométrica de solos. In: Materlaia para obras rodoviárias. Brasilia, 1964. p.1 7. (DNER-ME, 51-64).

BRINGEL, S.R.B.; SANTOS, U. de M.: RIBEIRO, M.N.G.; BERGAMIN FILHO, H. Bacia do rio Parauari-Maues Açu. I. Aspectos químicos devidos às alteraçes hidrológicas da bacia. Acta Amazonica, Manaus, 14(1- 
2): $77-85,1984$.

BRINKMANN, W.L.F. \& SANTOS, A. dos. Natural waters in Amazonia VI. Solube calcium properties. Acta Amazonia, $3(3): 33-40,1973$.

CAPUTO, M.V.: RODRIGUES, R.: VASCONCELOS, D.N.N. Litoestratigrafia da bacia do rio Amazonas. Belfm, PETROBRBS/REROR, 1971. (Relatório técnico interno, 64iA).

CARVALHO, C.M.D. de. O Rio Amazonas e sua bacia.Revisto Brasileira de Geografia, Rio de Janeiro, 4(2):333-50, 1942.

DARNELL, R.M. Organic detritus in relation to the estuarine ecosystem. American Association Advances Science. Estuaries, 83:376-82, 1975.

DAVIS, P. The Amazon's rate of flow. Natural History, New York, 73:14-9, 1980.

DEFELIPO, B.V. \& BIBEIRO, A.C. Análise química do solo; Metodologia. Vicosa, UFV, 1981. 17p. (Boletim de extensåa) .

ELSTER, H.J. Das limnologische seetypensystem, ruckblick und ausblick. Verhandlingen des Internationalen Vereins fur Limnologio, Stuttgart, 13:101-20, 1958. 
FERREIRA, A.B.H. Hovo diciongrio de lingua portuguesa. Rio de Janeiro, Nova Fronteira, 1975. 1516p.

FITTKAU, E.J.; IRMLER, U.; JUNK, W.J.; REIS, F.; SCHYIDT, G.N. Productivity, Biomass and populations dynamics in Amazonian water bodies. In: GOLLEY, F.B. \& MEDINE, E. eds. Tropleal ocologleal gytom tronds in terratrial and aquarle research. Berlin, Springer - Vorlag, 1975. p. $289-312$

FURCH, R. Water Chemistry of the Amazon basin: The distribution of chemical elements among freshwater. In: Sioli, H., ed. The Amazon limnology and landzcape ecology of a might tropical river and its basin. Dordrecht, w. Junk, 1984. p. $167-200$.

FORSBERG, B.R. Nutrients Processing in Amazon flood plain lakes. Verh. Internat. Veroin. Limnol. Stuttgart, $22: 1294-1298,1984$.

FORSBERG, B.R.; DEVOL, A.: MARTINELLI, L.A.; SANTOS, U.M. Factors controlling nutrient concentratins in Amazon floodplaine lakes (No prelo).

GIBBS, J.R. The Geochemistry of the Amazon Basin. San Diego, 1965. 95 p. (PhD University of California). 
GARCANTINI, H.; COELHO,.F.A.S.; VERLENCIA,.F.; SOARES, E. Levantamento de fertilidade dos solos do Estado de Săo Paulo. Săo, Søeretaria de Agricricultura, 1970.

GATES, R.R. A botanist in the Amazon valley; an account of the flora and fauna in the land of floods. London, witherby. 1927. 203p.

GESSNER, F. Untersuchungen uber phosphathaushalt des Amazonas. Int. Rev. Ges. Hidrobiol, 45:339-45, 1960.

GOLTERMAN, H.L. Methods for chemical analysis of freshwater. London, Blackwell, 1970. v.8, 166 p. (International biological program).

GUIMARAES, G. de A.: BASTOS, J.B.; LOPES, E. de C. Retodos de analises física, quimica e instrumental de solos. Bel6m, PERN, 1970, 108 p. CS6rie: Química de solos).

GUNTHER, K. A naturalist in Brazil. Boston, Mifflin, 1931, $339 \mathrm{p}$.

HUTCHINSON, G.E. \& LOFFER, H. The thermal classification of lakes. Proc. Not. Acad. Science Washington, Washington $42: 84-6,1956$. 
INSTITUTO BRASILEIRO DE GEOGRAFIA E ESTATISTICA. Gøograf 19 do Broll; a grande regiăo Norte. Rio de Janeiro, 1957. 422 p.

IPEAAOC. Solos do Distrito Agropecusrio da SUFRAMA. 56rit Solos, Manaus, 1(1):13 - 99, 1971.

IRION, G. Mineralogisch-geochemische untersuchungen an der polifischen fraktion amazonischer oberduden und sedimente. Biographic, Washington, 7:7-25, 1976.

IRION, G. Mineralogical and geochemical contribution to climatic history in cental Amazonia during quaternary time. Tropical Ecology, 1(2):76-85, 1982.

IRION, G.: ADIS, J.: JUNK, W.J.; WUNDERLICH, F. Sedimentological etudies of "Ilha de Manchantaria" in the Solimres/Amazonas river near Manaus. Amazoniana, Kiel, $8(1): 1-18,1983$.

IRION, G. Sedimentation and sediments of Amazonia river and evolution of the Amazonian landscape since pliocene times. In: Sioli, H. Od. The Amazon: Limnology and landacape ecology of migthy tropical and itz bacin. Dordrecht, w. Junk, 1984. 763 p. (Monographias biological) 
IRION, G. Soil infertility in the Amazon rain forest. Naturwiฐangchaft@n, Berlin, 65:515 - 19, 1978.

IRION, G. Clay minerals of Amazonian soils. In: Sioli, H. ed. The Amazon limnology and landacap ocology of a might tropical rivor and its bain. Dordrecht, w. Junk, $1984 b$, p. $537-77$.

JACKSON, M.L. Soll Chemical Analyais. New Jersey, PrenticeHal 1, 498p.

JUNK, w.J. Invertigation on the ecology and production biology of the "floating meadows" (Paspalo(ichinocholoentum) on the midle Amazon I. The floating vegetation and its ecology. $495,1970 a$

JUNK, w. Investigations of the ecology and production biology of the "floating meadows" (PagpaloQichinoachootum) on the midde Amazon. Part II. The aquatic fauna in the Rood zone of floating vegetations. Amazoniana, Kiel, 4:9 - 102, 1970b.

JUNK, W.J. Areas imundáveis; Um desafio para a limnologia. Acta Amazonica, Manaus, 10(4)775 - 815, 1980.

JUNK, w.J. \& FURCK, K. Qurmica da agua, macrofita aquatica de rios e igarapes da bacia Amazonica e 
nas áreas adjacentes. Act Amzonlca, Manaus, 10(2):611 $-635,1980$.

JUNK, W.J. Ecology of the varzea floodolains of Amazon white-water river. In: Sioli, H. ed., The Amazon limnology and landscape ecology of a might tropical river and its basin. Dordrecht, w. Junk, 1984, p. 271 $-293$.

KATSER, P.E. Geologie des centeren Amazonasgebietes; des Staates Pará in Brasilien. Leipzig, Mx. Weg, 1903, $298 p$.

KLAMMER, G. The relief of the extra Andian Amazon basin. In: Sioli, H. ed. The Amazon limnology and landscape ecology of a might tropycal river and its basin. Dordrecht, w. Jung, 1984, p. $49-83$.

KLINGE, H. Podzol soils: a sourse of blachwater river in Amazonian. In: SIMPOSIO SOBRE A BIOTA AMAZONICA, 3., Rio de Janeiro, 1967, Atas. CNPq, 1967, p. $117-126$

KLINGE, H.: FURCK, K.: REVILLA, J. Foliar nutrient levels of native tree species fron central Amazonia. I. Inundatison florest. Amazoniana, Kiel, $9(1): 19-45$, 1983. 
KUHLMANN, E. Vegetaçăo. In: INSTITUTO BRASILEIRO DE GEOGRAFIA E ESTATISTICA. Goograria do Brasil; a grande regi"ao Norte, Rio de Janeiro, 1957, p.59-90

LANDIN, P.M.B.; BOSIO, N.J.: MEYER JUNIOR, E.A.; CASTRO, P.R.M. Heavy minerals from Amazon river bed: Environmental Seience, 59(4):227, 1978 .

LE COINTE, P. Le bas amazone. Annalos de Goographje, Paris, 12:54-6, 1903 .

LEINZ, V. \& AMARAL, S.E. do A. Goologia Goral. 7 . ed. Såo Paulo, Nacional, 1978, 397p.

LEENHER, J.A. \& SANTOS, U. de M. Consideraçס̃es sobre os processos de sedimentaço na agua preta acida do rio Negro (Amazonia Central). Acta Amazonica, Manaus, $10(2): 343-55,1980$.

LOPES, U.B.; SANTOS, U. de M.: RIBEIRO, M.N.G. Limnologia química do lago do Arroz (Ilha do Careiro), sua flutuaçôes em funça do meio hidrico do rio Amazonas. Acta Amazonica, Manaus, 13(2):227-53, 1983.

MALAVOlta, E. Manual de química agrícola. Såo Paulo, Agronceres, $1976,453 \mathrm{p}$.

MARLIER, G. Ecological estudies on same lakes of the Amazon vally. Amazoniana, Kiel, 1(2):91-115, 1967. 
MARTINELI, L.A. Composiqå química e isotopica $\left({ }^{13} \mathrm{C}\right)$ de sedimentos de varzeas e suas interaçes com alguns rios da bacia Amazónica. Piracicaba, 1986, 214 p. (Mestrado Escola Superior de Agricultura "Luiz de Queiroz"/ USP).

MCGRILL, W.B. \& CHRISTIE, E.K. Biogeochemical aspects nutrients cycle interactions in soils and organisms. In: BOLIN, B. \& COOK, R.B., eds., The major biogeochemical cyclo and their interactions. Chichester, John Wiley, 1983, p. $271-96$.

MEADE, R.H.; NORDIN FUNIOR, C.F.; CURTIS, w.F. Sediment in rio Amazonas and some of principal tributaries during the hiht-water seasons of 1976 and 1977. In: SIMPOSIO BRASILEIRO DE HIDROLOGIA, 3., 1979. Doe. Final. Ş๐o Paulo, ABHRH, 1979. v.2, p. $472-85$.

MEADE, R.H.; DUNNE, T.; RICHEY, J.E.; SANTOS, U.M.; SALATI, E. Strorage and remobilization of suspended sediment in the lower Amazon river of Brazil. Science, Washington, 228:488-90, 1986 .

MELO, F.A.F. de; ARZOLLA, S.; KIEHL, J.C. Hotodos do

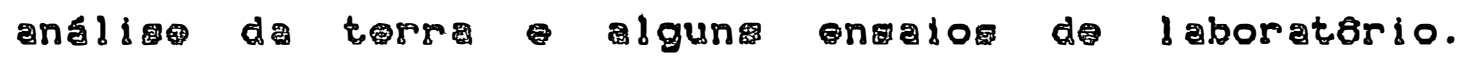
Piracicaba, ESALQ/Dep. Solos o geologia, s.d. 28pp.

MOURA, P. Gograrla do balxo Amazonas. Rio de Janeiro, 
M.A., 1951, (Boletim do Serv. Geografico e Mineralogico, 19).

NORDIN JUNIOR, C.F., \& MEADE, R.H.; CURTIS, W.F.: BOSIO, N.J.; LANDIN, P.M.B. Distribuiço do sedimento do leito do rio Amazonas; nenhuma mudança apreciável rio abaixo. Acta Amazonica, Manaus, 11(4):769 -72, 1981 .

OLIVEIRA, A.S. \& LEONARDO, O.H. Goologi do Brasil, Rio de Janeiro, M.A., 1943, 425 p.

OLTMAN, R.E.; STENBERG, R.E.; AMES, F.C.; DAVIS, L.C. Amazon River Investigation, Reconnaissance Mensurements of july 1963. Geological Survey, Circular, Washington, $486(3): 1-15,1964$.

OLTMANN, R.E. Reconnaissance investigations of the discharge and water quality of the Amazon. In: IMPOSIO SOBRE A BIOTA AMAZONICA, 3., Rio de Janeiro, 1967. Atæa Rio de Janeiro, CNPq, 1967. p.163 - 86.

PIRES, J.M. Noçðes sobre ecologia e fitogeografia da Amazonia.Norte Agrononico, Bel 6m, 3(3): $37-54,1957$.

PIRES, J.M. Tipos de Vegetaçes que ocorrem na Amazonia (cerograph.). In: SIMPOSIO SOBRE A BIOTA AMAZONICA, 2. Bélem, 1966. Atas, Rio de Janeiro, CNPq, 1966, 17p. 
PIRES, J.M. Tipos de vegetą̧̧o da Amazônia. Bol. do İuma Em lds0 Gooldl, Belém, 20:179-202, 1973.

PUTZER, H. The geological evolution of the Amazon basin and its mineral resorces. In: Sioli, H., ed. Tho Amazon limnology and landscape acology of a right tropical river and ite basin. Dordrecht, W. Junk, 1984. p. $15-45$.

RAI, H. \& HILL, G. Classiflcation of central Amazon lakes on the basin of their microbiological and physicochemical characteristics. Hydrobiology, Sophia, 72:85$98,1980$.

RAI, H. \& HILL, G. Primary production in the aquatic ecosysten. In: SIOLI, H., ed., The Amazon limnology and landscape ecology of a might tropical river and its bagin. Dordrecht, w. Junk,1984. p. $311-36$

RANZANI, G. Recursos pedol6gicos da Amazônia. Acta Amazonica, Manaus, 9: (suplemento): $23-5,1979$.

REGO, L.F. de $M$. Notas sobre a geografia do territorio do Acre e da bacia do Javari, Manaus, 1930. 44p.

RIBEIRO, J.S.B. Fatores ecologicos, produfăo primaria e fitoplancton em cinco lagos da Amazonia central. 
estudos preliminar. Såo Carlos, 1978. 143 p. (MestradoUniv. Federal de Sao (arlos).

RIBEIRO, J.S.B. Estudo sazonal de fatores ambientais, nutrientes e biomassa de fitoplancton no lago Jacaretınga (Amazônı a Central). Săo Carlos,1983. 99 p. (Doutorado-Univ. Federal de Săo Carlos).

RICHEY, J.E.; BROCK, J.T.; NAIMAN, R.J.; WISSMAR, R.C.; STALLAND, R.F. Organic carbon: oxidation and transport in the Amazon river. Scionce, Washington, 207:1348 - 51, 1980.

RICHEY, J.E.; MAEDE, R.H.; SALATI, E.; DEVOL, A.H.: NORDIN, C.F.; SANTOS, U.M. Water discharge and suspended sediment concentration in the Amazon river 1982 - 1984. Water Bosooure Bøarch. (No prelo).

RIZZINI, G.T. Delimitaç̋es, caracterizaço e relaç̃es da flora hileiana. In: SIMPOSIO SOBRE A BIOTA AMAZONICA, 3., Rio de Janeiro, 1967. Ata. Rio de Janeiro, CNPq, 1967. v.4, p. $13-36$.

RUTTNER, F. Fundament $1 \mathrm{l}$ of 1 imnology. Toronto, University of Toronto Press 1952. 242 p.

SAKAMOTO, T. Trabalhos sedimentologicos geomorfologicos 
- podogenticos reforontes à Amazonla. Belom, SPVEA, 1957. $120 \mathrm{p}$.

SANCHEZ, P.A.: BANDY, D.E.; VILLACHICA, J.H.; NICHOLAIDES, J.J. Amazon basin soils; management for continous crop productions. Science, Washington, 216:821 - 827, 1982.

SANTOS, A. dos.: RIBEIRO, M.N.G.; RIBEIRO, J.S.B.; BRINGEL, S.R.B. Hidroquímica da Amazonia Central. III. Quŕmica da agua da lavagem da floresta no ecossistema Campina Amazônca (stemflow). Acta Amazonica, Manaus, $11(2): 335-346,1981$.

SANTOS, J.O.s. Consideraçชes sobre a bacia cenozbica Solimós. In: CONGRESSO BRASILEIRO DE GEOLOIA, 28., Porto Alegra, 1974. Anais. Săo Paulo, SBG, 1974. v. 3, p. $3-1.1$

SANTOS, U de M. Aspectos limnol6gicos do lago grande do Jutai (Amazônia Central), face as alteraçes quimicas do meio hídrico da regiðo. Acta Amazonica, Manaus, $10(4): 797-822,1980$.

SANTOS U de M.; BRINGEL, S.R.B.: BERGAMIN FILHO, H.: RIBEIRO, M.N.G.; BANANEIRA, M. Rios da Bacia Amazonica I. Afluentes do rio Negro. Acta Amazonica, Manaus, 14(12): $222-37,1984$. 
SANTOS U de M.; BRINGEL, S.R.B.; RIBEIRO, M.N.G.; SILVA, M.N.O. da. Rios da Bacia Amazonica II. Os afluentes do rio Branco. Acta Amzonica, Manaus, 15(1-2): $147-56$, 1985.

SCHLESINGER, W.H. \& MELACK, J.M. Transport of organic carbon in the world's river.Tellus, 33:172 - 87, 1981.

SCHMIDT, G.W. Amounts of suspended solids and dissolved substances in the middle reaches of the Amazon over the course of one year (agust 1969 - july 1970). Amazoniana, Kiel, 3(2): $208-23,1972 a$.

SCHMIDT, G.W. Chemical properties of some water in the tropical rain forest region of Central Amazonia along the Road Manaus - Caracarai. Amezoniana, Kiel, 3:199$207,1972 b$.

SCHIMDT, G.W. Primary production of phytoplancton in the three types of Amazonian water I. The limnology of a tropical floodplain lakes in Central Amazonia (lago do (astanho). Am ฮzoniana, Kiel, 4(2):139-203, 1973a.

SCMIDT, G.W. Primary productions of phytoplankton in the three types of Amazonia waters. II. Primary productivity of phytoplankton in a tropical floodplains lake of a central Amazonia, lago do Castanho, Amazonas, 
Brasil. Ammazoniana, Kiel, $4(2): 379-404,1973 b$.

SCHWOERBEL, J. Einfunhrung in die limnologie. Stuttgart, Gustav Fischer Verlag, 1971. 170p.

SCHUBART, U.O.R. Ecologia e utilizaço das florestas. In: Salati, E.; Schubart, H.O.R.; Junk, W.J.; Oliveira,

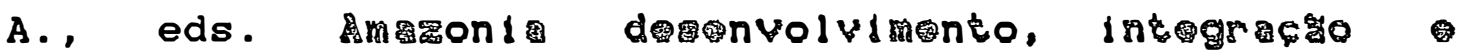
- colog!

Sioll, H. Das wasser in Amazonasgebiet. Fortgehr, 26:274 80,1950 .

SIOLI, H. Estudo preliminar das relaçoses entre a geologia e a limnologia da zona Bragantina. Boletim Ţendeo Instituto Agronônico do Morte, Belem, 24:67$76,1951$.

SIOLI, H. O. rio Arapiuns; estudo limnologicos de um corpo de agua do terciario, plioceno das barreiras do Baixo Amazonas. Boletim Tónico Instituto Agronsinico do Nort, Bel $6 \mathrm{~m}, 32: 1-116,1956 \mathrm{a}$.

SIOLI, H. As sguas do alto rio Negro. Boletim Teenico do Ingtituto Agronsinico do Most. Belem, $32: 117-55,1956 b$. SIOLI, H. \& KLINGE, H. Solos, tipos de vegetaç⿰丿⺄⿱ na Amazônia. Boletim do Mugeu Emilio Gooldi, Belém, 1:27 $-41,1962$. 
SIOLI, H. A Limnoloyia e a sua importância em pesquisas da Amazonia.Amazonlana, Kiel, 1(1):11 - 35, 1965.

SIOLI, H. The cururu region in brasilian Amazonia, a transition zone between hylea and cerrado. Journal Botanical Society, $46(4): 453-62,1967$.

SIOLI, H. Zur skologie des amazons-gebiets. In: Blogeography ecology in South America. 1968a. v.2, pt. 1, p. $137-70$.

SIOLI, H. Hydrochemistry and geology in the brasilian region. Amazoniana, Kiel, 1(3):267- 77, $1968 b$.

SIOL, H. Tropical river; the Amazon. In: WHITTON, B.A., ed. River cology. Berkeley, U.C. Press, 1975a. p. 461 87.

SIOLI, H. Tropical river as expressions of their terrestrial environments. In: GOLLY, F.B. \& MEDINA, E., eds. Tropical ecological systems trends in terrestrial and aquatic research. Berlin, Springer - Verlag, $1975 b$. p. $289-312$

S1OLI, H. The Amazon and its main affluents. Hydrography, morphologyof the river courses and river types. In: SIOLI, H. ed. The Amazon I Imnology and landscape ecology 
of a might tropical river and 1 t basin. Dordretch, $w$. Junk, 1984 - p.127 65 .

SMITH-NORRILL, L. The exchance of carbon, nitrogen, and phosphorus between the sediments and water - column of an Amazon floodplain lake. Maryland, 1987. 208 p. ( PhD Univ. of Maryland).

SOARES, L de C. A regi ão Norte do Brasil I. Boletım Gøografico, Rio de Janeiro, 5(58):1114-54, 1948a.

SOARES, L. de C. A regiz̃o Norte do Brasil II. Boletim Gøogrgrico, Rio de Janeiro, 6(60):1474-84, $1948 b$.

ŚARES, L. dec. A vegetą̧̃o, regiăo Norte do Brasil. Bolotim Gogrsfico, Rio de Janeiro, 6(60):1476 - 84, $1948 c$.

SOARES, L. de C. A origem da planície Amazônica. Boletim Googrśleo, Rio de Janeiro, 10(105):998 - 1000, 1951.

SOARES, L. de C. Excursion guide book of the eighteenth international geographical congres, Rio de Jameiro, s. ed., 1956. 216p.

SOARES, L. de C. Hidrografia. In; INSTITUTO BRASILEIRO DE GEOGRAFia E ESTATISTICA. Geograria do Brasil: a grande - regiăo Norte. Rio de Janeiro, 1959. cap. 5; p.128 - 94. 
SOMBROECK, W.G. Amazon soil. Reconnaissance of the soils of the brazilian Amazon region. Wageningen, Center for Argricult., 1966. $292 \mathrm{p}$.

SOMBROECK, W.G. Soils os the Amazon region. In: SIOLI, H., ed. The Amazon limnology and landseape ecology of a might tropical river and its basin. Dordretch, w. Junk, 1984 p. $523-35$.

SPRUCE, R. Notes of botanist on the Amazon and Andes the years 1849 - 1864. London, Macmillian, 1908. $2 \mathrm{v}$.

STALLARD, R.F. \& EDMOND, J.M. Geochemystry of the Amazon 2. The influence of geology and Weathering Environment of the dissolved load. Journal of Geophisical Rezearch, Washington, 88:9671-88, 1983 .

THOMPSON, L.M. \& TROEH, F.H. SOIl and soll fortility. 4 a. ed. New York, McGraw-Hill, 1978. 495p.

ULE, E.H.S. Die pflanzenformatiomen des Amazonas-gebiets. Bot. Jahrb. Engler. $80: 114-72,1907$.

VAN RAIJ, B. Avaliaç̧o da fertilidade do solo.2a ed. Piracicaba, Instituto de Potasea fosforo, 1983. $142 p$.

VELOSO, H.P. Os grandes climas do Brasil. II. 
Consideracões gerais sobre a vegetaço da regiăo Amazônica. Imen. Inst. Orvaldo Cruz, Rio de Janeiro, $60(3): 393-403,1962$.

VELOSO, H.P. Consideraçes gerais sobre a vegetaço da regiăo Amazônica. Boløîtin Goograrico, Rio de Janeiro, $192: 311-18,1966$.

VIEIRA, L.S. Hanual de ciôncia do solo. Şo Paulo. Agroneeres, 1975. 453p. 